\title{
Reactor Fundamentals Handbook
}

S. Bays, A. Abou Jaoude, G. Borlodan

April 2019

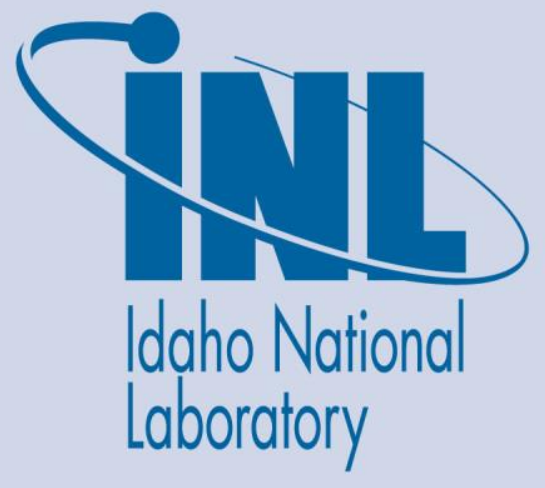

The INL is a U.S. Department of Energy National Laboratory operated by Battelle Energy Alliance 


\section{DISCLAIMER}

This information was prepared as an account of work sponsored by an agency of the U.S. Government. Neither the U.S. Government nor any agency thereof, nor any of their employees, makes any warranty, expressed or implied, or assumes any legal liability or responsibility for the accuracy, completeness, or usefulness, of any information, apparatus, product, or process disclosed, or represents that its use would not infringe privately owned rights. References herein to any specific commercial product, process, or service by trade name, trade mark, manufacturer, or otherwise, does not necessarily constitute or imply its endorsement, recommendation, or favoring by the U.S. Government or any agency thereof. The views and opinions of authors expressed herein do not necessarily state or reflect those of the U.S. Government or any agency thereof. 
INL/EXT-19-53301

Revision 0

\title{
Reactor Fundamentals Handbook
}

\author{
S. Bays, A. Abou Jaoude, G. Borlodan
}

2019

Idaho National Laboratory Idaho Falls, Idaho 83415

http://www.inl.gov

\author{
Prepared for the \\ U.S. Department of Energy \\ Office of Nuclear Energy \\ Under DOE Idaho Operations Office \\ Contract DE-AC07-05ID14517
}




\section{Reactor Fundamentals Handbook}

INL/EXT-19-53301

Revision 0

April 2019 


\section{FOREWORD}

The objective of the Knowledge Transfer Workshop is to transfer selected fundamental nuclear energy technology knowledge and experience to the nuclear industry's next generation of leaders. The Workshop will examine the original bases for fundamental safety concepts, design features, and reactor technologies. The Workshop discusses the "why" and the "how" for decisions that led to the current commercial nuclear reactor designs and regulatory framework. Various accidents and their attributes as well as other events that have strongly affected the evolution of the safety case, plant design, and operations are discussed.

To prepare the course participant for the topics discussed, this handbook provides a crash course into the current state of commercialized Light Water Reactor technology. The material is introductory for the interested layperson and also serves as a refresher for scientists and engineers that may have studied Light Water Reactors at one time, but are currently not an expert in this field of nuclear engineering. 


\section{CONTENTS}

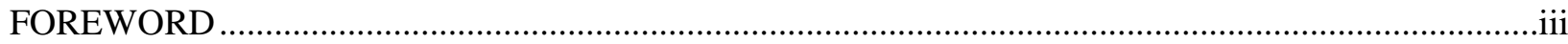

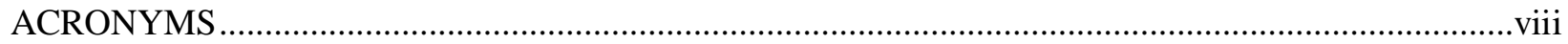

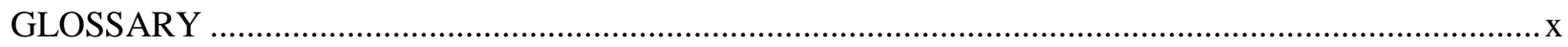

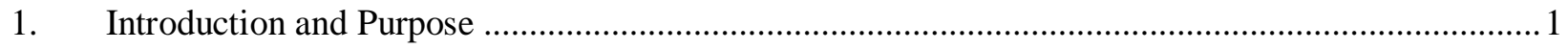

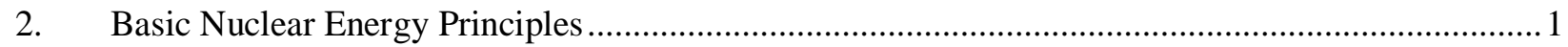

2.1 Radioactive Decay and Ionizing Energy ......................................................................... 1

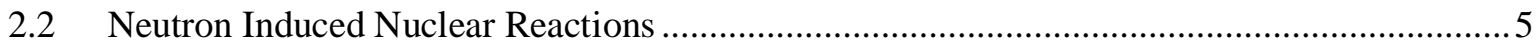

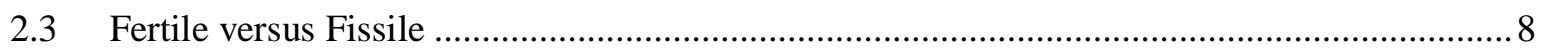

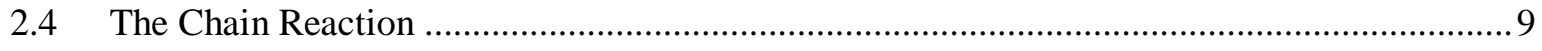

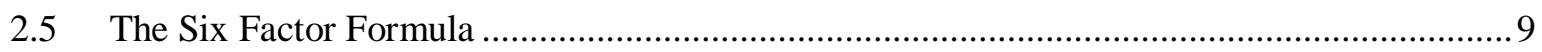

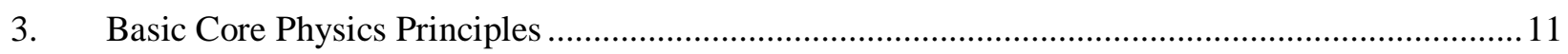

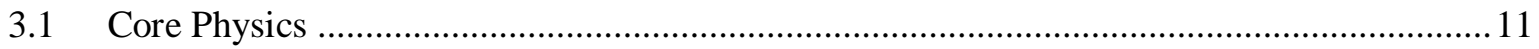

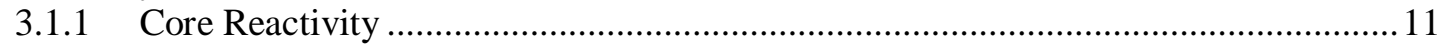

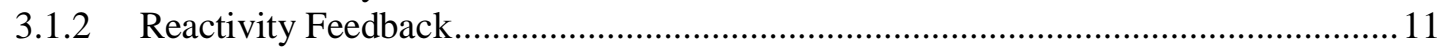

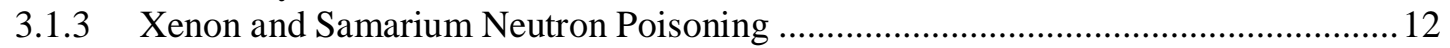

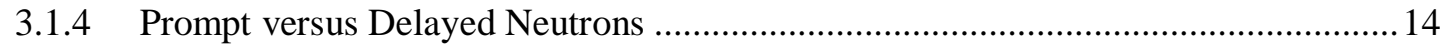

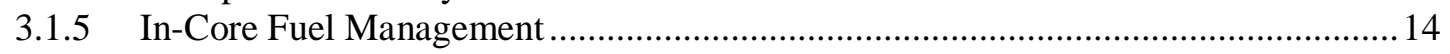

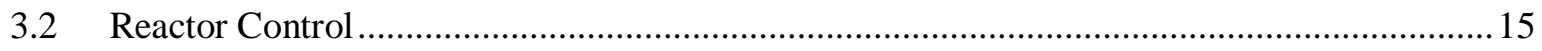

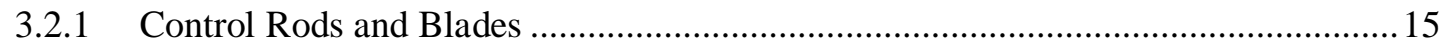

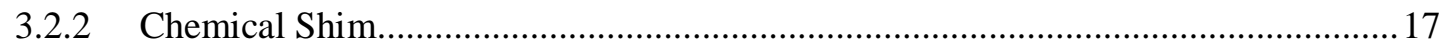

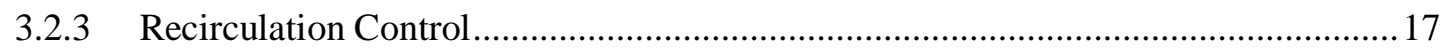

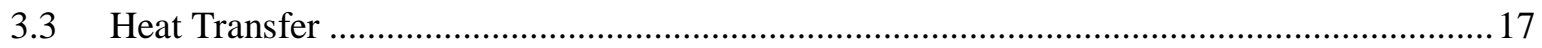

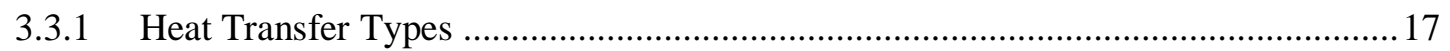

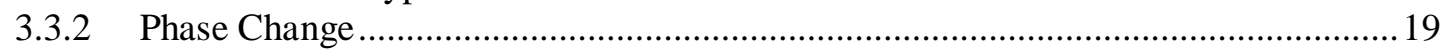

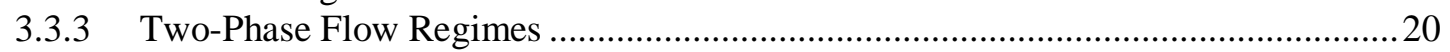

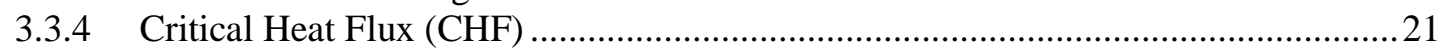

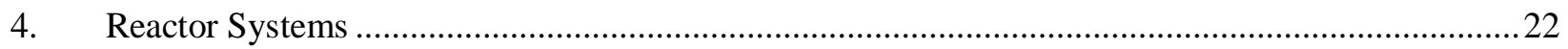

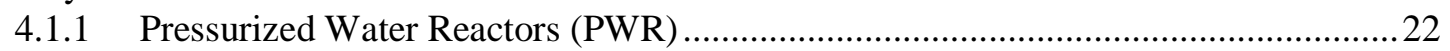

4.1.2 Boiling Water Reactors (BWR) ...................................................................... 31

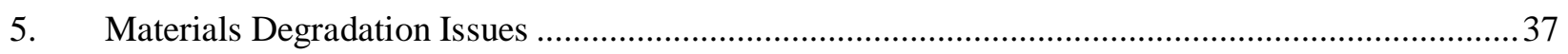

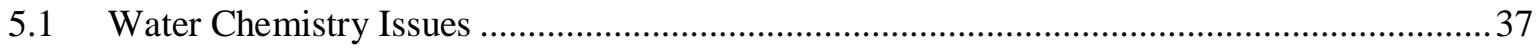

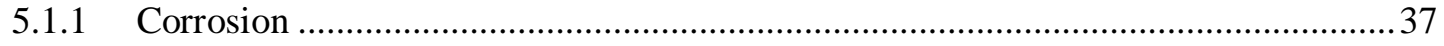

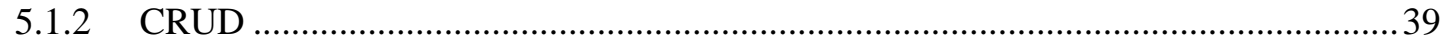

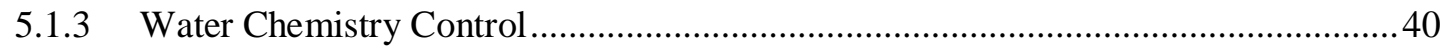

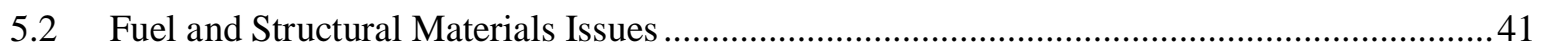

5.2.1 Low Temperature Radiation Hardening and Embrittlement ...................................4 41

5.2.2 Radiation Induced Solute Segregation or Phase Change ......................................... 43

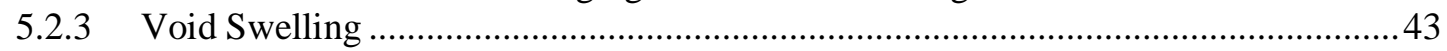

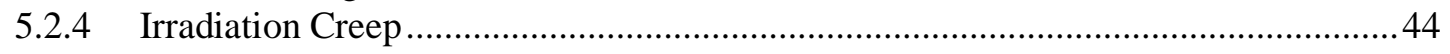




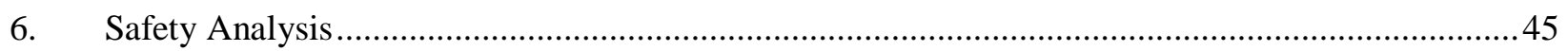

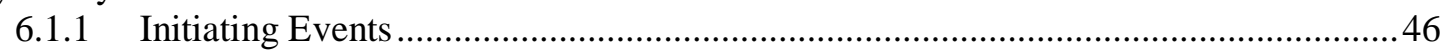

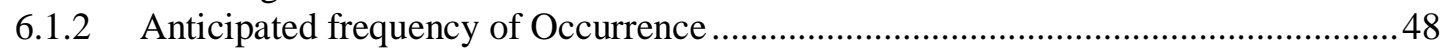

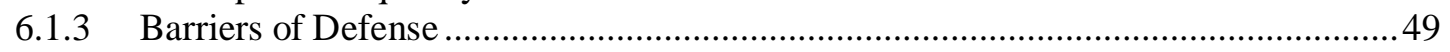

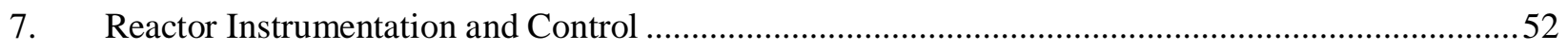

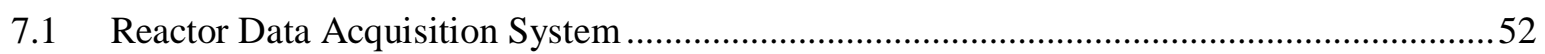

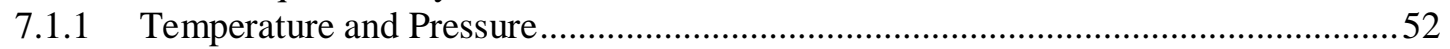

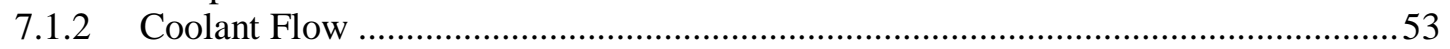

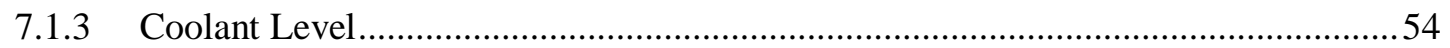

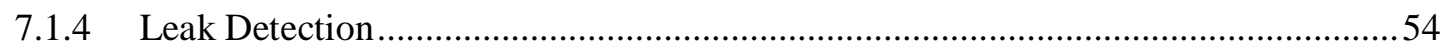

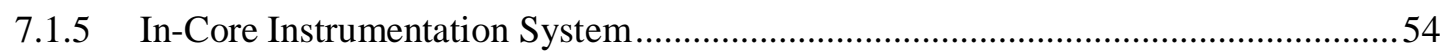

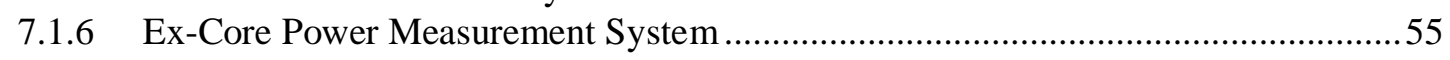

7.2 Reactor Protection \& Engineered Safety Feature Actuation System …..............................56

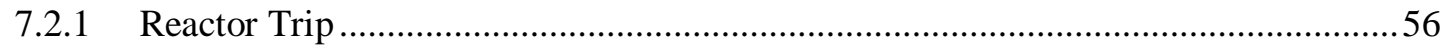

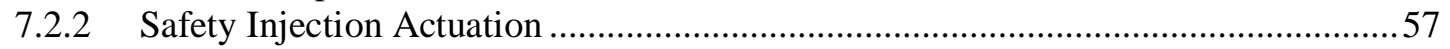

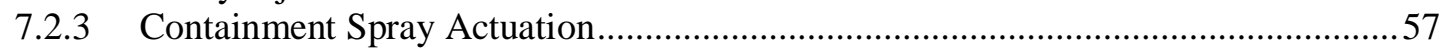

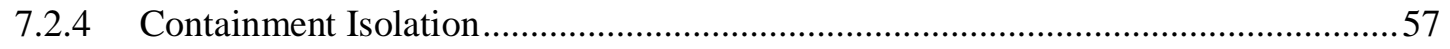

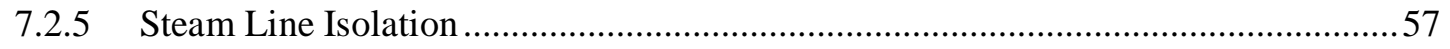

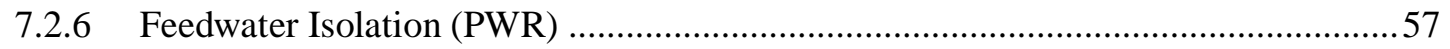

7.2.7 Auxiliary Feedwater Actuation (PWR) ……............................................................

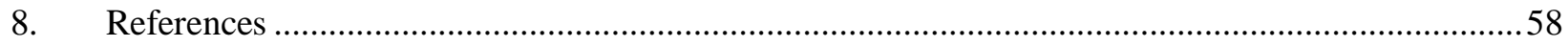

\section{FIGURES}

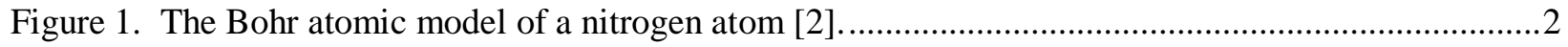

Figure 2. Illustration of stopping power for different types of radiation.................................................

Figure 3 Illustration of nuclear fission. For a very brief moment a U-236 atom is formed which scission into fission products, prompt neutron and gamma-rays, and neutrino constituents.

Figure 4. Distribution of fission fragments with percentage of their yield following a fission. ................. 7

Figure 5. Comparison of fissile and capture cross-sections for Pu-239 and U-238 plotted with the neutron spectra of a High Temperature Gas Reactor (thermal spectrum HTGR) and a Sodium-cooled Fast Reactor (fast spectrum SFR). ..............................................................

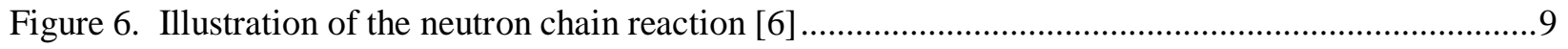

Figure 7. The neutron life-cycle for thermal reactors [7]..................................................................... 10

Figure 8. Illustration of neutron feedback due to $\mathrm{k}_{\mathrm{eff}}$ alone.................................................................11

Figure 9. Illustration of neutron feedback with thermal-hydraulic influences. ........................................12

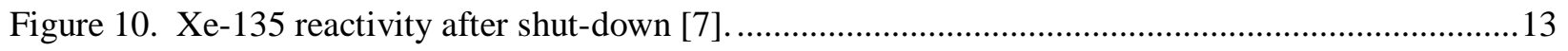

Figure 11. Production of a delayed neutron from the $\mathrm{Br}-87$ decay chain.............................................14

Figure 12. A low-leakage core refueling scheme: $0=$ fresh fuel; $1=$ once burned fuel; $2=$ twice burned fuel; $3=$ third burned fuel [8]...... 
Figure 13. PWR fuel assembly with control rod "spider" clusterr (A), BWR control blade (B). 16

Figure 14. Illustration of power tilt due to control rod insertion [7] ..................................................17

Figure 15. Overview of the heat transfer through a reactor fuel rod and into the coolant.........................19

Figure 16. Illustration of the subcooled boiling process with bubbles formed at the wall and

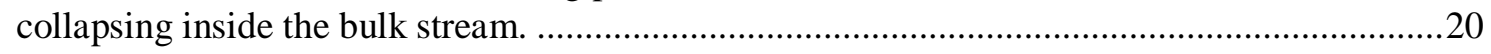

Figure 17. Schematic of the different flow regime in a vertical pipe [9]. ...........................................21

Figure 18. Schematic of two different types of CHF mechanisms. G refers to the mass flux, and $q$

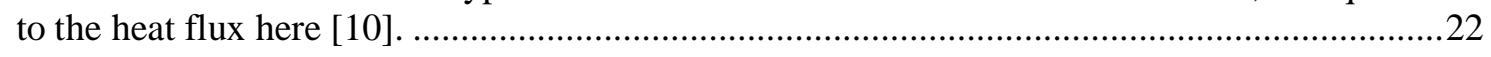

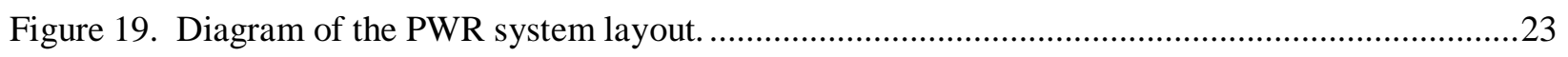

Figure 20. Diagram of the primary system in a Westinghouse PWR ...................................................24

Figure 21. Cross-section view of the reactor pressure vessel (RPV) (left) and the steam generator

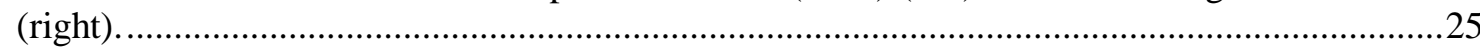

Figure 22. Cross sectional view of a typical four-loop pressurized water reactor showing orientation of core, baffle, shields and reactor pressure vessel [11] .......................................26

Figure 23. Illustration of a PWR fuel assembly and its fuel rods........................................................27

Figure 24. Diagram of the PWR Emergency Core Cooling System [12] .............................................29

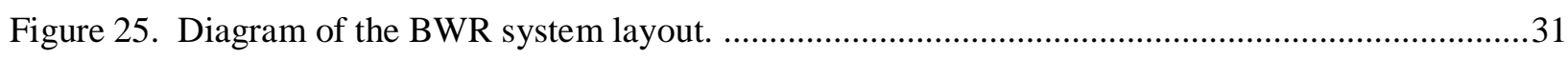

Figure 26. Illustration of the BWR containment building systems. .....................................................32

Figure 27. Cross-section view of the BWR pressure vessel. ..............................................................3

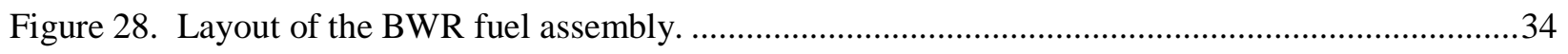

Figure 29. Diagram of the BWR high pressure Emergency Core Cooling System [13].........................36

Figure 30. Diagram of the BWR low pressure Emergency Core Cooling System [13]..........................37

Figure 31. Illustration of aspects affecting stress corrosion cracking (SCC). ...........................................38

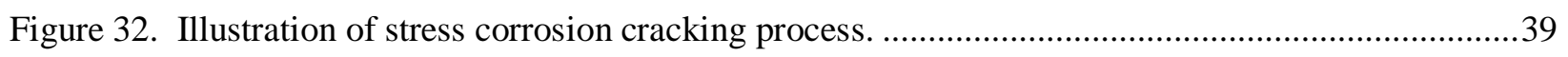

Figure 33. Picture of CRUD formation on a PWR fuel rod (taken from [14])........................................39

Figure 34. Neutron damage cascade production of: Primary Knock-on Atom (PKA) (a), dislocation cascade (b), interstitial/vacancy self-annihilation (c), final dynamic stage of displacement cascade (d-e), ultimate vacancy formation into voids and dislocation precipitation [17].

Figure 35. Example of ductile versus brittle failure. Ductile materials will deform plastically before "total elongation" occurs. Brittle materials will experience elastic yield until fracture. Irradiation induced defects generally cause metals to become more brittle.

Figure 36. Stress-strain curve showing loss of ductility due to irradiation hardeing. ..............................43

Figure 37. Evolution of swelling regimes due to neutron dose ............................................................4

Figure 38. Mechanisms of He induced weld cracking. .......................................................................45

Figure 39: The physical barriers to limit radioactive release: (1) the fuel cladding, (2) the reactor cooling system, and (3) the reactor containment structure. 
Figure 40. Simplified sketch of the PWR RCS loop instrumentation without bypass manifolds.

$\mathrm{T}_{\mathrm{h}}$ stands for hot leg temperature. Tc stands for cold leg temperature [21].

Figure 41. Reactor coolant flow detection via pressure traps in the intermediate-leg pipe bend.

The intermediate-leg connects the steam generator to the primary coolant pump [22].

Figure 42. PWR In-Core Instrumentation [23].

\section{TABLES}

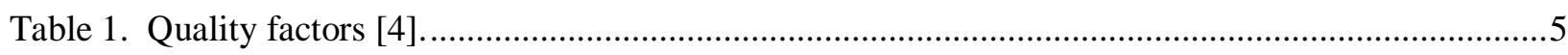

Table 2. Occupational dose annual limits set by 10CFR20.1201, Subpart C [4]....................................5

Table 3. The average energy produced in the fission of U-235 by thermal neutrons. For those mechanisms in which some energy is not recoverable in a reactor core, the recoverable energy is shown in parentheses [5]. 


\section{ACRONYMS}

ADS

Automatic Depressurization System

ALARA

As Low As is Reasonably Achievable

$\mathrm{AOO}$

Anticipated Operational Occurrence

ATWS

ATWT

AVT

BWR

$\mathrm{CHF}$

CLA

CPR

CVCS

DNB

DNBR

DPA

EC

ECCS

EFWS

ESFAS

GDC

General Design Criteria

HPCI

High Pressure Coolant Injection

HTGR

High Temperature Gas Reactor

IPCI

Intermediate Coolant Injection

KERMA

LOCA

Loss of Coolant Accident

LPCI

Low Pressure Coolant Injection

LWR

Light Water Reactor

MCPR

Minimum Critical Power Ratio

NMCA

Noble Metal Chemical Addition

NRC

Nuclear Regulatory Commission

PWR

Pressurized Water Reactor

RCS

Reactor Coolant System

PKA

Primary Knock-on Atom

PPS

Plant Protective System 
RWC

RHR

RHRS

RPS

RPV

RTD

SCC

SAR

SFR

SG

SI

SMR

TEDE

\author{
Reactor Water Cleanup \\ Residual Heat Removal \\ Residual Heat Removal System \\ Reactor Protection System \\ Reactor Pressure Vessel \\ Resistance Temperature Detector \\ Stress Corrosion Cracking \\ Safety Analysis Report \\ Sodium-cooled Fast Reactor \\ Steam Generator \\ Safety Injection \\ Small Modular Reactor \\ Total Effective Dose Equivalent
}




\section{GLOSSARY}

Burn: $\quad$ Consumption of the fuel isotopes by the chain reaction.

Burnup: A quantitative measure of fuel burn.

Burnable: Atoms in the fuel rod or assembly that is consumable by the chain reaction. This does not apply solely to fuel atoms (i.e., uranium or plutonium), but can also be partially inserted control rods. Also, neutron poison fuel pellet coatings, dilutions in the pellet, and/or special rods can be used for reactivity hold-down and power flattening across the fuel assembly.

Chemical Shim: Dissolved boric acid used for reactivity hold-down in a PWR. The concentration of boric acid is weakened as the reactivity of the fuel decreases due to burnup.

Coulombic: Referring to the electrostatic force between two charged particles as dictated by Coulomb's Law.

Dose: A quantitative measure for radiation damage experienced by a material or living organism.

Flux: $\quad$ The average rate that radiation particles pass through a differentially small area in space. Flux is not angularly dependent, meaning that the particles passing through the differential area do not need to be passing perpendicular to the area. More formally it is the average particle density per differentially small volume multiplied by the average speed (not velocity) of the particles that are passing through the volume.

Fluence: The time integrated flux. Fluence is often used as a metric for neutron exposure or neutron damage to reactor structures. It is related to the concept of the Displacements per Atom (DPA).

Half-Life: Time for a radioactive substance to lose half of its radioactivity due to radioactive decay. At the end of one half-life, $50 \%$ of the original material has decayed.

Hold-Down: The negative reactivity attributed to a control rod, chemical shim, or other neutron poisoning feature. The full hold-down worth is subtracted from the positive reactivity of the nuclear fuel when the control rod is fully inserted.

Poison: A non-fuel (i.e., not uranium or plutonium) atom that removes a neutron from the chain reaction by absorption without leading to fission.

Power: The thermal energy produced by the nuclear core due to the ionizing energy created by fission resulting in the thermal motion of fuel atoms, summarily transferred to the coolant and removed to the turbine. Electrical power work energy is created from the turbine converting the thermal power into electromotive force in the electrical generator.

Precursor: An event that precedes another of the same kind, a forerunner.

Radiation: A form of electromagnetic energy having both wave and particle properties. Radiation from radioactive decay possesses a much higher energy than thermal "black-body" radiation (e.g., heat from a fireplace).

Radioactive: Giving off energy in the form of particles and rays by the disintegration of atomic nuclei.

Radioactivity: Spontaneous emission of radiation from the unstable nucleus of an atom. It is a natural process that is stochastic (i.e., random). It is not possible to predict the exact time of emission of radiation.

Suppression: The removal of latent heat from pressurized steam into a pool of water thereby resulting in a temperature increase in the water temperature, e.g., the suppression pool or torus in a BWR. 


\title{
Reactor Fundamentals Handbook
}

\author{
1. Introduction and Purpose
}

This handbook is a brief tutorial and refresher training material on basic Light Water Reactor (LWR) core physics and plant systems. It is reference material for attendees of the Knowledge Transfer Workshop. There are two types of LWR technologies, Pressurized Water Reactor (PWR) and Boiling Water Reactors (BWR). This handbook discusses fundamental design traits of each providing contrasts between performance and safety features. The intent is to provide the participants with an understanding of nuclear terminology associated with LWR technology, including fundamentals, systems, safety, and regulations.

This handbook is not an original textbook. Many authors have contributed collegiate level introduction to nuclear engineering texts. Rather, this material is intended to be a graded summary of important aspects of LWR reactor core and plant systems. It draws heavily on other resources. The interested reader is encouraged to follow citations made in this handbook to more thorough or detailed public references.

\section{Basic Nuclear Energy Principles}

Section 2.1 begins by providing a basic introduction to the concepts of radioactive materials and radioactivity. The various types of radioactive particles and waves are described with selected discussion on the potential effect on the human body and the effectiveness of example radiation shielding methods.

Sections 2.2-2.5 then transition to an introduction of reactions in fissile material and the resulting decay products as the various forms of radioactivity are produced, emitted and absorbed. These neutron-induced nuclear reactions are the building blocks for operation of a nuclear reactor.

\subsection{Radioactive Decay and lonizing Energy}

The atom is the fundamental building block of matter. There are three fundamental sub-atomic particles that comprise and atom. Protons and neutrons make up the atomic nucleus. Protons and neutrons have approximately the same mass. Protons have a positive charge. Neutrons have no charge. Electrons are much smaller in mass and have a negative charge. It is common to think of an atom as a neutron/proton nucleus with orbiting electrons comparable to the relationship between planetary bodies orbiting the sun in the solar system. However, it is also useful to note that these particles have wave-like properties.

There are four fundamental forces in physics: gravitational, electromagnetic, the strong, and the weak forces [1]. The electromagnetic force holds the electrons in balance with the protons, via the law of opposite charges attract. However, these same coulombic forces cause particles of the same charge to repel one another. Therefore, the protons of the nucleus would tend to force each other apart if it were not for the strong force binding them together. The strong force binds together the quarks that make up protons and neutrons and is the "glue" that holds together the atomic nucleus. It should be noted that the gravitational force is in play even at the atomic level. However, the effect is much weaker than on the length-scale of the solar system. The weak force is responsible for the "flavor" of the quarks constituents of the proton and neutron. Thus, it is responsible for the form and function of the sub-atomic particles, and thus dictates radioactive decay of the nucleus. 
Nuclear interactions of interest to nuclear reactors occur between traveling sub-atomic particles and atomic nuclei (and sometimes their electron orbits or shells). These reactions can be governed by classical physics, such as billiard balls. However, these reactions can also have resonant or harmonic behaviors following the laws of modern physics. The result of these reactions can lead to new atoms with different radioactive properties than that prior to the particle-nucleus interaction. It is necessary to introduce a few terms before beginning the discussion of nuclear reactions.

- Radiation: A form of electromagnetic energy having both wave and particle properties. Radiation from radioactive decay possesses a much higher energy than thermal "black-body" radiation (e.g., heat from a fireplace).

- Radioactive: Giving off energy in the form of particles and rays by the disintegration of atomic nuclei.

- Radioactivity: Spontaneous emission of radiation from the unstable nucleus of an atom. It is a natural process that is stochastic (i.e., random). It is not possible to predict the exact time of emission of radiation.

- Half-Life: Time for a radioactive substance to lose half of its radioactivity due to radioactive decay. At the end of one half-life, $50 \%$ of the original material has decayed.

The type of radiation emitted by a nucleus, is related to the ratio of protons to neutrons. Stable isotopes tend to have near equal proportions of neutrons and protons. Heavier elements require more neutrons than protons in order for the nucleus to exist. All elements with a number of protons greater than 83 are radioactive due to this neutron/proton imbalance. Nuclear decay reactions occur to bring the nucleus to a less excited state which has more balanced nucleons. The radiation emission is preceded by a process that generally brings the proportion of neutrons and protons closer to equality or stable. These reactions often leave the nucleus in an excited metastable which is further brought closer to the ground state by the emission of gamma-rays.

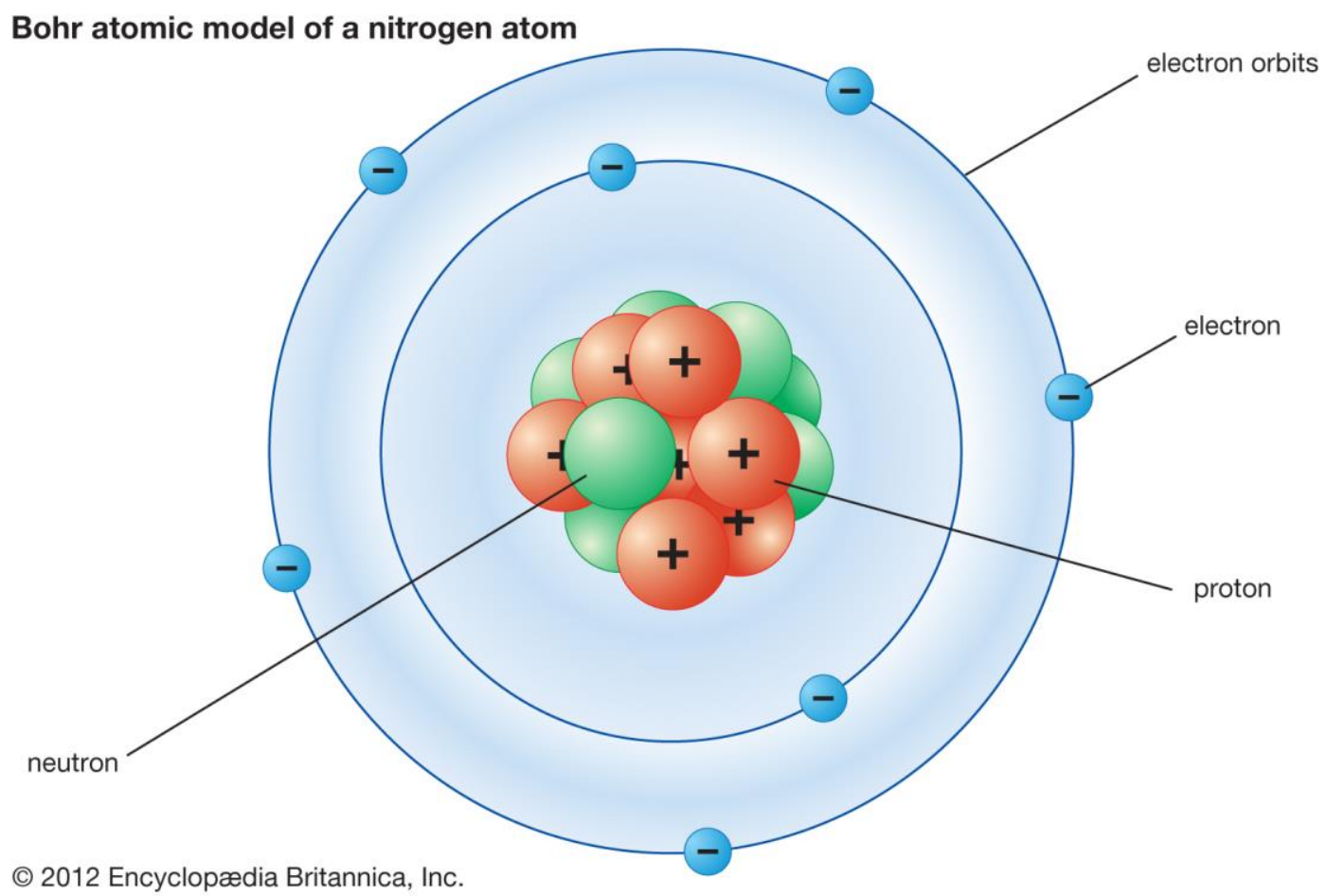

Figure 1. The Bohr atomic model of a nitrogen atom [2]. 
The different types of radiation have different properties.

- Alpha particles are charged particles of helium nuclei that have been emitted at high energy. They are slowed down by coulombic interactions with the electrons of the atoms for which they are traveling through, eventually gaining electrons and becoming a helium atom.

- Beta particles are emitted high energy electrons. They are slowed down in a similar fashion as alpha particles, but are stopped less readily. Positrons are the antiparticle equivalent of beta particles. Unlike electrons they have a positive charge.

- Gamma-rays are high energy photons. Visible light is also comprised of photons, only at much smaller energy. Gamma-rays interact with the electrons of the media for which they are traveling, displacing the electrons, thus causing ionization. Therefore materials with a high proton (i.e., Z-number) stop gamma-ray fields more readily than low Z-number materials, e.g., lead. However, they can be stopped by lower-Z materials, such as water, but less efficiently.

- Protons and neutrons can be emitted from the nucleus. Protons, like alpha, beta, and positron particles interact via coulombic interactions.

- Neutrons do not have a charge. Also, they do not interact with electrons, but do interact with the nucleus of the atoms for which they are traveling through. These interactions are related to the type of nucleus and the neutron speed. For slowing down neutrons, the amount of energy lost per interaction is proportional to the nucleus mass. More energy is lost by collision with a small atom than a large atom. As neutrons slow down the probability of interaction goes up. Therefore, neutrons tend to interact more with elements with smaller mass, e.g., the hydrogen in the $\mathrm{H}_{2} \mathrm{O}$ molecule.

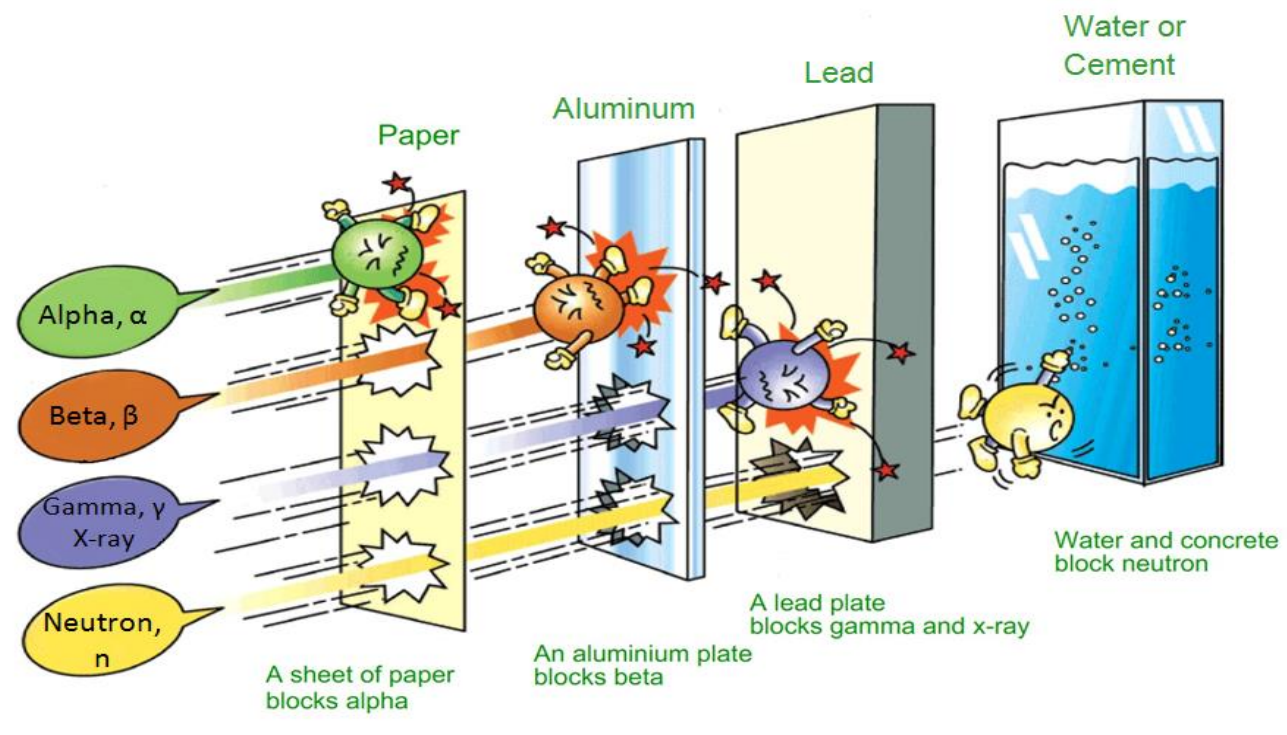

Figure 2. Illustration of stopping power for different types of radiation.

For humans working or living near nuclear reactors, four types of radiation present any kind of meaningful risk. The harm that radiation can cause to humans is in the form of ionization within a living cell that damages cellular function. Hence, this radiation is called 'ionizing radiation'. The following types of radiation are most associated with nuclear reactors.

Alpha particles are emitted from actinides (Z-number 89 - 103) such as uranium or plutonium. Alpha particles are not dangerous to humans if exposure is to the outside of the body because the dead layer of skin on the epidermis is a sufficient attenuator or shield. If ingested or inhaled, the sources of alpha 
particles can be very dangerous because various digestive and respiratory tissues critical to life functions can be damaged by the ionization created by exposure.

Neutrons are also emitted from actinides via fission either spontaneously during radioactive decay or induced during the chain reaction. Only various transuranic isotopes such as those of plutonium, curium, or californium have radio-activities sufficiently great to pose a risk from decay. However, neutron fields from the chain reaction within the nuclear core can present a hazard to workers if not managed well. The reactor core is surrounded by a thick steel baffle, shroud, and for some plants a shield wall which attenuate the high energy prompt neutrons and photons prior to impinging upon the reactor pressure vessel. This reduces the amount of heat generated within the vessel as well as reduces neutron damage which increases its service life. A high density concrete bioshield outside the reactor further attenuates the radiation in order to protect workers.

Beta particles are emitted from fission products. Beta particles can cause damage to the outside of the skin or cause damage to tissues within the body if ingested or inhaled. This type of exposure does not present a hazard to workers, but is relevant to the protection to the public. In the event of a reactor accident, the reactor primary containment building is designed to minimize to near zero the leakage of airborne radioactive fission products (beta emitting) and transuranics (alpha emitting) such that the dose to the public outside of a defined "exclusion zone" is below safety limits.

Gamma rays are emitted by both radioactive decay as well as by the fission event. They are not readily slowed down in the body, but can be hazardous if the field intensity is sufficiently high. Examples of gamma-ray fields could be from the nuclear core itself or from activated materials, i.e., materials that become gamma-ray radioactive following exposure to the nuclear core's neutron field. Activated materials could be reactor hardware such as control rod drive mechanisms requiring maintenance. It can also be from impurities in the reactor coolant becoming radioactive prior to being deposited on plant components further from the core thus creating some hazard to workers that need to be appropriately mitigated. Dose to workers from relocated activation is typically mitigated by administrative controls set by the plant operator's As Low as Reasonably Achievable (ALARA) goals which is an important part of the plant's health and safety program.

The amount of damage radiation can pose to a human being is not only a property of type and energy of radiation, but what bodily tissue or biological system that is exposed to the radiation. The amount of exposure to radiation is normally referred to as "dose".

Dose equivalence accounts for the radiation hazard to the tissue being exposed. Simplistic models of dose equivalent assume a "quality factor" multiplied against the absorbed dose. The effective dose equivalent for the whole body is referred to as the Total Effective Dose Equivalent (TEDE). Radiation safety regulations typically provide limits to both radiation workers and members of the public in terms of dose equivalent to specific tissues as well as TEDE [3].

Dose equivalent (or effective dose) combines the amount of radiation absorbed and the medical effects of that type of radiation. For beta and gamma radiation, the dose equivalent is the same as the absorbed dose. By contrast, the dose equivalent is larger than the absorbed dose for alpha and neutron radiation, because these types of radiation are more damaging to the human body. Units for dose equivalent are the roentgen equivalent man (rem) and sievert $(\underline{\mathrm{Sv}})$, and biological dose equivalents are commonly measured in 1/1000th of a rem (known as a millirem or mrem). The dose in rem equals the dose in rad multiplied by the quality factor $(\mathrm{Q})$. 
Table 1. Quality factors [4].

\begin{tabular}{|l|l|}
\hline Type of Radiation & Quality Factor $(\mathrm{Q})$ \\
\hline X-ray, gamma-ray, $\beta^{-}$ & 1 \\
\hline $\begin{array}{l}\alpha, \text { charged particle, fission } \\
\text { fragments, etc. }\end{array}$ & 20 \\
\hline${ }^{1}$ n of unknown energy & 10 \\
\hline High-energy protons & 10 \\
\hline
\end{tabular}

Table 2. Occupational dose annual limits set by 10CFR20.1201, Subpart C [4].

\begin{tabular}{|l|l|}
\hline Total Effective Dose Equivalent & 5 rems \\
\hline $\begin{array}{l}\text { Sum of deep-dose equivalent and committed dose } \\
\text { equivalent to any individual organ or tissue other } \\
\text { than the lens of the eye }\end{array}$ & 50 rems \\
\hline Lens of the eye & 15 rems \\
\hline Shallow-dose to the skin & 50 rems \\
\hline
\end{tabular}

\subsection{Neutron Induced Nuclear Reactions}

Because neutrons interact with the nucleus, they can change its nuclear properties. Other forms of radiation can do this too, but neutrons serve a great many practical applications converting stable into radioactive isotopes to be later used in medical and industrial applications.

A nuclear reaction can be endothermic or exothermic. When two reactants (e.g., a ray or particle and a target nucleus) are brought together, collided, they will form one or more products. The difference in total kinetic energy between the products and reactants is referred to as the Q-value. This energy corresponds to the amount of mass converted to energy (or energy converted to mass) during the nuclear reaction.

The probability of nuclear reaction is defined by the cross-section with units of barns $\left(10^{-24} \mathrm{~cm}^{2}\right)$. A reaction rate is defined by the following equation.

$$
R=N \times \sigma \times \phi
$$

Where: $\mathrm{N}$ is the atomic density with units of atom/b-cm. $\sigma$ is the nuclear cross-section in barns. $\phi$ is the neutron flux with units of $\mathrm{cm}^{-2} \mathrm{~s}^{-1}$. $\mathrm{R}$ is the reaction rate per unit volume with unis of $\mathrm{cm}^{-3} \mathrm{~s}^{-1}$. Note that flux, $\phi$, represents neutron density, $\mathrm{cm}^{-3}$ multiplied by the average neutron speed, $\mathrm{cm} / \mathrm{s}$. Note that $\mathrm{N}$ can be computed from the mass density following $\mathrm{N}=\rho \times \mathrm{N}_{\mathrm{A}} / \mathrm{A}$. Where $\rho$ is the mass density in $\mathrm{g} / \mathrm{cm}^{3} . \mathrm{N}_{\mathrm{A}}$ is Avogadro's number 6.022E23 atom $/ \mathrm{mol}$. A is the atomic mass in gram $/ \mathrm{mol}$.

Nuclear fission is a type of nuclear reaction where the addition of a neutron to a fissionable nucleus induces the nucleus to split into: on average two "fission-products", two to three high energy neutrons, two to three gamma-rays and a neutrino. The additional neutrons are used to promulgate further nuclear fissions. 


$$
{ }_{0}^{1} \mathrm{n}+{ }_{92}^{235} \mathrm{U} \rightarrow{ }_{92}^{236 *} \mathrm{U} \rightarrow \mathrm{Y}_{1}+\mathrm{Y}_{2}+v_{\mathrm{n} 0}^{1} \mathrm{n}+v_{\gamma} \gamma+\mathrm{v}
$$

Very little kinetic energy is invested in creating fission compared to what is liberated. Most of the Qvalue is converted into kinetic energy of the fission products which then undergo coulombic interactions in the fuel until they gain enough electrons to become atoms lodged within the crystalline matrix of the fuel. This kinetic energy manifests itself as heat which is carried away from the fuel by the reactor coolant to later be converted into electrical energy.

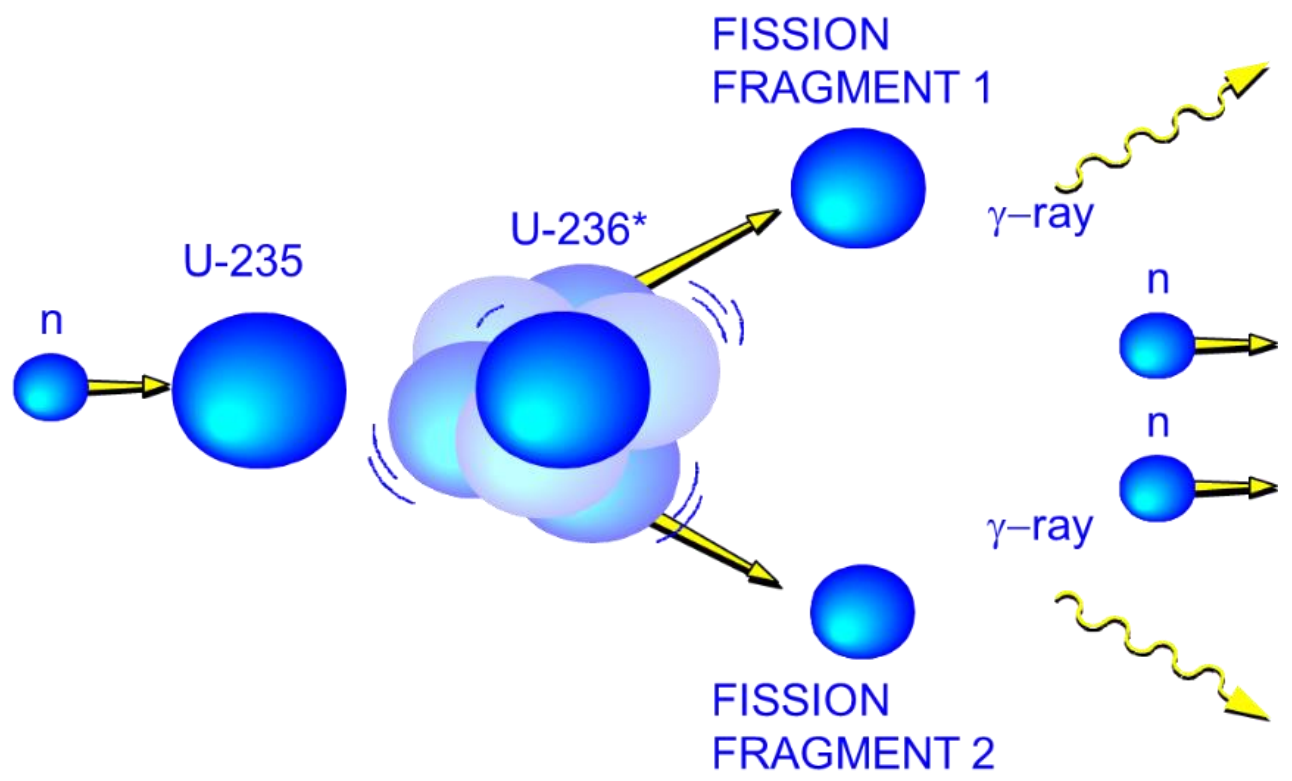

Figure 3 Illustration of nuclear fission. For a very brief moment a U-236 atom is formed which scission into fission products, prompt neutron and gamma-rays, and neutrino constituents.

When a fissile isotope absorbs a neutron it can either fission or undergo a neutron-capture reaction. For example, U-235 will fission $\sim 80 \%$ after every absorption in neutron spectrums typical of a LWR. The remaining $\sim 20 \%$ are neutron capture reactions that convert the U-235 into U-236 and release a gamma-ray in the process. If the compound U-236 nucleus does fission, it will split into two fission products along with prompt gamma-ray, neutron, and neutrino emissions. Fission fragments are created stochastically over a spectrum of possible proton and mass numbers. These fission fragments deposit their kinetic energy into the fuel media, but are also radioactive with half-lives ranging from microseconds to millennia.

The radioactive decay of these fission products creates a source of heat (as much as $6 \%$ of the power just prior to reactor shut-down) that must be removed continuously even after the fission reaction rate is stopped. In other words the core must maintain a minimum level of cool-ability for the long term as this decay heat continues for decades. The beta/gamma-radioactivity from these fission products not only creates this heat, but also is a source of radiation exposure even when the irradiated fuel is removed from the core. Therefore, used nuclear fuel must be stored under-water in order for cool-ability and radiation worker protection for years after it is irradiated. Eventually the radioactivity drops to a level where used nuclear fuel can be stored in dry-storage casks but these still provide shielding and air-cooling. 
Table 3. The average energy produced in the fission of $U-235$ by thermal neutrons. For those mechanisms in which some energy is not recoverable in a reactor core, the recoverable energy is shown in parentheses [5].

\section{Prompt:}

Kinetic Energy of the Fission Fragments: $168 \mathrm{MeV}$

Kinetic Energy of the Prompt Fission Neutrons: 5

Fission $\gamma$-rays: 7

$\gamma$-rays from neutron capture: (3-12 recoverable)

\section{Delayed:}

Fission product $\beta$-decay energy: 8 ( 8 recoverable)

Fission product $\gamma$-decay energy: 7 (7 recoverable)

Neutrino kinetic energy: $12(0)$

Total Fission Energy: 207 (198-207 recoverable)

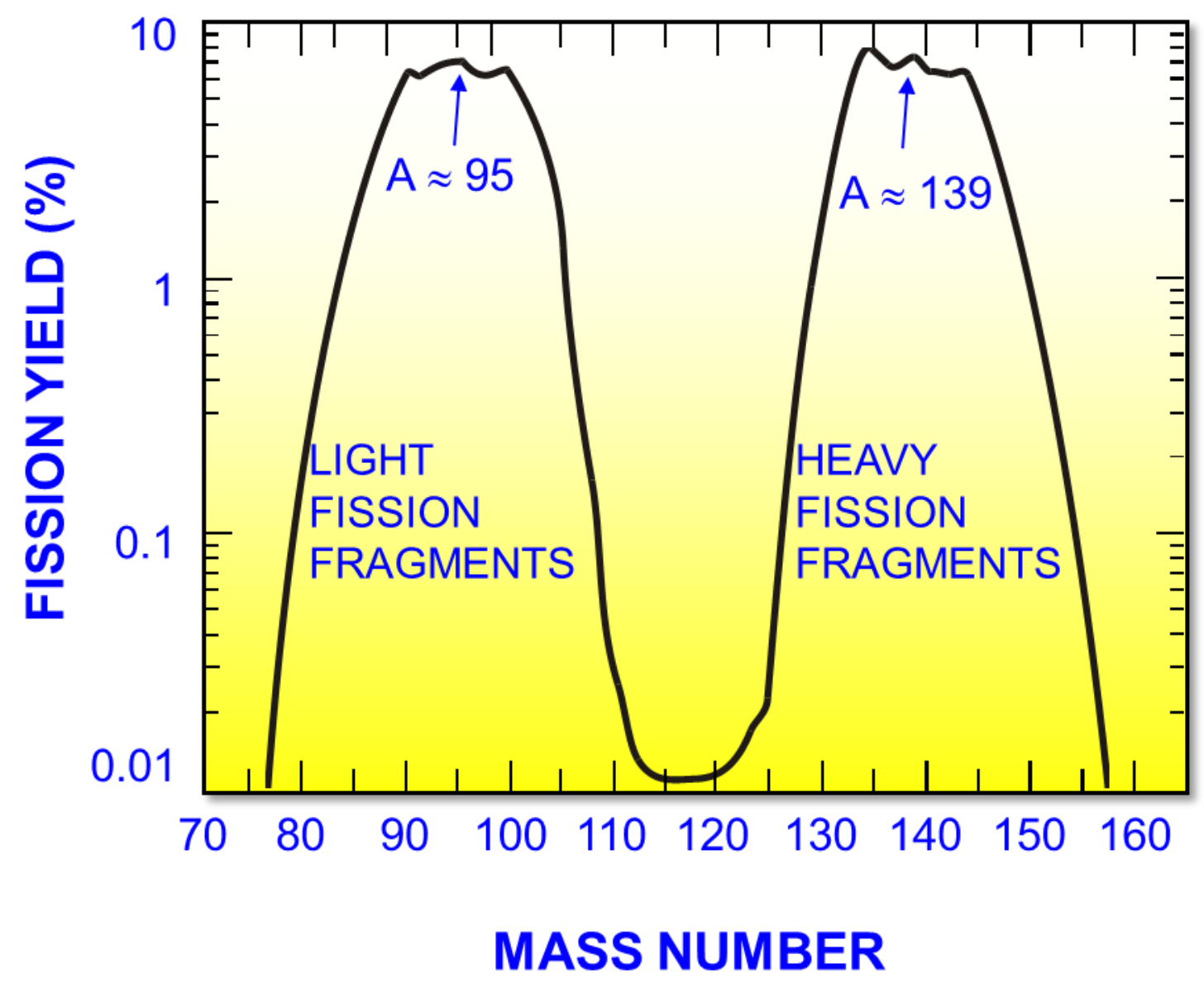

Figure 4. Distribution of fission fragments with percentage of their yield following a fission. 


\subsection{Fertile versus Fissile}

An element is distinguished by the number of protons (Z-number) in the atom. An isotope is a member of an element defined by the number of neutrons (i.e., Z-number subtracted from the mass number, A). The number of protons is typically balanced by the number of electrons. Thus, the Z-number distinguishes at atom's chemical properties from other elements, whereas the neutron number distinguishes the atom's nuclear properties from other isotopes. A fissile isotope will fission with slow (thermal) neutrons, e.g., U-233, U-235, Pu-239, Pu-241 are all considered fissile. A fertile isotope can be converted into a fissile isotope by the capture and subsequent decay-chain from the capture reaction daughter. For example, Pu-239 is created by the short-lived beta decay of U-239 and Np-239, created from the neutron capture by U-238. Fertile isotopes can fission also, but there is a threshold energy that must be overcome. Fissile isotopes are heavy metal elements with an odd neutron number. Fertile isotopes are heavy metal elements with an even neutron number.

Neutrons are born from fission with a mean energy of approximately $1.2 \mathrm{MeV}$. This energy is above the energy threshold for fast fission in most fertile isotopes. In a High Temperature Gas Reactor (HTGR) or a LWR, the neutrons lose energy rapidly via collisions with the graphite or water moderator, respectively, until they are at 'thermal' energies. Therefor the contribution to fission from fast neutrons is very small. In a reactor without a moderator such as a Sodium-cooled Fast Reactor (SFR), neutron multiplication from fertile isotopes is significant. Cross-sections are larger at thermal than fast energies, thus the flux magnitude is less in thermal reactors than in fast reactors for the same fission reaction rate (i.e., power) density.

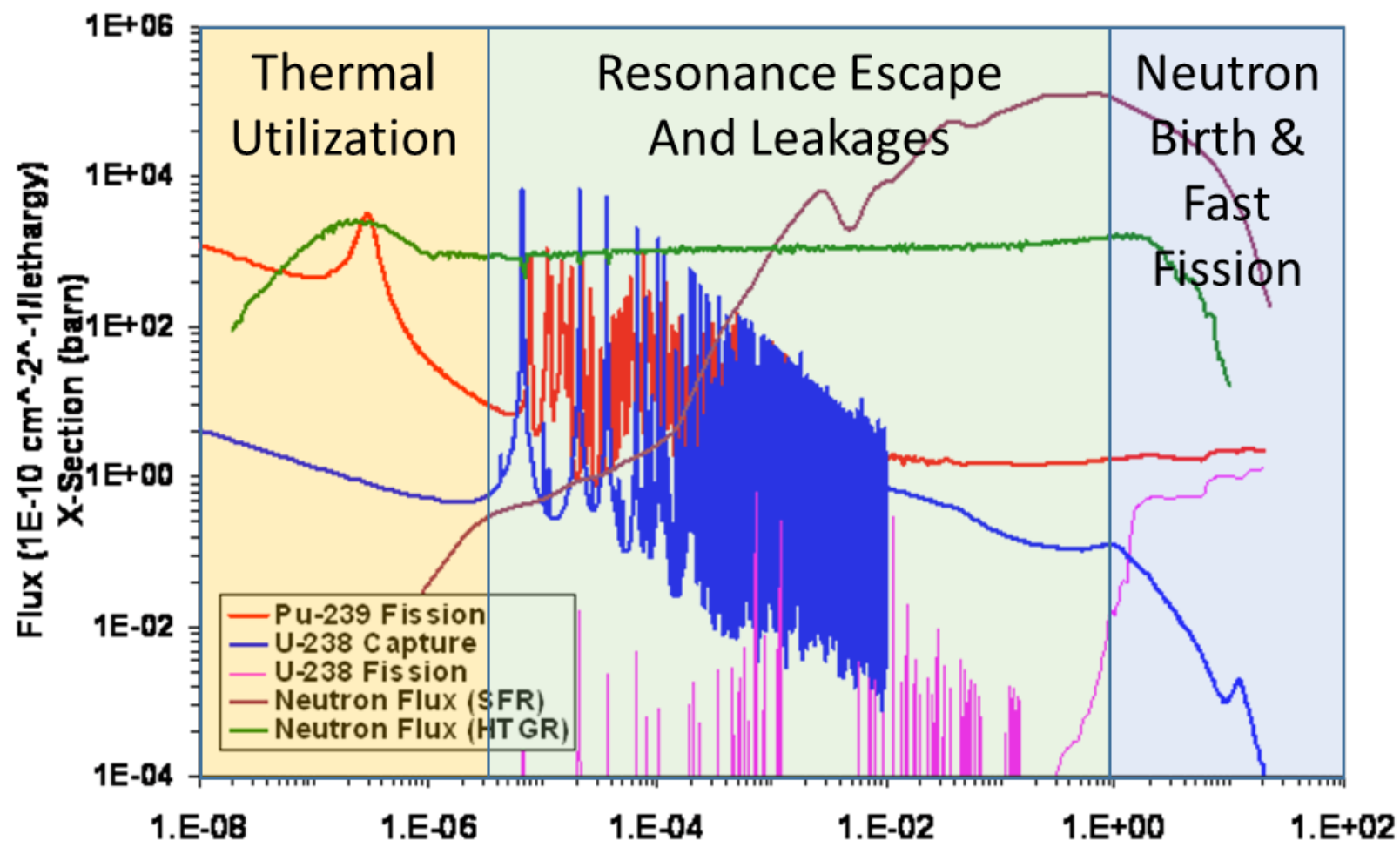

\section{Energy (MeV)}

Figure 5. Comparison of fissile and capture cross-sections for Pu-239 and U-238 plotted with the neutron spectra of a High Temperature Gas Reactor (thermal spectrum HTGR) and a Sodium-cooled Fast Reactor (fast spectrum SFR). 


\subsection{The Chain Reaction}

The chain reaction is a continuing series of nuclear fission events that take place within the fuel of a nuclear reactor. Neutrons produced by a split nucleus collide with and split other nuclei using a chain of fission events. After birth the prompt neutron must survive several types of processes before leading to the creation of a new fission event. The 'life-cycle' of a neutron born from fission usually occurs on the order of $10^{-4}$ (thermal) to $10^{-6}$ (fast) seconds. If the neutron population density of a nuclear reactor is on average invariant from one generation to the next, the reactor is said to be critical. If it is increasing, it is said to be super-critical; if it is decreasing, it is said to be sub-critical. The ratio of the neutron population to the previous population is the neutron multiplication factor, denoted with the letter ' $\mathrm{k}$ '.

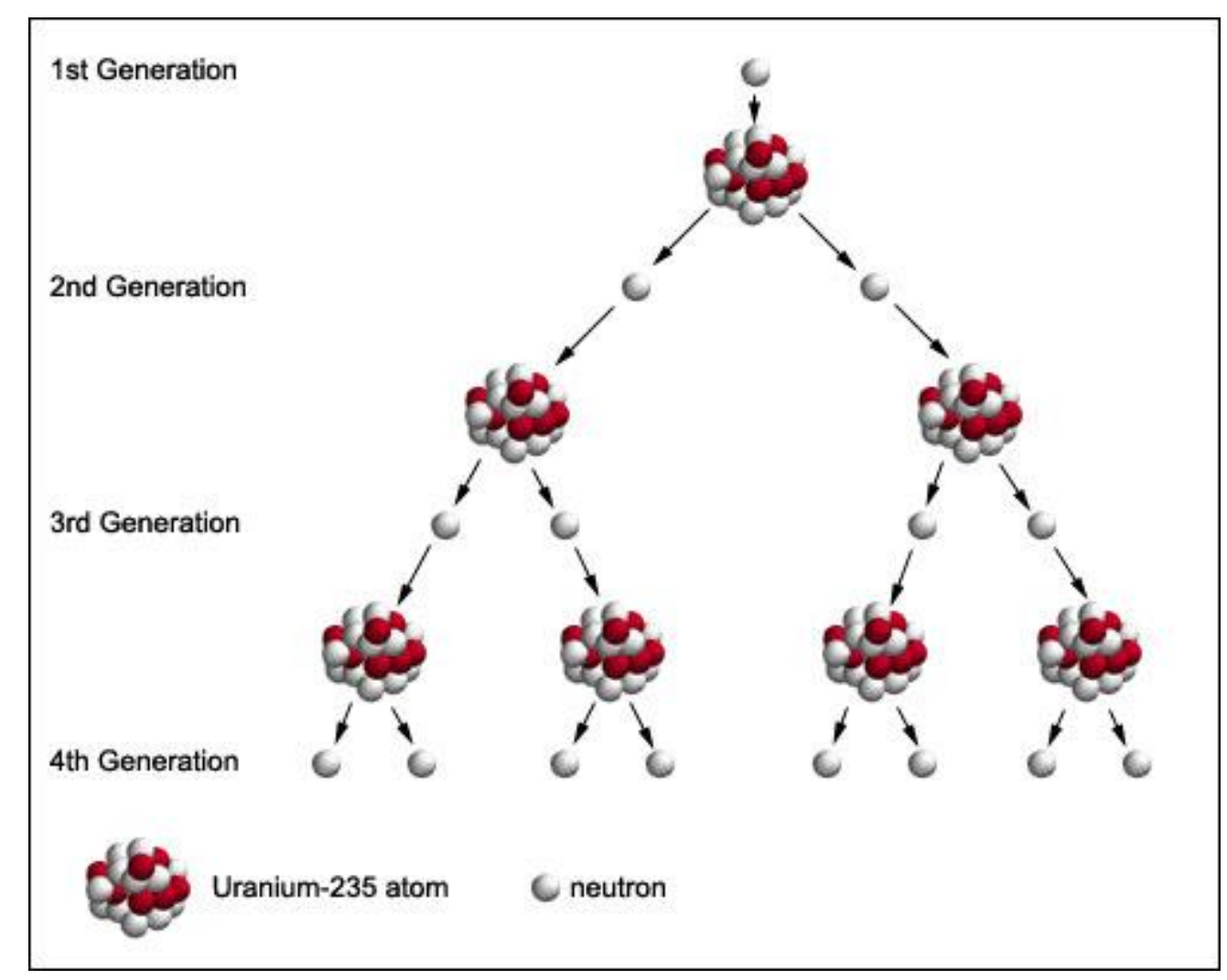

Figure 6. Illustration of the neutron chain reaction [6]

\subsection{The Six Factor Formula}

The neutron life-cycle is a high-level model of the physical processes that a fission neutron undergoes over the course of a generation. Each step in the life-cycle corresponds to the ratio of neutrons leaving the process or entering the process. Multiplication of these ratio (or factors) is known as the six-factor formula and yields the neutron multiplication factor, $\mathrm{k}$. Each step in the neutron life-cycle is discussed here.

1. Fast Fission: Fast fission occurs when a fast neutron causes fission without first slowing down. It is the ratio of all fast neutrons produced by fission due to both thermal and fast neutrons divided by those produced by fission due to thermal neutrons only. 
2. Fast non-Leakage: The probability that the neutron will not escape the reactor at fast energies. It is simply the ratio of fast neutrons that remain within the reactor boundary divided by all fast neutrons produced.

3. Resonance Escape: Most neutrons bounce around (scattering of low-mass nuclei). This causes the neutrons to lose energy with each scatter. This is known as moderation. If the neutron energy is of the order of atomic motion of the fuel nuclei in their crystalline lattice, the neutron is considered at "thermal" energies. The probability of atomic interaction increases for decreasing energy. As neutrons slowdown from fast to thermal energies they must survive being absorbed by absorption reactions which exhibit resonance behaviors in this energy range. Resonance escape probability is the ratio of the number of neutrons that reach thermal energies divided by those that began to slow down.

4. Thermal non-Leakage: The probability that the neutron will not escape at thermal energies. It is simply the ratio of thermal neutrons that remain within the reactor boundary divided by all thermal neutrons.

5. Thermal utilization: Some neutrons are captured by non-fuel atoms or are captured by non-fissile fuel atoms. This is the ratio of thermal neutrons absorbed in the fuel divided by those absorbed in all reactor materials.

6. Reproduction: The fuel atom absorbs one neutron and may fission. Once it fissions it produces two to three high energy, or "fast", neutrons. The Reproduction factor is the number of fast neutrons produced by thermal fission divided by thermal neutrons absorbed in the fuel.

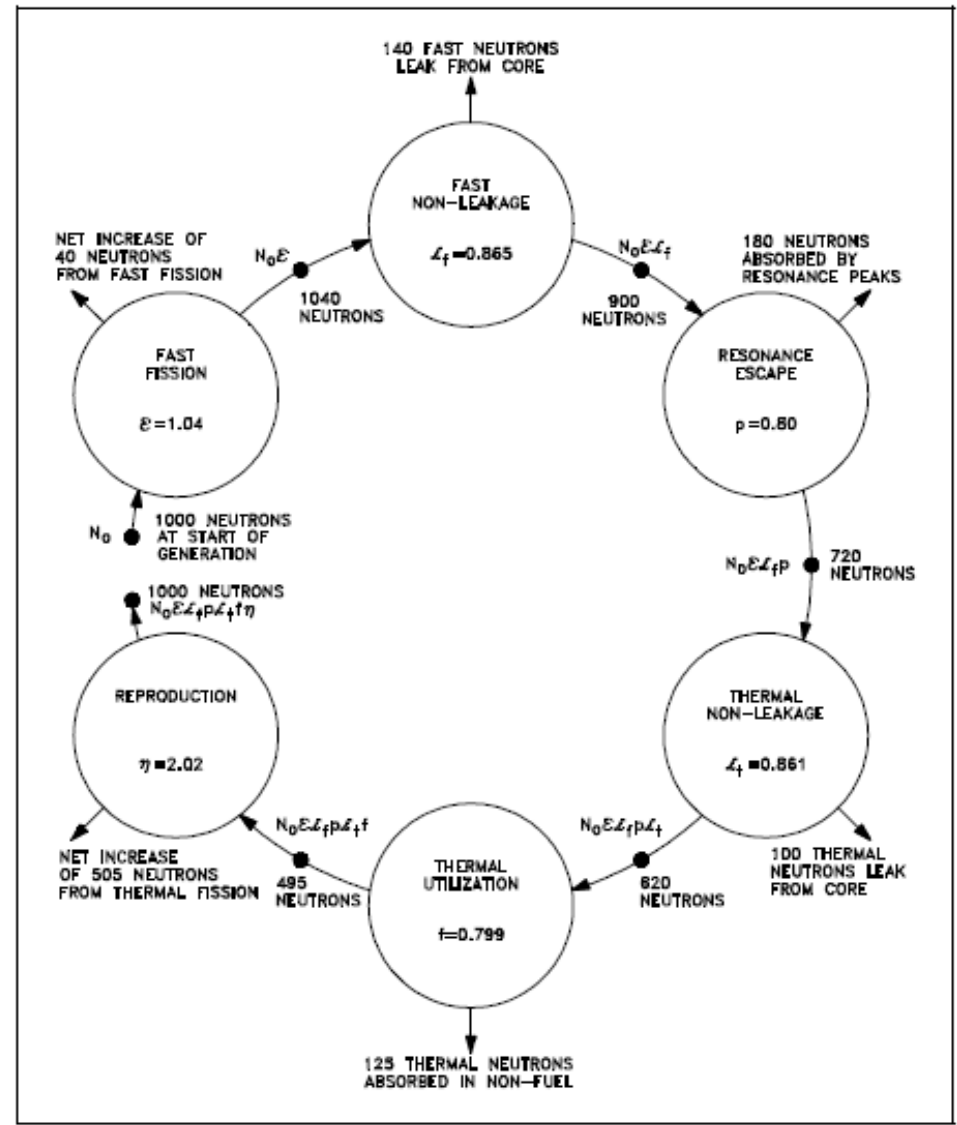

Figure 7. The neutron life-cycle for thermal reactors [7]. 


\section{Basic Core Physics Principles \\ 3.1 Core Physics}

\subsubsection{Core Reactivity}

The measure of deviation (or departure) from criticality is known as reactivity. Therefore reactivity is most simply stated as $\rho=(\mathrm{k}-1) / \mathrm{k}$. Reactivity is described operationally as being "added or removed" from the core using control rods to change the neutron population, dissolved neutron absorbers, changes in fuel temperature, and changes in moderator density.

\subsubsection{Reactivity Feedback}

A reactivity coefficient is a measure of a change in reactivity per change in core condition. Examples:

- Fuel temperature.

- Moderator temperature or density

- Fission Product Poisons

Reactivity coefficients can be positive or negative indicating positive or negative dynamic feedback. Core condition and reactivity changes are dynamically coupled. Overall, it is desired that the net effect be in a safe direction for the reactor, i.e., if power or temperature is increasing negative reactivity occurs. This would ensure a self-controlling or limiting situation. In reality, feedback is much more complicated. It is three-dimensional, non-linear, and sensitive to initial conditions.

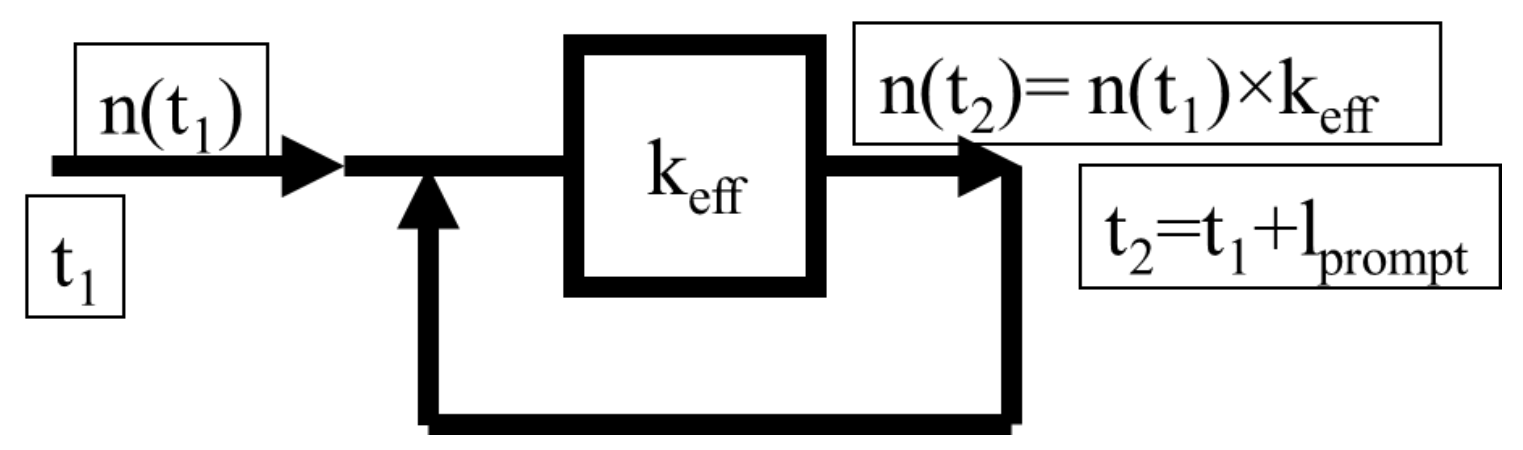

Figure 8. Illustration of neutron feedback due to $k_{\text {eff }}$ alone.

Reactor neutron physics is a coupled phenomenon with coolant thermal-hydraulics. Coolant temperature and pressure sets the state (gas or liquid) of the coolant in the core. The resulting changes in density influences the amount of moderation. In the case of PWR, moderator density changes also influences the density of soluble boron in the core. In the case of BWRs, changes to the moderator density via the steam quality (vapor/liquid ratio) can be sufficiently significant to change reactor power. These are essentially modulations of the fuel utilization factor. In both PWR and BWR, changes to fuel temperature changes the resonance escape probability of the fuel. 


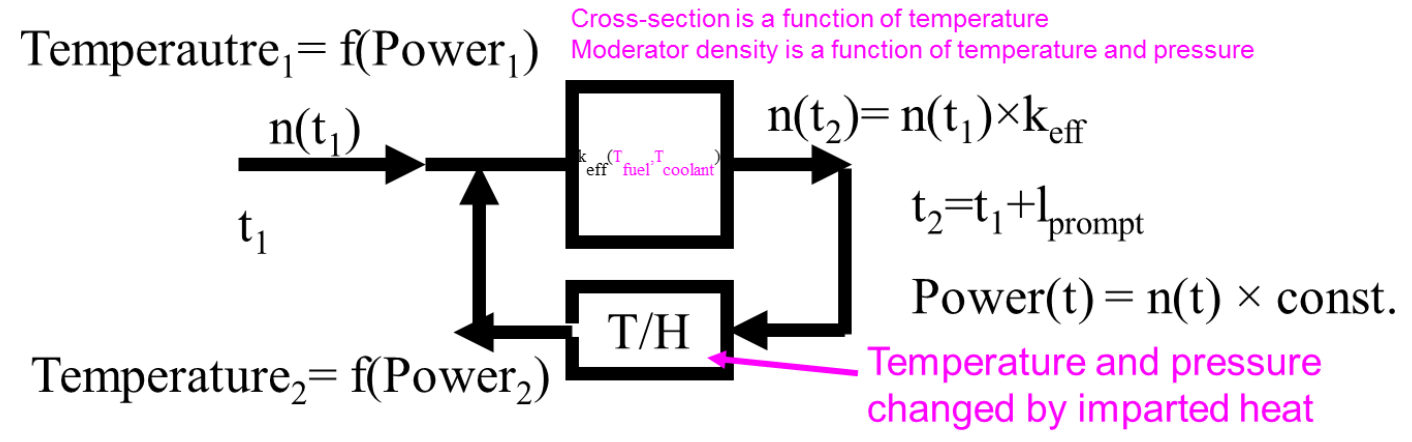

Figure 9. Illustration of neutron feedback with thermal-hydraulic influences.

The critical condition is essentially a function of the fuel and coolant temperatures and densities, and control poison insertion or withdrawal. Prompt changes in power level result in nearly instantaneous changes to fuel temperature (prompt feedback). In general, the power level changes the coolant temperature and pressure by imparting heat energy as it passes through the reactor. For example, coolant density changes near the inlet can influence moderation and criticality near the outlet. Bulk changes in coolant temperature and pressure have to propagate through the primary system before reentering the core. Feedback is on the order of seconds, minutes, or hours.

\subsubsection{Xenon and Samarium Neutron Poisoning}

Fission product poisoning is an important feedback behavior of fuel burnup. Fission products absorb neutrons as they are slowed down, typically by resonant $(n, \gamma)$ reactions. Thus, as they accumulate, due to cumulative fissions, they reduce the resonance escape probability (from the six factor formula). Thus, the available reactivity to sustain the chain reaction is predicated on the available fuel to make fission as well as the chain reaction stifling via fission product poisoning.

Of the >2000 fission products that are produced during the fuel's burnup, roughly 200 of these are important neutron absorbers. Isotopes not of this 200 will quickly decay by $\beta$ - emission or Electron Capture (EC) into new isotopes of the same mass, but different neutron-to-proton ratios. These decay chains ultimately lead to isotopes that are stable or have half-lives long enough to be present in the fuel throughout its irradiation. Of these absorbing isotopes, two have significantly high neutron capture crosssections, xenon-135 and samarium-149.

The precursor isotopes for the production of Xenon-135 are Te-135 and I-135. The independent fission yields for Te-135 and I-135 are both approximately 3\%, while Xe-135 is about 7.5E-2\%. Te-135 decays to I-135 which decays into Xe-135. I-135 is not a strong absorber, but its half-life plays an important role in the creation of Xe-135. A high neutron capture cross-section makes Xe-135 a chainreaction inhibitor. Also if the reactor power density (and thus neutron flux intensity) is sufficiently high, the concentration of xenon can reach an equilibrium proportional to power level. Different power levels will lead to different equilibrium Xe-135 concentration.

$$
{ }_{52}^{135} \mathrm{Te}\left(\mathrm{T}_{1 / 2}=19 \mathrm{~s}\right) \rightarrow{ }_{53}^{135} \mathrm{I}\left(\mathrm{T}_{1 / 2}=6.57 \mathrm{hr}\right) \rightarrow{ }_{54}^{135} \mathrm{Xe}\left(\mathrm{T}_{1 / 2}=9.1 \mathrm{hr}\right) \rightarrow{ }_{55}^{135} \mathrm{Cs}\left(\mathrm{T}_{1 / 2}=2.3 \mathrm{E} 6 \mathrm{yr}\right) \rightarrow{ }_{56}^{135} \mathrm{Ba}
$$

Xe-135 also has a relatively short half-life $\left(\mathrm{T}_{1 / 2}=9.1\right.$ hours $)$, which is slightly less than $\mathrm{I}-135\left(\mathrm{~T}_{1 / 2}=\right.$ $6.57 \mathrm{hrs})$. Therefore, the concentration of Xe-135 continues to accumulate after shut-down proportionately to the production rate of the I-135 precursor. Consequently, the associated reactivity hold-down worth of xenon can be correlated by the pre-shut-down power level as well the time following shut-down (e.g., a long period of high power level operation prior to shutdown results in high Xenon levels and an extended shutdown period allow the Xenon to decay). In fact this power and decay-time dependent nature of xenon reactivity hold-down can actually preclude restart of the nuclear reactor for a 
period of time until the Xe-135 has decayed away. This scenario is more important for high power density reactors and less important for low power density reactors.

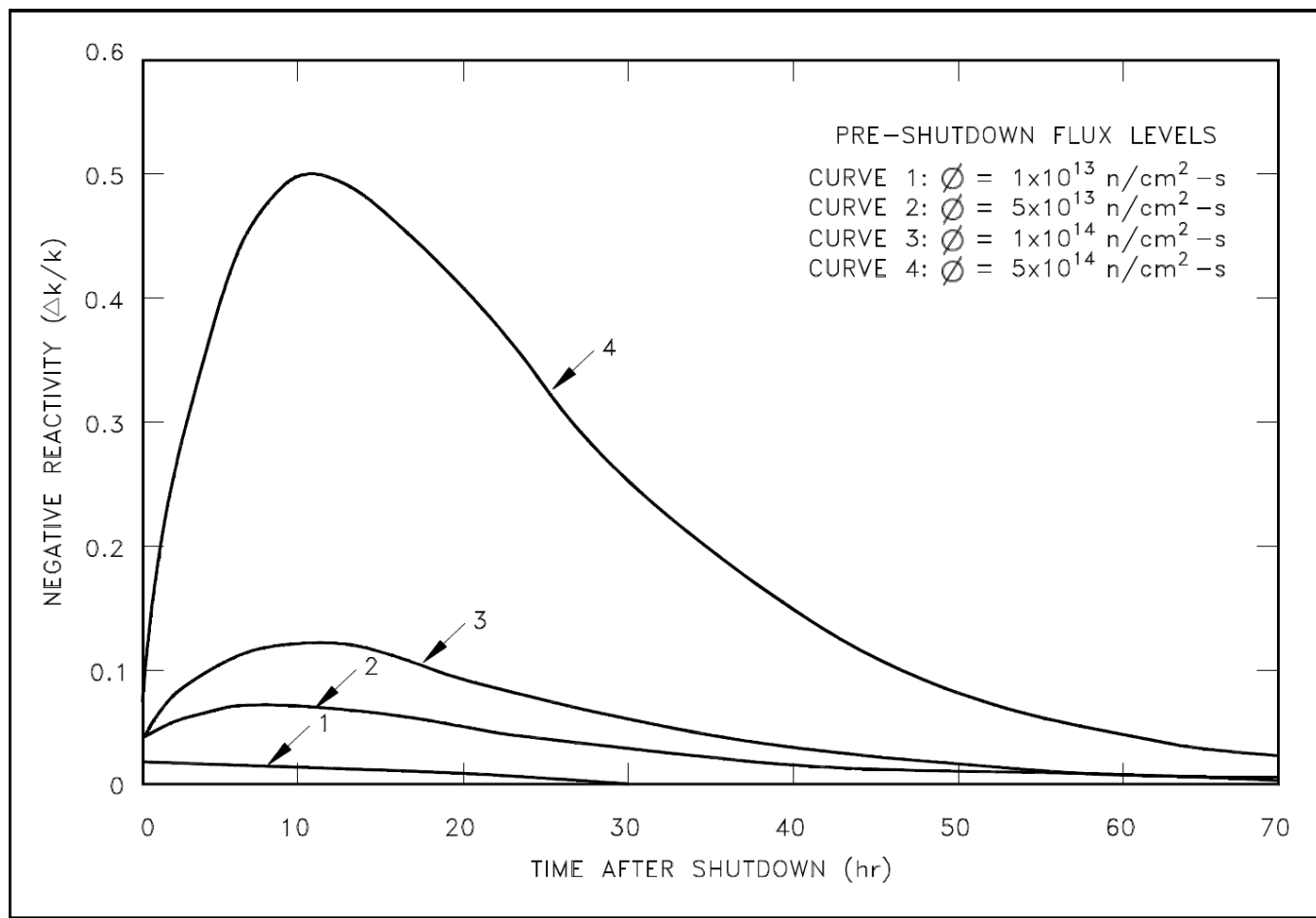

Figure 10. Xe-135 reactivity after shut-down [7].

The interplay between I-135 creation by fission and loss by both neutron capture and radioactive decay can lead to a dynamic behavior known as xenon oscillation. Xenon oscillation is caused by lack of symmetry in the core power distribution (e.g., due to a power tilt caused by control rod insertion) which causes an imbalance in fission rates within the reactor core, and therefore in the I-135 buildup and Xe-135 capture rate. In the high-flux region, Xe-135 burnout allows the flux to increase, while in the low-flux region, the increase in Xe-135 cause a reduction in flux. Due to the higher fission rate, the I-135 concentration increases where the flux is high and decreases where the flux is low. After the I-135 concentration recovers, decay to Xe-135 reverses the initial situation. Flux decreases in this area, and the former low-flux region increases in power. Repetition of these patterns can lead to xenon oscillations moving about the core resulting in corresponding power oscillations. These power oscillations have resulted in axial offset challenges that exceed power distribution limits and require downpower.

Sm-149 is also an important neutron poison that accumulates after reactor shut-down. Nd-149 decays into Pm-149 which decays into Sm-149. The half-life of Nd-149 $\left(\mathrm{T}_{1 / 2}=1.73\right.$ hours) is much shorter than that of Pm-149 ( $\mathrm{T}_{1 / 2}=53.1$ hours). Therefore, one can assume that the production of Pm-149 is the result of the combined cumulative fission yield of Nd-149 and Pm-149 (cumulative yield of 1\%). Sm-149 is stable and thus is not eliminated by radioactive decay. Its only loss process is by neutron capture. Because its production (fission yield of Nd-149 and Pm-149) and loss (neutron capture) are both dictated by neutron flux, the equilibrium concentration of Sm-149 is independent of flux and by extension reactor power.

$$
{ }_{60}^{149} \mathrm{Nd}\left(\mathrm{T}_{1 / 2}=1.72 \mathrm{hr}\right) \rightarrow{ }_{61}^{149} \mathrm{Pm}\left(T_{1 / 2}=53.1 \mathrm{hr}\right) \rightarrow{ }_{62}^{149} \mathrm{Sm}
$$

Because Sm-149 is stable, its production rate following irradiation is equivalent to the radioactive decay rate of its parent, Pm-149. Given the Pm-149 half-life is 53.1 hours, 97\% of the Pm-149 during steady state operation is added to the Sm-149 steady state concentration after $\sim 11$ days (i.e., after five 
half-lives). The effect on core reactivity is not as significant as Xe-135. After reactor startup, the added Sm-149 buildup is removed by neutron capture until it reaches its original steady state concentration.

\subsubsection{Prompt versus Delayed Neutrons}

As discussed previously, prompt neutrons are emitted instantaneously from splitting the atom. Delayed neutrons are produced by a subset of fission fragments called delayed neutron precursors. First a fission fragment decays by a metastable state and then by neutron emission to reach the next least energetic state. The fraction of total neutrons resulting from fission which are produced by the decay of delayed neutron precursors is called the Delayed Neutron Fraction.

The kinetic response of a reactor due to changes in its state has two contributions, prompt and delayed. Prompt physics occurs instantly, whereas delayed physics occurs a few to 100s of seconds later. Delayed neutrons play an important role in the climb and descent in reactor power. Emission of delayed neutrons is fixed to the decay rate of their precursor fission products which are decaying by beta emission. Delayed neutron precursors are grouped into six groups of similar half-life. Reactors cannot shut down any faster than dictated by the slowest delayed neutron group $\left(\mathrm{T}_{1 / 2}=55.6\right.$ seconds $)$.

If the core reactivity condition is changed slowly enough for delayed neutrons to play a role in the chain reaction, reactor power will evolve slowly at the pace of delayed neutron half-lives (seconds to minutes). If the core reactivity condition is changed too rapidly (e.g., large injection of significantly colder water to the core; accidental control rod ejection), core power changes will be prompt at the pace of the neutron life cycle (micro- to milliseconds) which is extremely unstable and unsafe. Light Water Reactors are designed to operate within the control of delayed neutrons.

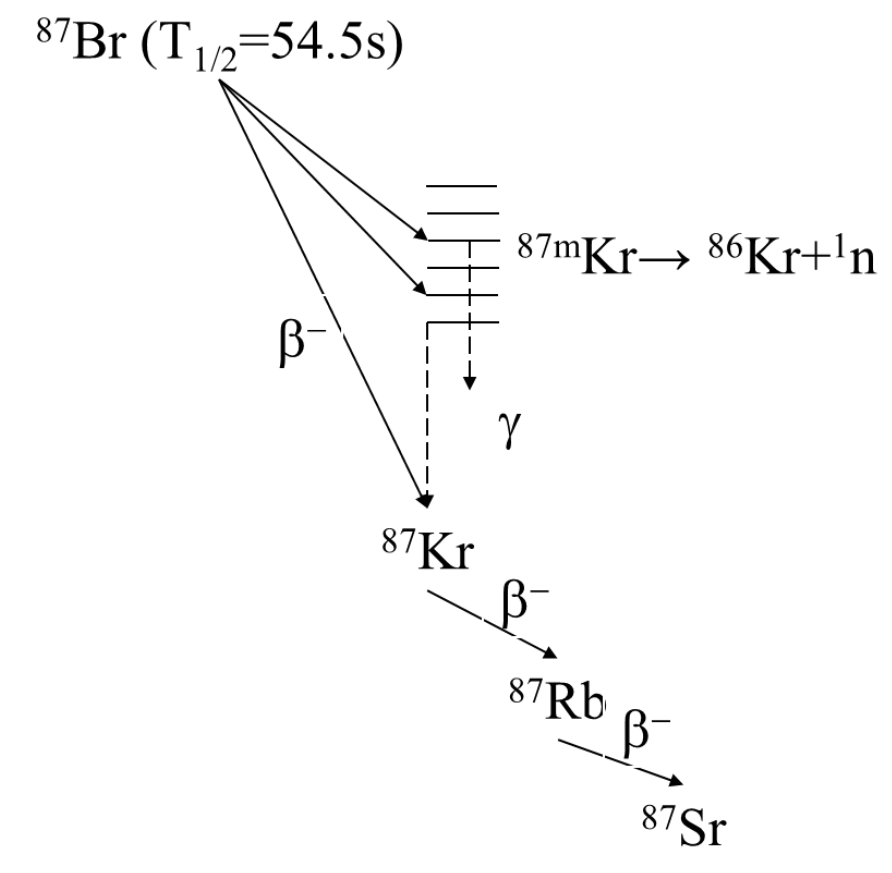

Figure 11. Production of a delayed neutron from the Br-87 decay chain.

\subsubsection{In-Core Fuel Management}

Nuclear fuel is typically burned for two to four cycles in an LWR. It is the primary role of the reactor engineer to select fuel elements at various stages of life and arrange them in the reactor core that will ensure the requested cycle length, irradiate the fuel to as close to the burnup limit as reasonable, minimize power peaking, and ensure all safety limits. This is done by selecting a combination of fresh and burned 
fuel. By using a batched core loading, as opposed to all fresh every cycle, the negative reactivity contribution of the burned fuel performs the role of reactivity hold-down and power flattening. Finer power flattening at the pin level is typically accomplished by burnable absorbers in the pin. The combination of burned fuel, and burnable absorbers requires less neutron hold-down from the control rods and chemical shim. It is desirable that the burnable absorber be near completely burned away by the end of the first cycle so that there are no latent impacts on cycle reactivity in subsequent cycles.

\begin{tabular}{|c|c|c|c|c|c|c|c|c|c|c|c|c|c|c|}
\hline & & & \multirow[b]{2}{*}{3} & \multirow[b]{2}{*}{1} & 2 & 1 & \multirow{2}{*}{$\frac{2}{0}$} & \multirow[b]{2}{*}{1} & & & & & \\
\hline & & & & & & 0 & 2 & & & 3 & & & & \\
\hline & & & 2 & 0 & 0 & 2 & 0 & 2 & 0 & 0 & 2 & & & \\
\hline & & 2 & 0 & 0 & 2 & 0 & 2 & 0 & 2 & 0 & 0 & 2 & & \\
\hline & 3 & 0 & 0 & 3 & 1 & 1 & 1 & 1 & 1 & 3 & 0 & 0 & 3 & \\
\hline & 1 & 0 & 2 & 1 & 2 & 1 & 2 & 1 & 2 & 1 & 2 & 0 & 1 & \\
\hline 2 & 0 & 2 & 0 & 1 & 1 & 1 & 1 & 1 & 1 & 1 & 0 & 2 & 0 & 2 \\
\hline 1 & 2 & 0 & 2 & 1 & 2 & 1 & 3 & 1 & 2 & 1 & 2 & 0 & 2 & 1 \\
\hline 2 & 0 & 2 & 0 & 1 & 1 & 1 & 1 & 1 & 1 & 1 & 0 & 2 & 0 & 2 \\
\hline & 1 & 0 & 2 & 1 & 2 & 1 & 2 & 1 & 2 & 1 & 2 & 0 & 1 & \\
\hline & 3 & 0 & 0 & 3 & 1 & 1 & 1 & 1 & 1 & 3 & 0 & 0 & 3 & \\
\hline & & 2 & 0 & 0 & 2 & 0 & 2 & 0 & 2 & 0 & 0 & 2 & & \\
\hline & & & 2 & 0 & 0 & 2 & 0 & 2 & 0 & 0 & 2 & & & \\
\hline & & & & 3 & 1 & 0 & 2 & 0 & 1 & 3 & & & & \\
\hline & & & & & & & 1 & 2 & & & & & & \\
\hline
\end{tabular}

Figure 12. A low-leakage core refueling scheme: $0=$ fresh fuel; $1=$ once burned fuel; $2=$ twice burned fuel; $3=$ third burned fuel [8].

\subsection{Reactor Control}

\subsubsection{Control Rods and Blades}

Control rods contain neutron absorbers known as "poisons". These poisons can be placed in movable "control rods" or fixed in the fuel itself, "burnable poisons". Neutron poisons are designed to remove neutrons in order to keep the reactor critical, not supercritical, when extra fuel is loaded or other positive reactivity effects are taking place. They are also used to start-up the reactor from a shutdown state by removing the poisons. Most importantly they are used by the reactor protection system to rapidly shutdown the reaction.

Control rod reactivity worth is a function of poison material, poison concentration, rod diameter, neutron spectrum, and location within the reactor core. Control rods placed toward the center of the reactor are generally more reactive. Control rods are generally considered "black" or "gray". Black control rods are very absorbing; a neutron has little chance of escape. The flux distribution near the control rod is significantly depressed. Gray control rods are less absorbing. Control rods have greater reactivity worth in high flux compared to low flux regions. The influence on the neutron distribution in nearby fuel assemblies is less severe. Common control rod materials are: Silver, Indium, Cadmium, Boron, Gadolinium, or Hafnium. 
Control rods are used for quick operator response and core protection. Operators can withdraw or insert in increments. Protection systems will "Trip" or "SCRAM" all rods rapidly into the reactor to effect a shutdown. Control rods are typically organized into clustered groups or banks. Banks of control rods are inserted or removed as opposed to individual control rods.
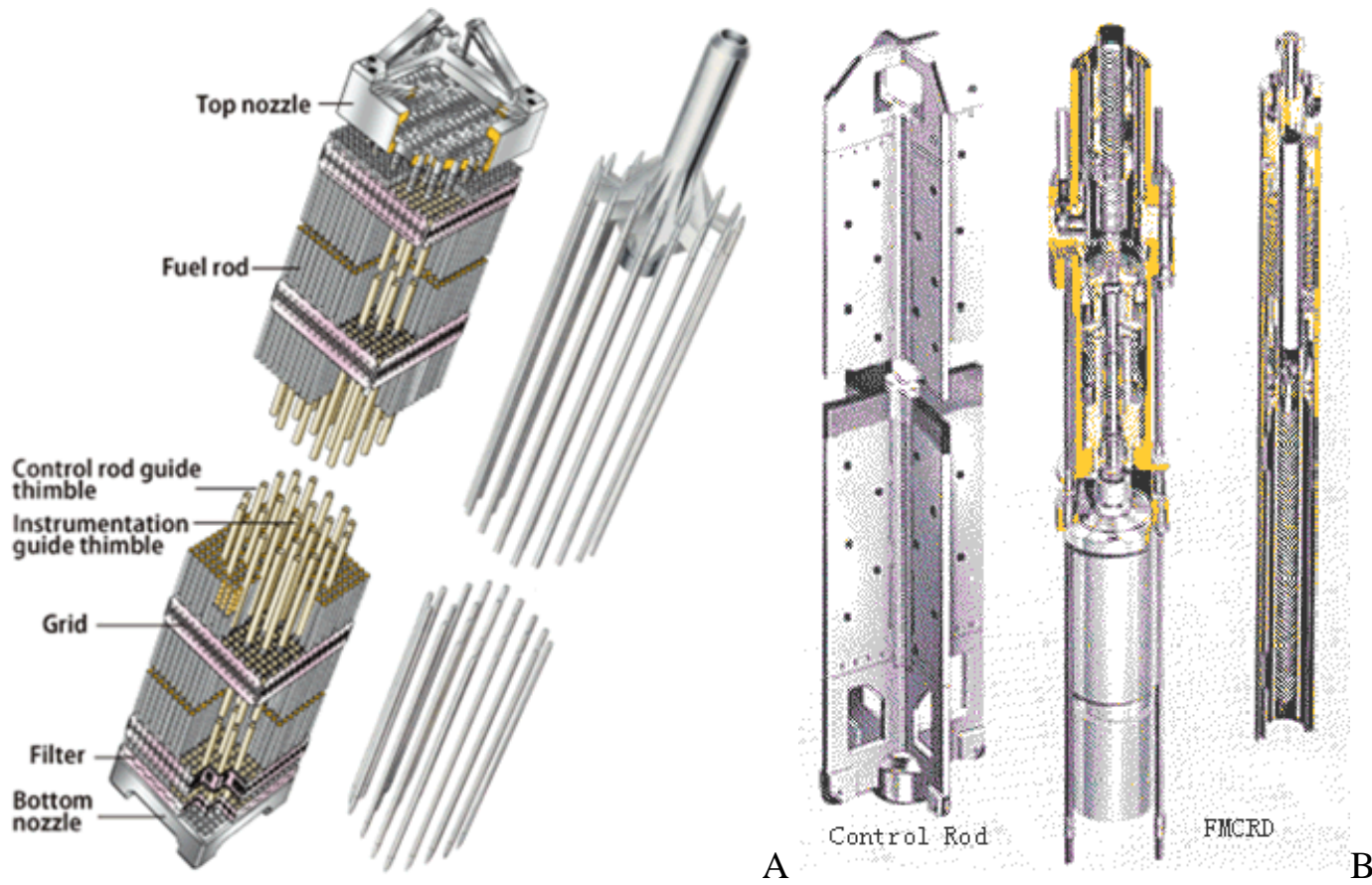

Figure 13. PWR fuel assembly with control rod "spider" clusterr (A), BWR control blade (B).

Control rod insertion typically creates shifts or "tilts" in reactor power. During steady state operation, the reactor operates at constant power. If neutrons are absorbed in one region, flux (and power) is suppressed. This must be compensated elsewhere by an increase. Power tilt is the result of asymetric neutron poisoning. It can be radial or axial. Control rod insertion can be used to shape the power distribution in the core. However, it is often desirable to operate with all rods out to achieve even burnup of the fuel and to extend control rod life. Thus slow reactivity changes such as reactivity decrement due to burnup can be compensated with chemical shim (PWRs), burnable poisons (both PWR and BWR) or controlling the steam quality in the core (BWR). 


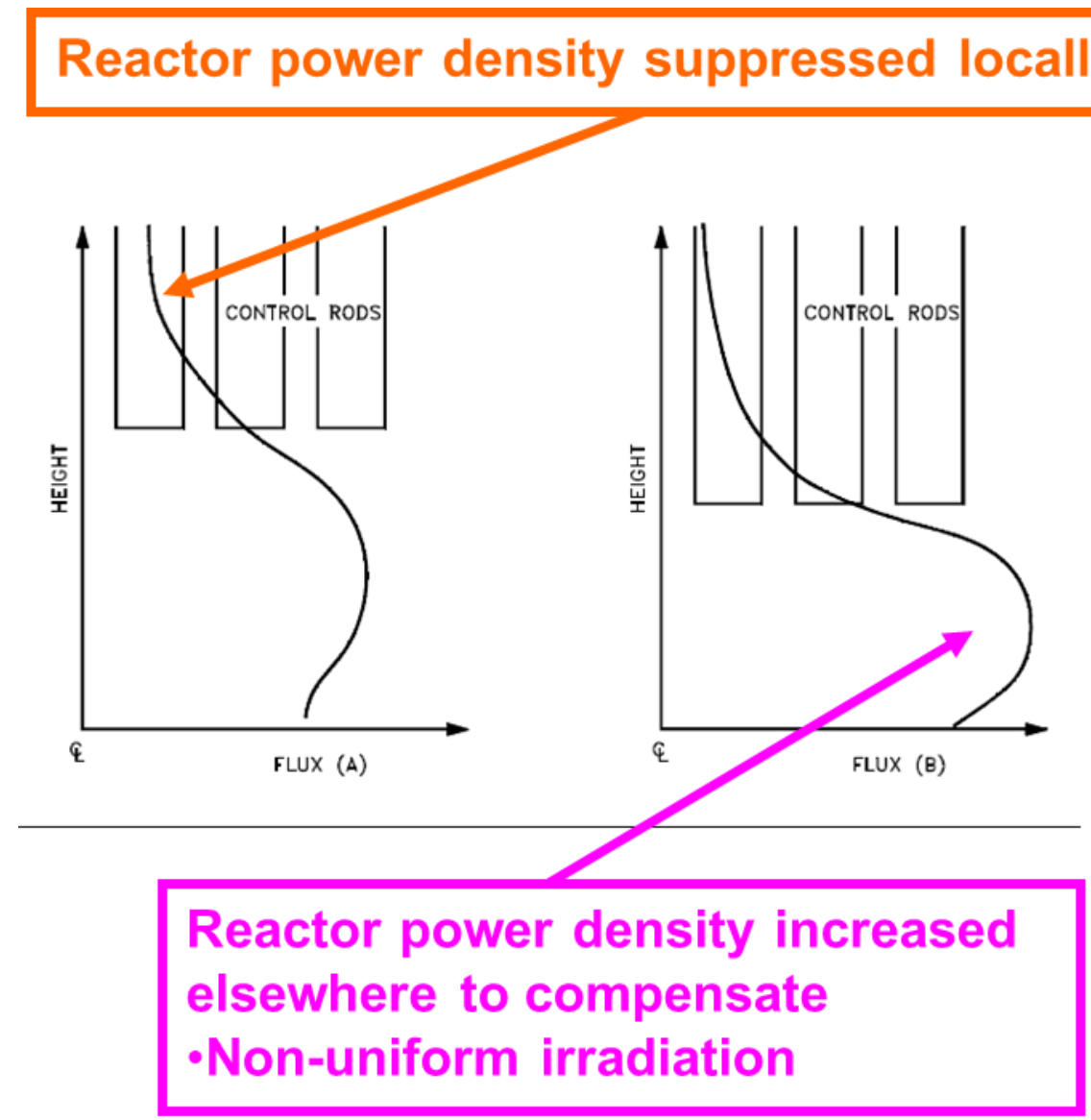

Figure 14. Illustration of power tilt due to control rod insertion [7].

\subsubsection{Chemical Shim}

Soluble neutron absorbers such as boric acid can be used to offset excess reactivity in new fuel and the reactivity decrement due to fuel depletion. In a PWR, the soluble boron is used for control and accident mitigation. A BWR cannot use soluble boron for control, but can add it for accident mitigation. Soluble boron can be injected rapidly into the coolant as part of the emergency backup system. Gadolinium nitrate solution is used in CANDU reactors for this purpose.

\subsubsection{Recirculation Control}

A BWR uses the adjustment of recirculation flow to vary the amount of voids as a control. This is done either by variable speed recirculation pumps or constant speed pumps with flow control valves. A reduction in recirculation flow will result in an increase in voiding (more steam bubbles to form within the reactor). The voiding does not moderate neutrons as well therefore negative reactivity occurs and power decreases. The opposite is of course true.

\subsection{Heat Transfer}

\subsubsection{Heat Transfer Types}

Heat can be transferred to and from a system using three mechanisms. Conduction is a direct form of a heat transfer caused by the interactions of adjacent molecules. Vibrations at the atomic level (due to elevated temperatures) propagate within a material or from one material to the next, thus transferring heat. Conduction can take place in all phases of matter. Due to the second law of thermodynamics, heat spontaneously flows from a hot body to a colder one. The rate of heat transfer is dictated by the 
temperature gradient within or between systems. The larger the difference in temperature, the greater the heat transfer. This is shown in the equation below where the heat transfer $q$ is proportional to the temperature gradient, $\Delta \mathrm{T} / \Delta \mathrm{x}$. Different mediums have different propensities to transfer heat via conduction. Some materials (notably metals) conduct heat much more efficiently than others (e.g. ceramics or inert gases). The variable $k_{c}$ quantifies this ease of heat transfer and is referred to as conductivity. $\Delta \mathrm{x}$ defines the distance the heat travels across a system (typically the thickness of a material).

$$
q=k_{c} \frac{\Delta T}{\Delta x}
$$

Convection, the second mechanisms, relies on the kinetic movement of a fluid. Heat is transferred within a fluid from a hotter location to a colder location. This phenomenon dominates over conduction in liquids and gases. The mechanism relies on the bulk motion and mixing of macroscopic portions of the fluid. The heat transfer rate is dependent upon fluid velocity and can be divided into two-subcategories. Free or natural convection relies on the buoyancy effect resulting from density variations between hot and cold portions of the fluid. When a fluid is in contact with a hot surface, heat transferred to the fluid causes it to expand and decrease its density. This increases the buoyancy of this fluid portion causing it to flow upwards naturally. Further away from the heat source, the fluid transfers heat away from it (into adjacent surfaces) cools down, increases in density, and sinks downwards as a result. The other type of convection arises from forced flow, i.e. driven by an artificial system such as a pump. Convective heat transfer is dictated by the relation below. It is proportional to the wetted area, $A$, the heat transfer coefficient $h$ (driven by fluid properties and flow geometry), as well as the difference between the bulk fluid and surface temperatures $T_{f}$ and $T_{s}$.

$$
q=h A\left(T_{f}-T_{s}\right)
$$

The last heat transfer type is radiation. Note that this is different from radiation stemming from radioactivity. Radiation here refers to radiant thermal energy. Very high temperatures causes electromagnetic radiation (i.e. light) to emanate from a body. This form of heat transfer between two systems can occur without a medium (e.g. the Sun transferring heat through the void to Earth). While all matter emits thermal radiation when its temperature is greater than absolute zero, the rate of heat ejection increases rapidly with the temperature as shown in the equation below, where $\sigma$ is the Stefan-Boltzmann constant (fixed) and $A$ is the area of the emitting body. Temperature drives this process to the fourth order, which is why this type of heat transfer increases substantially the higher the temperature. It should be noted that while a body radiates light into another system, the other system also radiates heat back. A more complex relation than the one below is needed to account for this feedback effect by taking surface emissivity into consideration.

$$
q=\sigma A T^{4}
$$

In a nuclear reactor, heat is generated through fission energy inside a fuel pellet. Heat (energy) is conducted through the pellet and its cladding via conduction. It is then transferred into the circulating liquid via convection, which then uses the same mechanism to transfer heat inside the steam generator. In most LWR systems, primary pumps are relied on to efficiently remove heat from the fuel pins via forced convection. In emergency conditions, natural convection may be sufficient to expel decay heat from the nuclear fuel. In some extreme circumstances, a high temperature reactor design (such as a HTGR) can use radiative heat flux from the pressure vessel to dissipate energy. The figure below summarizes the different heat transfer phenomena at play inside an LWR. The peak temperature is at the center of the fuel pellet and is typically referred to as "centerline fuel temperature". Care must be taken to ensure this temperature remains within acceptable bounds to avoid fuel clad failure and/or fuel melting and the release of radioactive fission products. 


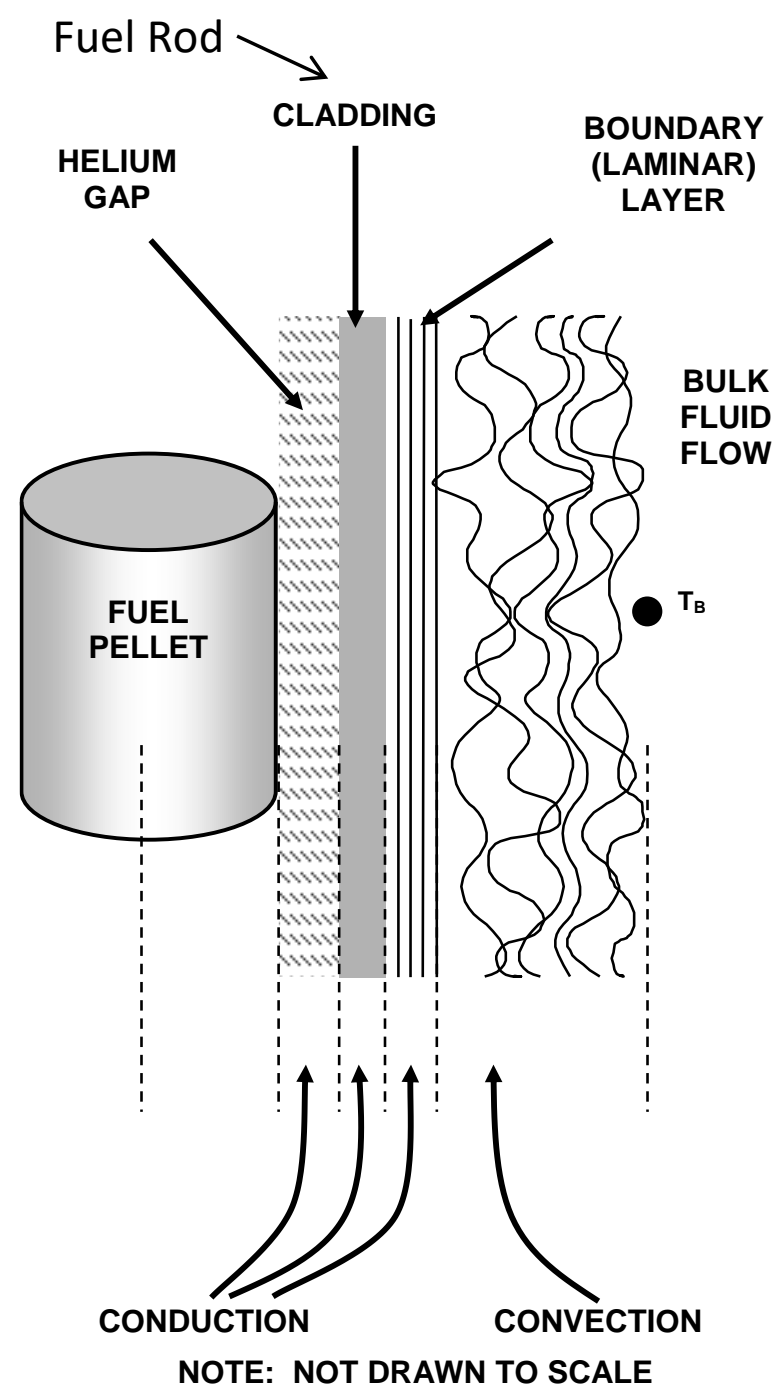

Figure 15. Overview of the heat transfer through a reactor fuel rod and into the coolant.

Note: Heat transfer from the fuel cladding to the turbulent boundary layer in forced circulation is by convection. There is no laminar boundary layer and no appreciable conduction in the fluid in such a circumstance.

\subsubsection{Phase Change}

As heat is added into a liquid system, it can change its phase at the saturation point. The term 'saturation' refers to water at a given pressure being at the specific temperature above which evaporation occurs if any further heat is supplied. This is also referred to as boiling point. At any lower temperature, the liquid is termed 'subcooled'. This saturation point is strongly dependent upon both the temperature and pressure of a system. While water boils around $100^{\circ} \mathrm{C}$ at atmospheric pressure, its boiling point can be as high as $345^{\circ} \mathrm{C}$ in a PWR in light of the 155 bar pressure in such a system. The energy required to transform a liquid into a gas is termed the latent heat of vaporization. The opposite holds true to condense steam back into water. If insufficient heat is provided to boil all the liquid phase, the coolant turns into a combination of steam and water (i.e., steam with a non-zero moisture content).

Conversely, when vapor is heated beyond the saturated state, it is termed "superheated". In such a case, the addition of more heat will raise the steam temperature but not its pressure. Because water is incompressible in reactor conditions, pressure in one part of a static system is the same as in another. As a result, the saturation temperature is the same across the coolant. 
Saturated steam is in equilibrium with the heated water and at the same pressure. As such, both phases can coexist. This type of steam tends to be at or close to its saturation point for a given condition. Heating saturated steam slightly can increase its temperature and avoid condensation of steam back to water (an issue for steam turbine blades for instance). If dry steam is heated past the saturation point, it enters the superheated regime. While this results in a decrease in heat transfer properties (since water/moisture has a higher heat transfer coefficient than vapor) it is desirable to preclude moisturerelated erosion of steam-driven equipment.

When describing a saturated mixture, it is useful to rely on the 'steam quality', which quantifies the amount of vapor inside the system. It is the ratio of the vapor mass over the total fluid mass and is often denoted as $x$ (equation below). A steam quality of $100 \%$ essentially corresponds to saturated steam (no liquid phase). A quality of $0 \%$ corresponds to a saturated liquid.

$$
x=\frac{m_{\text {vapor }}}{m_{\text {total }}}=\frac{m_{\text {vapor }}}{m_{\text {vapor }}+m_{\text {liquid }}}
$$

\subsubsection{Two-Phase Flow Regimes}

As heat is incrementally added to a system, the interaction between the liquid and vapor starts to change. Eventually, even when the bulk of the fluid is below saturation, vapor forms on the heated surface in the form of bubbles. This is mostly due to small cavities and irregularities across a surface causing a local hot spot or spike in temperature. This is called subcooled boiling. The bubbles are formed at the wall in such conditions but collapse in the bulk coolant stream as shown in the figure below. The fluid is at an equilibrium in such a system with no net vapor generation (bubble creation equals bubble collapse). The water has a very small void fraction, i.e., a very low quality.

SINGLE PHASE FORCED CONVECTION

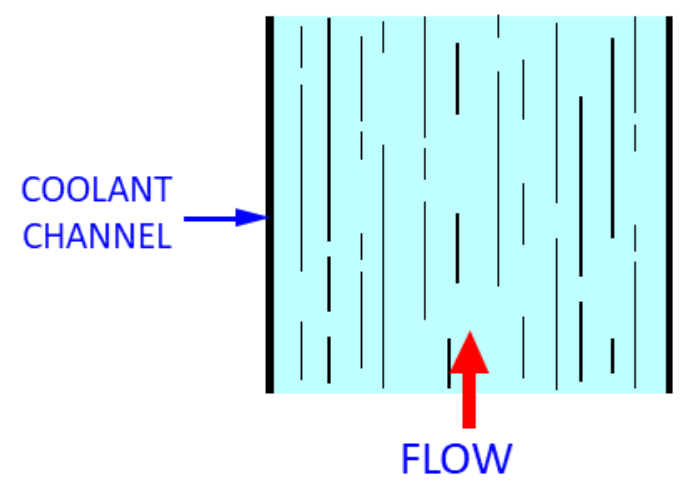

\section{SUBCOOLED BOILING}

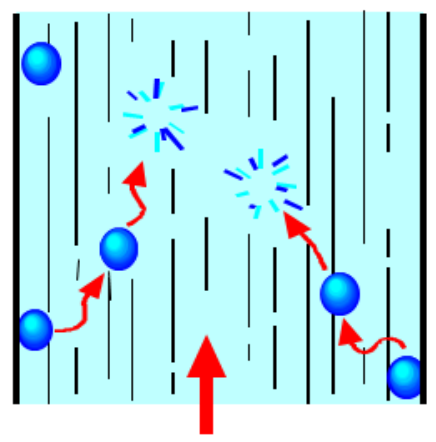

Figure 16. Illustration of the subcooled boiling process with bubbles formed at the wall and collapsing inside the bulk stream.

As heat continues to be added to a system, the bulk coolant stream approaches the saturation point. As more vapor is formed in the flow (steam quality increases), the interactions between the two phases strongly influences the heat transfer mechanisms. It is therefore important to distinguish between the different "flow regimes". They tend to occur in the following order within a vertical heated pipe:

- Bubble flow: Bubbles form at the wall but do not collapse in the coolant stream. The bulk coolant is at saturation temperature. The bubbles are not coalescing in this stage and the steam quality is still low.

- Slug flow: As boiling continues, bubbles coalesce and form larger slugs of vapor. The void fraction becomes significant, and the steam quality increases. 
- Churn flow: Vapor is carried upward in large waves. It is characterized by the presence of a thick and unstable liquid film along the wall that can oscillate up and down.

- Annular flow: A liquid film is carried upwards along the walls of the channels by vapor flowing in the center of the channel. The liquid velocity tends to be slower than the overall bulk vapor velocity.

- Mist flow: The liquid phase is here completely dispersed as droplets inside the vapor. It is the equivalent of the 'inverse' of the bubble flow regime. This regime is rare and tends to only occur under abnormal conditions (e.g. loss of coolant accident).

The different regimes are illustrated in the figure below. Plug and slug flow are often grouped together under a single regime. It is important to note that the flow area is 'flipped' inside of an LWR, i.e. the coolant is flowing outside a tube, not the inside of a tube. However, the different regimes behave in the same way.

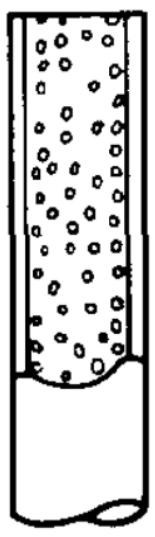

Bubble tlow
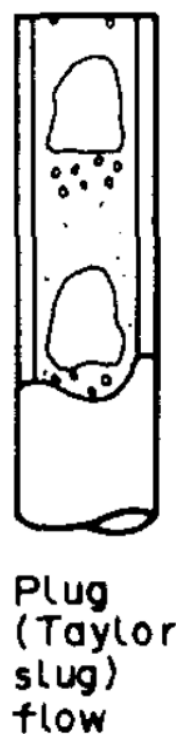

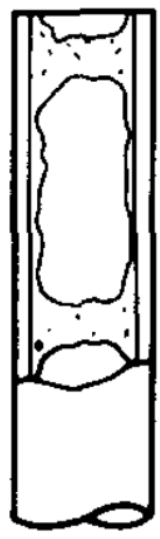

Slug

flow

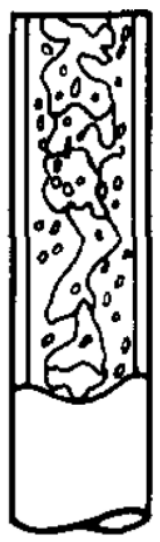

Froth

or churn turbulent flow
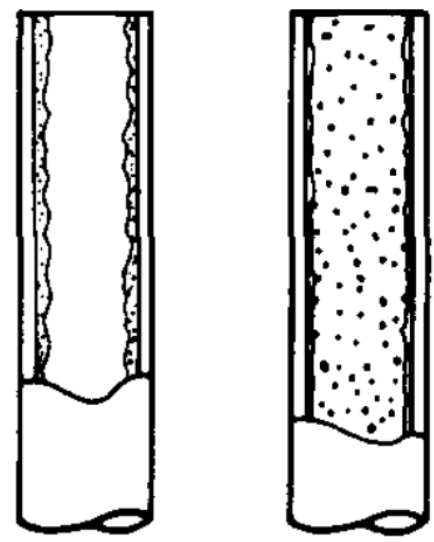

\section{Annular} flow

Annularmist flow

Figure 17. Schematic of the different flow regime in a vertical pipe [9].

\subsubsection{Critical Heat Flux (CHF)}

As heat is added to a system and the vapor fraction increases, a 'boiling crisis' can occur. This corresponds to a vapor film forming along the wall surface resulting in a drastic drop in heat transfer properties (liquid water is much more efficient at transferring heat than vapor). The abrupt change in the heat transfer coefficient, $h$, reduces the ability of the fluid to remove heat from the heated surface (usually a fuel pin), and this can result in large increases in wall temperature. This transition between nucleate boiling and film boiling is often termed Critical Heat Flux (CHF). It represents the maximum heat flux value from the wall that corresponds to the formation of a vapor film. There are two basic types of CHF phenomena encountered inside LWR systems:

- Departure from Nucleate Boiling (DNB): This form of CHF occurs in sub-cooled, low quality fluids. As bubbles form at increasingly high rates along the wall, a film of vapor can cause a detachment of bubble boundary layer. The resulting phase is sometimes referred to as "reversed annular flow", because the liquid phase is in the center of the channel, and the gaseous phase is along the wall. DNB is normally encountered inside a PWR accident 
conditions. The ratio between the DNB heat flux and the actual operating heat flux is called the Departure from Nuclear Boiling Ratio (DNBR). This ratio decreases as the coolant passes along the fuel rod and is heated. It reaches a minimum value somewhere downstream of the peak operating heat flux location. In normal operations and during anticipated operational occurrences in PWRs, a minimum DNBR is maintained to avoid overheating the fuel rod cladding.

- Burnout/Dryout: This phenomenon occurs in high steam quality conditions, typically in the annular flow regime. It occurs when a liquid film covering the wall "dries out" and exposes the surface to vapor. For this reason, it is sometimes also referred to as "dryout". Burnout can also be observed in medium-quality scenarios due to surface wave instabilities causing disruptions in the liquid layer. This type of CHF occurs in BWRs. The Critical Heat Flux Ratio (CHFR) is similar to the DNBR, and is the ratio of the CHF to the actual heat flux. A related quantity, used for BWRs, is the Critical Power Ratio (CPR). The fuel assembly (or rod) power which causes some point in the assembly (or rod) to experience CHF is called the critical power. The CPR is the ratio of the critical power to the actual power of the fuel assembly (or rod). The CPR is fundamentally a two-dimensional value as all axial effects are integrated into the critical power, whereas the CHFR can be calculated axially.

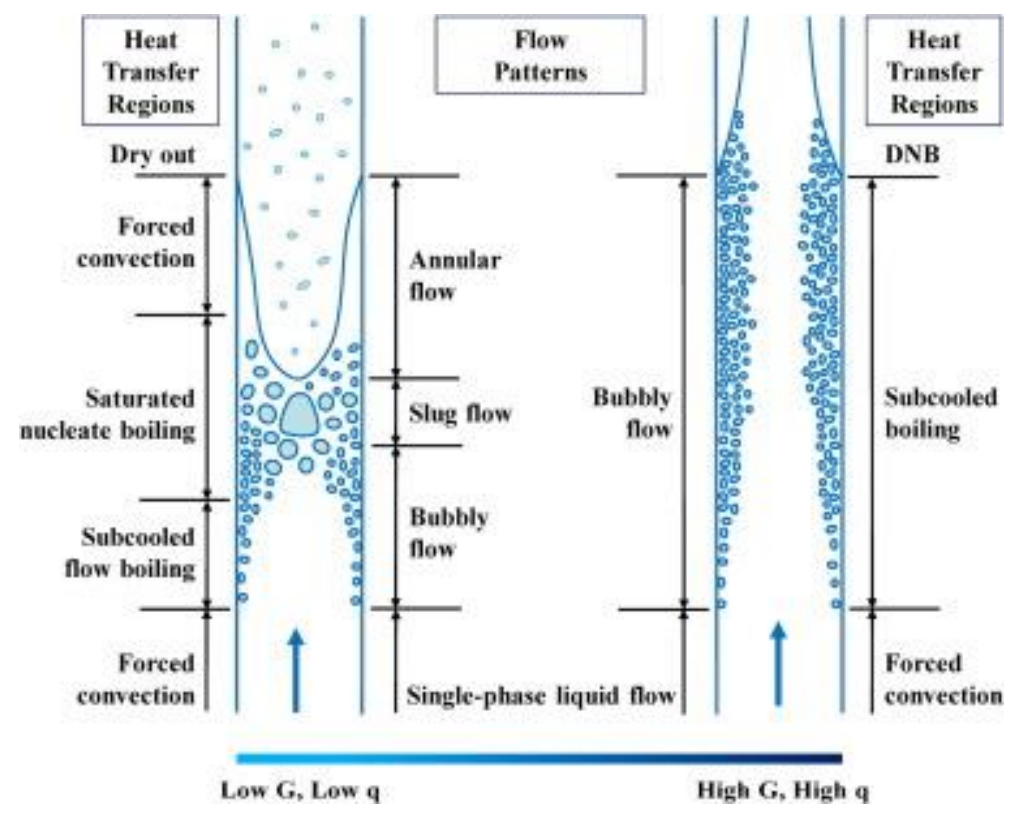

Figure 18. Schematic of two different types of CHF mechanisms. G refers to the mass flux, and q to the heat flux here [10].

\section{Reactor Systems}

\subsubsection{Pressurized Water Reactors (PWR)}

\subsubsection{Primary and Secondary System}

PWRs highlighted in the diagram, consist of a primary (red/orange) and secondary system (blue/black). As water is heated in the core it is pumped to a steam generator, transferring heat from the primary system, also known as the Reactor Coolant System (RCS), to the secondary system, also known as the Main Steam System. As the primary coolant gives up heat to the secondary system, its temperature decreases before it is pumped back into the bottom of the reactor core where heat is adde $3 \mathrm{~d}$ and the 
temperature increases. A pressurizer is needed to maintain the high water pressure and avoid boiling within the RCS.

Water is pumped into the secondary side of the steam generators where it is boiled to steam by heat coming into the secondary side from the RCS. Boiling can occur here because the fluid is at a lower pressure than the primary system. The steam is then used to run a turbine and generate electricity. Care is taken to ensure a high steam quality to avoid damaging the turbine blades. The steam is then directed to a condenser, a heat exchanger that then sends the rejected heat to cooling towers. The condenser condenses the steam back to liquid form before it is pumped back into the steam generator. Condensers are cooled by a tertiary cooling system, usually natural or forced-convection cooling towers, which depend on makeup water from natural or manmade sources.

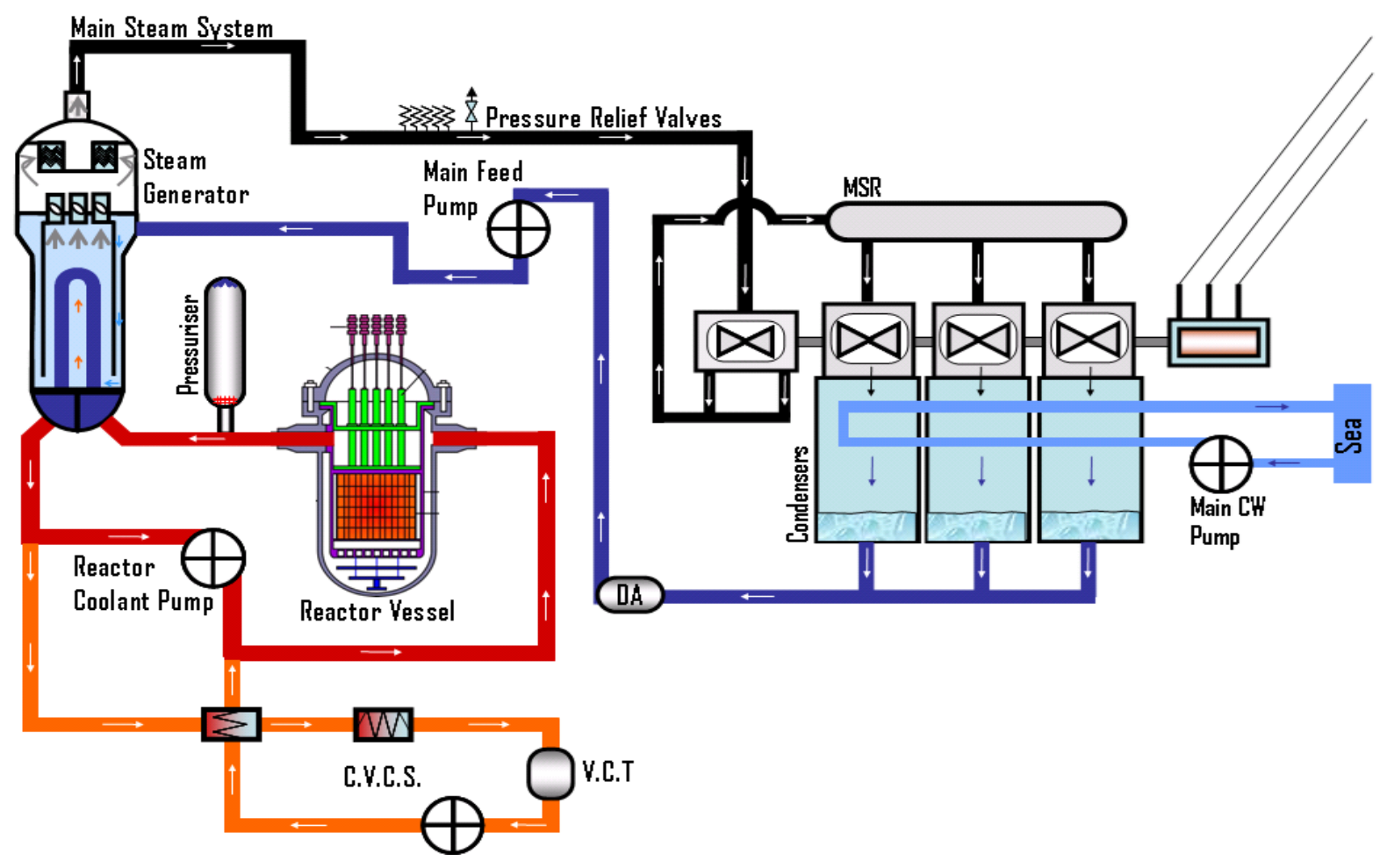

Figure 19. Diagram of the PWR system layout.

While only one Steam Generator (SG) is highlighted in the figure above, PWRs tend to have two or more in order to reduce sizes and increase redundancies. A standard Westinghouse PWR has four SG systems as shown below. 


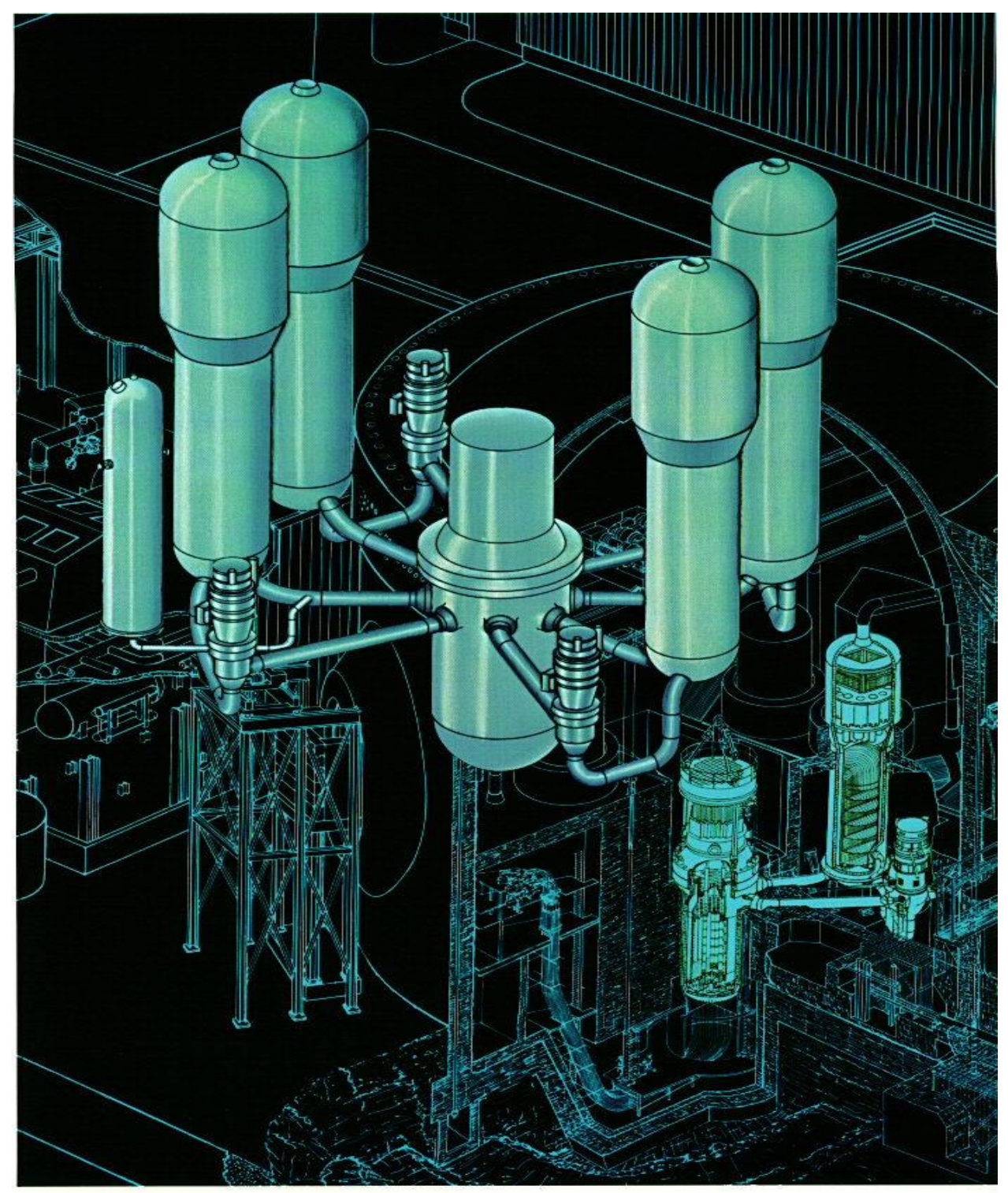

Westinghouse NUCLEAR STEAM SUPPLY SYSTEM

Figure 20. Diagram of the primary system in a Westinghouse PWR.

\subsubsection{Reactor Pressure Vessel and Steam Generator}

The Reactor Pressure Vessel (RPV) highlighted in the previous figures houses the reactor core and hence the nuclear fuel. As shown below, water is pumped through the inlet nozzles, flows through the down-comers and enters the core barrel where heat from fission reactions is transferred to the pressurized water. It then exits the RPV to enter the SG. As highlighted in the diagram, the primary coolant is diverted into tubular bundles to increase heat transfer surface area. The secondary system flows through the SG feedwater nozzle then into the bundles. As the secondary feed heats up, it evaporates and rises up the SG. Steam dryers eliminate any remaining water droplets to avoid damaging the turbine system. The high-quality steam then exists through the steam nozzles and is directed to the turbine. 

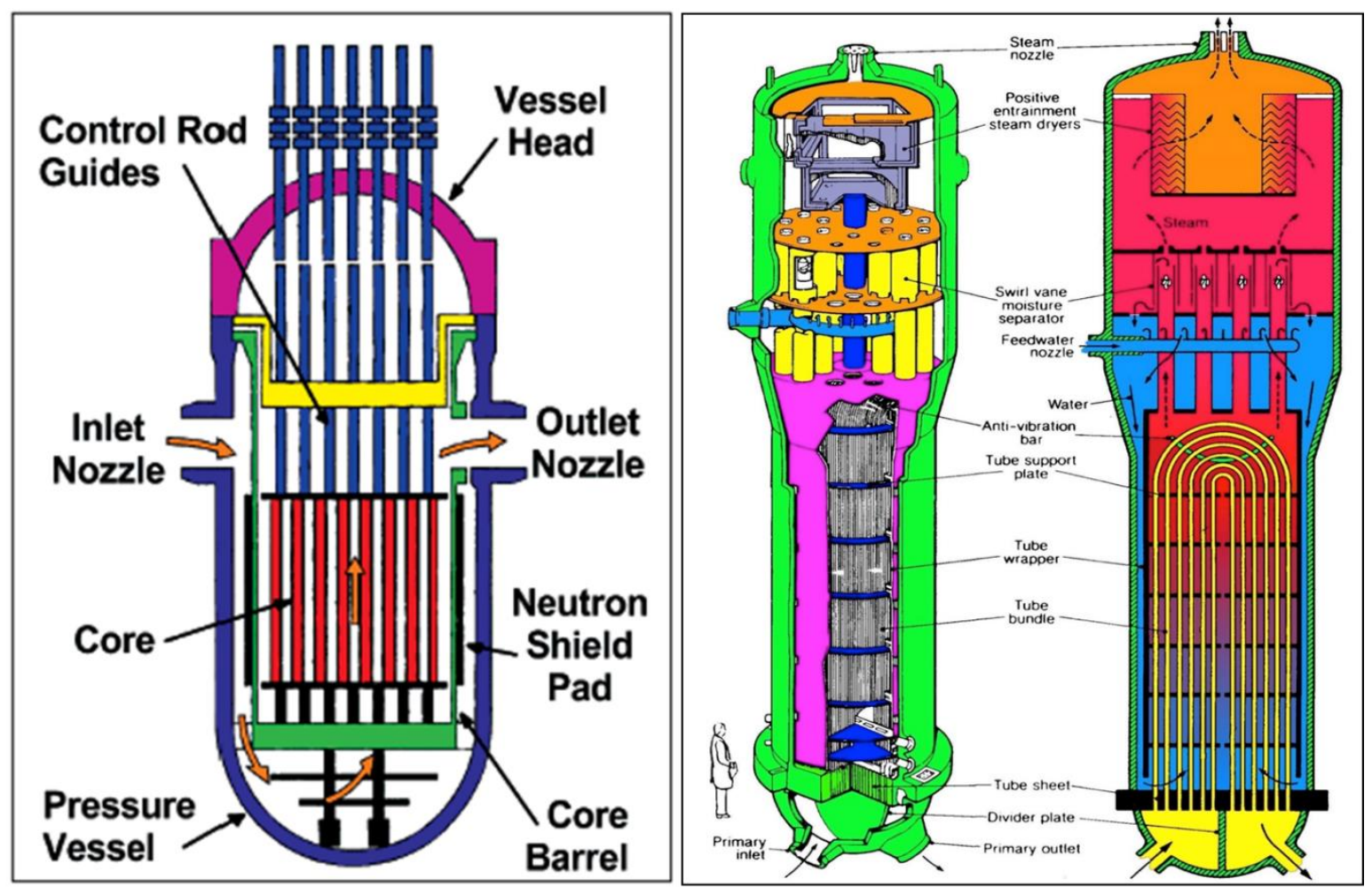

Figure 21. Cross-section view of the reactor pressure vessel (RPV) (left) and the steam generator (right).

Not all of the nuclear heat is generated within the fuel rods. The ionizing energy of the fission products is deposited directly in the fuel rods. However, roughly $8-12 \%$ of prompt energy rerelease is in the form of gamma-rays and neutrons, Table 3. Much of this energy is deposited locally within the reactor core, i.e., fuel pellets, cladding, and coolant. However, a non-negligible amount is deposited outside of the reactor core. The ionizing energy created within ex-core structures, e.g., RPV, must also be removed by the coolant. The kinetic energy deposition by these gamma-rays and high energy neutrons also creates irradiation damage within the RPV. To minimize heating and neutron damage to the RPV, the core baffle and/or additional neutron "thermal" shield panels attenuate the gamma and neutron flux leaving the core such that their ionizing kinetic energy is deposited in the shields instead of the RPV. 


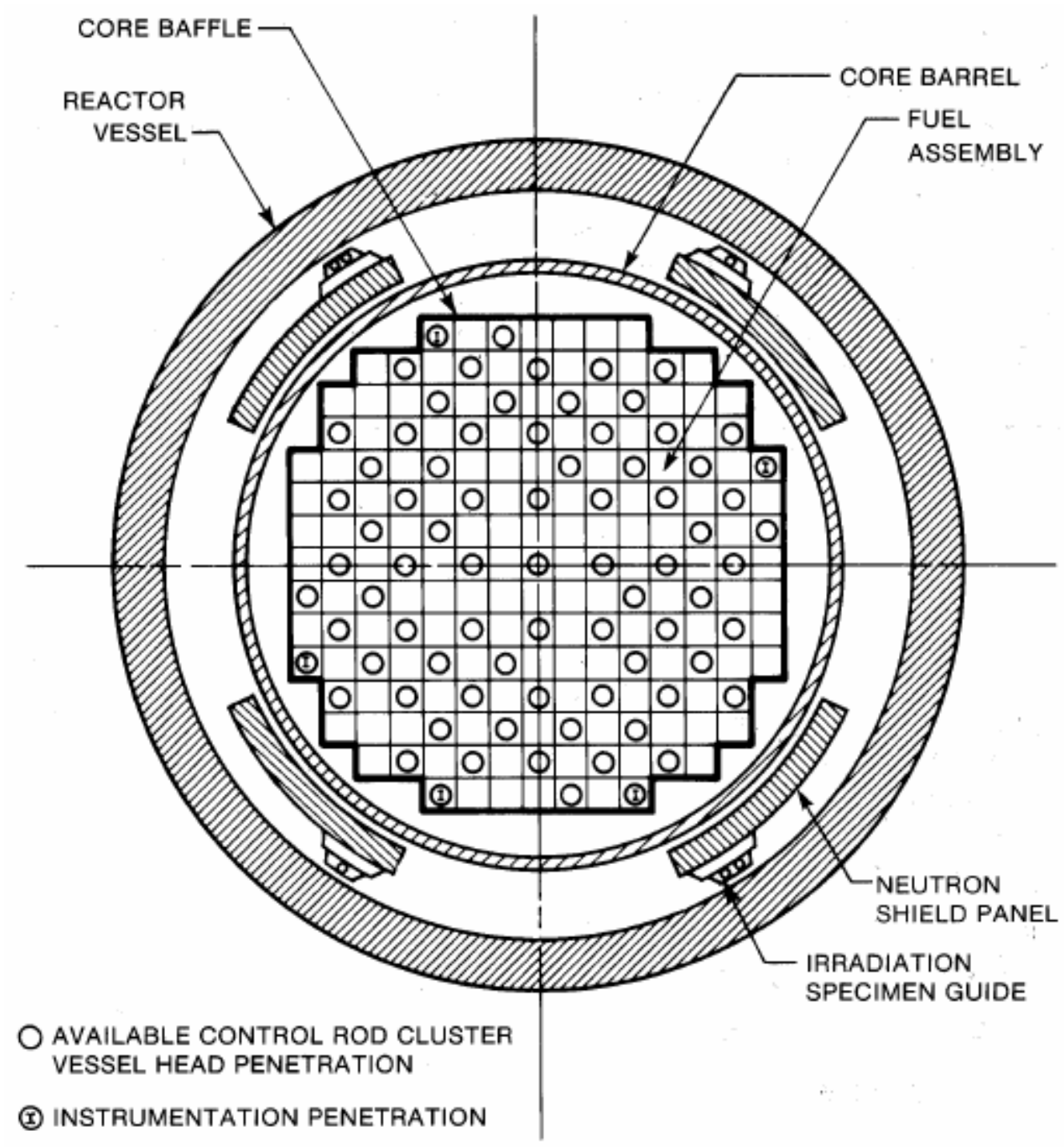

Figure 22. Cross sectional view of a typical four-loop pressurized water reactor showing orientation of core, baffle, shields and reactor pressure vessel [11].

\subsubsection{Fuel Assembly and Rods}

The core itself is made up of fuel assemblies (shown below) arranged in checkerboard pattern as highlighted in Figure 22. The assembly itself is made up of fuel rods (or pins) bundled together to form a square arrangement. The pins consist of a tubular clad with fuel pellets contained within it. A zirconium alloy (zircalloy) is used for the clad material due to its low neutron absorption cross-section. The fuel pellets consist of ceramic $\mathrm{UO}_{2}$ typically enriched in the ${ }^{235} \mathrm{U}$ isotope from 2 to $5 \%$. The inside of the inner tubes tends to be slightly pressurized with an inert gas such as helium. An assembly also contains guide tubes to allow control rods to be inserted. They are essentially structural skeleton that provide space for the control elements. A typical PWR assembly contains 264 fuel tubes, and a core tends to have up to 180 assemblies. The assemblies are around 3 to $4 \mathrm{~m}$ tall. 


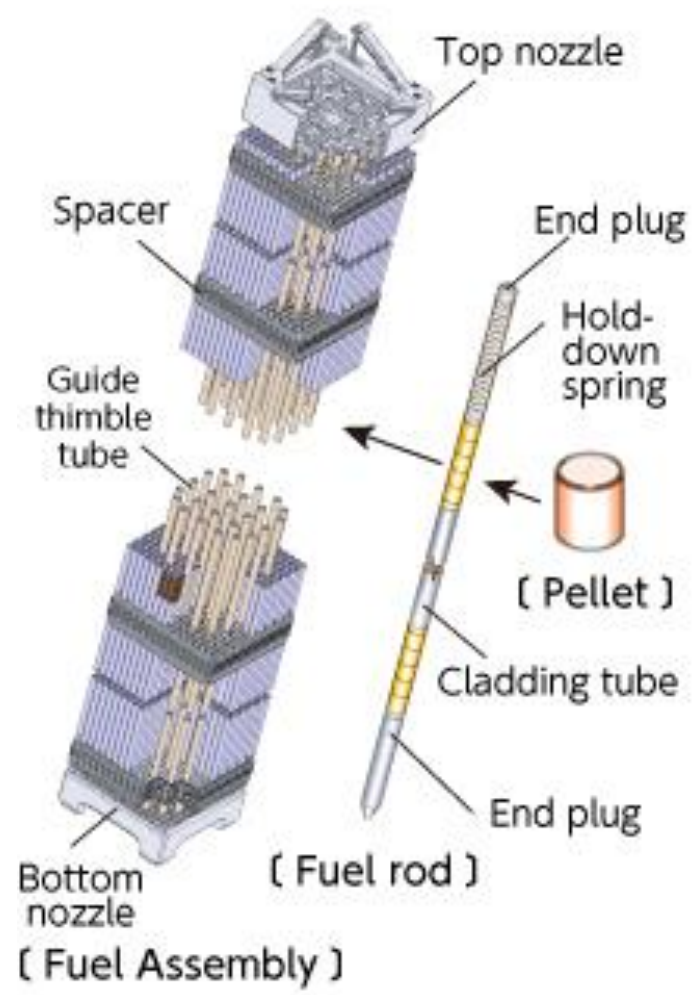

Figure 23. Illustration of a PWR fuel assembly and its fuel rods.

The fuel clad is the second barrier to the release of fission products, after the fuel pellet itself. Zircaloy is susceptible to stress corrosion, therefore chemistry control is very stringent in a PWR.

\subsubsection{Normal Operations}

The different (normal) modes of operation of a PWR can be determined by the reactor power and state of the reactor coolant. The modes can be summarized as:

- Mode 1 - Normal Power: The reactor is critical, produces more than 5\% of nominal power, and the coolant is at the operating temperature of $300^{\circ} \mathrm{C}$ and 155 bar.

- Mode 2 - Start-up: The reactor is critical, its power is beneath 5\% of nominal but its coolant is at normal operating temperature.

- Mode 3 - Hot Standby: The reactor is subcritical, no fission power is generated (only decay heat) and coolant temperature is above $150^{\circ} \mathrm{C}$.

- Mode 4 - Hot Shutdown: The reactor is subcritical, no fission power is generated and coolant temperature is between 100 and $150^{\circ} \mathrm{C}$.

- Mode 5 - Cold Shutdown: The reactor is subcritical, no fission power is generated and coolant temperature is below $100^{\circ} \mathrm{C}$.

- Mode 6-Refueling: The RPV is open (i.e. atmospheric pressure) and the coolant temperature is below $60^{\circ} \mathrm{C}$. No power is being generated.

To bring the coolant temperature to operating level, the primary pump is relied on to heat the system. The system is typically at normal operating temperature before the uranium fuel is used to produce heat. 
The cooldown is achieved by dumping steam via the steam generator to the main condenser, then by relying on the residual heat removal (RHR) heat-exchanger when the temperature drops below $150^{\circ} \mathrm{C}$.

Boron is dissolved inside the reactor coolant to control reactivity. Its concentration is used alongside control rods to start-up a reactor and bring it to a critical status. During normal operation, boron concentration is adjusted to compensate for fissile material depletion. Abrupt shutdowns or SCRAM is achieved by rapid control rod insertion.

\subsubsection{Auxiliary Systems}

The auxiliary systems are often termed Chemical and Volume Control Systems (CVCS). They are designed to ensure the following conditions are maintained in the reactor cooling system:

- Maintain the required water inventory even in the case of an accident in the primary or secondary system. The system must therefore provide an alternative mean of filling, draining, and pressurizing the cooling system both for normal modes and accident conditions.

- Reduce the concentration of corrosion and fission products in the coolant.

- Adjust the boric acid concentration for chemical shim control.

- Provide a high-pressure seal inside the reactor coolant pumps.

While the number of components required to achieve all of these tasks can number in the hundreds, it is worth mentioning a few of them in some level of detail. The Residual Heat Removal System (RHRS) for instance, is designed to reduce the coolant temperature down to $60^{\circ} \mathrm{C}$ within 20 hours after shutdown. It can also be deployed as part of a safety injection system for emergency core cooling under some accident scenarios. The RHRS consists of two independent and redundant mechanical subsystems. Each subsystem consists of a pump, a heat exchanger, along with all the required piping, valves, and instrumentation. It is directly connected to the primary reactor system.

\subsubsection{Engineered Safety Systems}

The Engineered Safety Systems have the direct responsibility to protect the public from the release of core damaging fission products. It does so by multiple means:

- Emergency Core Cooling Systems that rapidly inject borated water into the reactor to maintain the first boundary to the release of fission products, the cladding. These systems also provide long term cooling water flow.

- Containment Systems that can contain the entire leakage of the reactor coolant system without major release to the atmosphere. These also include Containment Cooling and Spray systems to remove the heat and lower the pressure; as well as Hydrogen control systems that prevent explosions that could challenge the integrity of the containment. In addition, Containment Isolation valves exist on all penetrations that are automatically closed to ensure the containment's integrity.

- Essential Cooling systems that remove the long term decay heat from the reactor and transport it to the "ultimate heat sink." This ultimate heat sink is established as part of the siting criteria and is the river, lake, ocean, or a man-made created reservoir.

- Emergency Electrical Power systems that provide the necessary motive force for the pumps and systems to provide their safety functions. This is typically Emergency Diesel Generators or other independent power sources.

There are two purposes of the PWR Emergency Core Cooling System (ECCS). The first is to provide a redundant means of providing core cooling in the event of a Loss of Coolant Accident (LOCA). The second is to inject boron into the core to ensure the reactor remains shutdown following the cooldown 
associated with a main steam line rupture. In the figure below, only one pump is shown for each injection system. However, there are actually two for redundancy. Keeping in mind that the reactor plant is designed to put electricity onto the grid, it pulls electricity off the grid to operate engineered safety systems. Implicit with nuclear safety analysis is that a common cause failure could cause a failure of the external supply of electricity as well; therefore, the ECCS can also be powered by the plant's emergency diesel generators or other emergency supply.

The PWR High Pressure Coolant Injection (HPCI) system is designed to provide water to the core during emergencies in which RCS pressure remains relatively high. Examples of this type of event is a small break in the RCS, steam break accidents, and leaks of reactor coolant through a steam generator tube to the secondary side. The Intermediate Pressure Coolant Injection (IPCI) system is designed for emergencies of greater loss of pressure and coolant inventory than the HPCI system.

The Cold Leg Accumulators (CLA) are designed to inject borated water into the RCS during emergencies in which the primary pressure drops very rapidly, such as postulated large piping breaks. They are comprised of borated water tanks with a pressurized nitrogen bubble in the top. If the primary system pressure drops below the pressure stored in the tank, the nitrogen bubble will force the borated water into the reactor coolant via check valves that precluded the RCS from back-feeding into the CLA. No electric power is required for this system to operate. This ensures that borated water is supplied instantly to the reactor on a large break LOCA.

The PWR Low Pressure Coolant Injection (LPCI) system is designed to respond to large breaks, which would cause a very large reduction in reactor coolant pressure. The ECCS injection systems draw water from the refueling water storage tank. However, once this supply is exhausted, water from the containment sump is pumped through the RHRS heat exchanger for cooling, before being returned to the RCS. This is called the long term core cooling or recirculation mode and then utilizes the essential cooling systems for transfer to the ultimate heat sink.

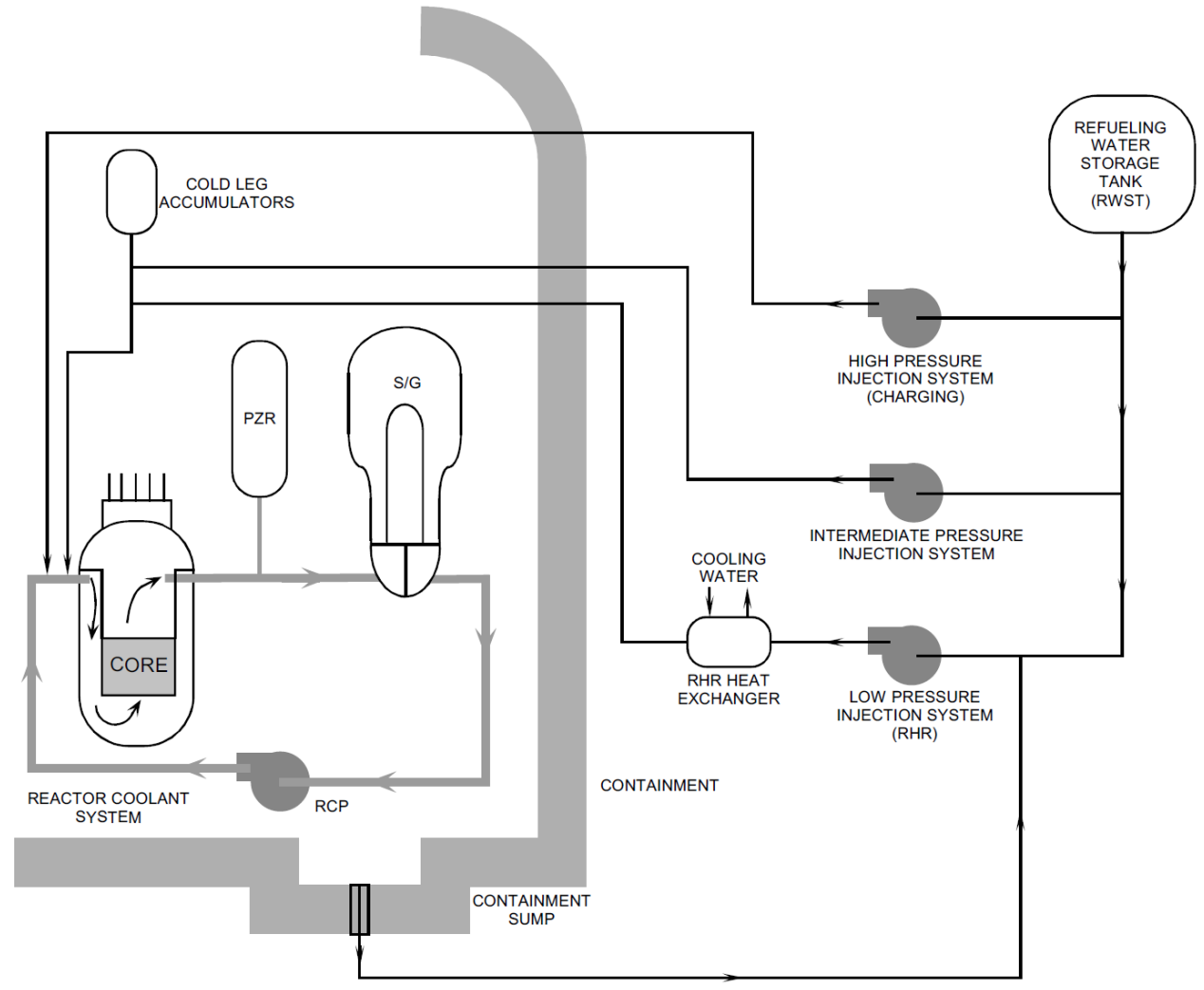

Figure 24. Diagram of the PWR Emergency Core Cooling System [12]. 
The ECCS and RHRS are tasked with supporting the primary system. The secondary side also has safety feature s such as Main Steam Line and Main Feed Line Isolation and Auxiliary Feedwater. The steam lines are automatically isolated in seconds to protect from steam break accidents and guarantee that only steam generator will blowdown. The Auxiliary Feedwater supplies feedwater to the steam generators following an accident or transient condition when the main feed is unavailable. It essentially maintains the capability of the steam generators to remove decay heat from the core.

\subsubsection{Primary Containment Building}

There is one final barrier of defense to ensure radioactive material is not released from the reactor plant, the primary containment building. All RCS components are located within this building. This building is typically made of steel reinforced concrete, and is designed to withstand pressures and temperatures that would accompany the release of the primary reactor coolant inventory into its volume. The capability to withstand the complete discharge of the RCS is normally accommodated by the free volume and pressure capability of the structure. However there are some unique designs that allow for less volume and pressure capability by utilizing ice condensers to remove some of the RCS energy during the LOCA. There is also a sub-atmospheric design that lowered the pressure within containment in order to limit its peak during the LOCA.

If a break occurred in the primary system, the coolant that is released into the containment building would contain radioactive material (e.g., activated particulates such as CRUD, fission products and transuranic actinides). Since the containment building is considered a final defensive barrier before radiologic release to outside the reactor plant, it is desirable that this structure be as leak proof as possible. The primary containment building's inside surface is covered by a steel liner. The liner acts as a vapor proof membrane to prevent any gaseous effluence from escaping through the cracks that may develop in the concrete.

There are also two systems designed to reduce the temperature and pressure. There is a fan cooler system which circulates the building's air through heat exchangers to accomplish cooling. The second system is a containment spray system. The containment spray system is designed to condense the released steam by contact with the cooler water. The containment spray pump takes water from the refueling water storage to spray nozzles in the top of the containment building. The water with condensate is collected in the containment sump. When the refueling water is exhausted, the containment sump water is then recirculated after being cooled by the RHRS heat exchanger.

\subsubsection{Modern PWR Designs}

Advanced PWR designs are relying on innovative approaches to improve the safety responses of a power plant. Some, like the Westinghouse AP-1000, rely more on passive systems to ensure core cooling. The AP-1000 uses gravity-driven emergency cooling and natural circulation to provide enough water without any human intervention - to keep the core cooled for up to seven days during a severe accident.

The French EPR followed a different design philosophy and relied more heavily on redundancy instead of passivity to ensure core cooling. Four independent safety trains can provide sufficient core cooling during anticipated accidents on their own. The EPR also has a double-containment building to provide an additional barrier to the release of radioactive material. A core catcher allows the EPR to even withstand meltdown scenarios by ensuring the corium (melted core) can be adequately contained.

More recently, interest in Small Modular Reactor (SMR) has increased. These smaller PWR designs can be mass-produced inside factories and can cater to a wider customer base. NuScale is one of the main U.S. vendors seeking to license its technology. The NuScale Power Module is an integrated PWR with all primary components housed within the RPV. The reactor does not use primary pumps to provide water to the core but can do so entirely using natural circulation. The containment structure is also integrated within the Power Module to offer a compact solution. The reactor can safely shutdown without any 
human intervention, AC or DC power, or additional water. The reactor is housed within a pool of water that can be leveraged to remove decay heat directly from the core in the case of an accident.

\subsubsection{Boiling Water Reactors (BWR)}

\subsubsection{Primary and Secondary System}

The main difference between a PWR and the BWR is the integration of the steam generator within the primary system of the latter. Rather than relying on a secondary coolant, a BWR boils primary coolant water within its core and directly feeds it to a turbine. In order to provide sufficient margins to DNB, the steam output from a BWR core is not of very high quality. A dryer is therefore relied upon to eliminate water droplets before directing the steam to the turbine. The steam is then sent to a condenser where it is returned to a liquid phase, before being pumped back into the reactor core.

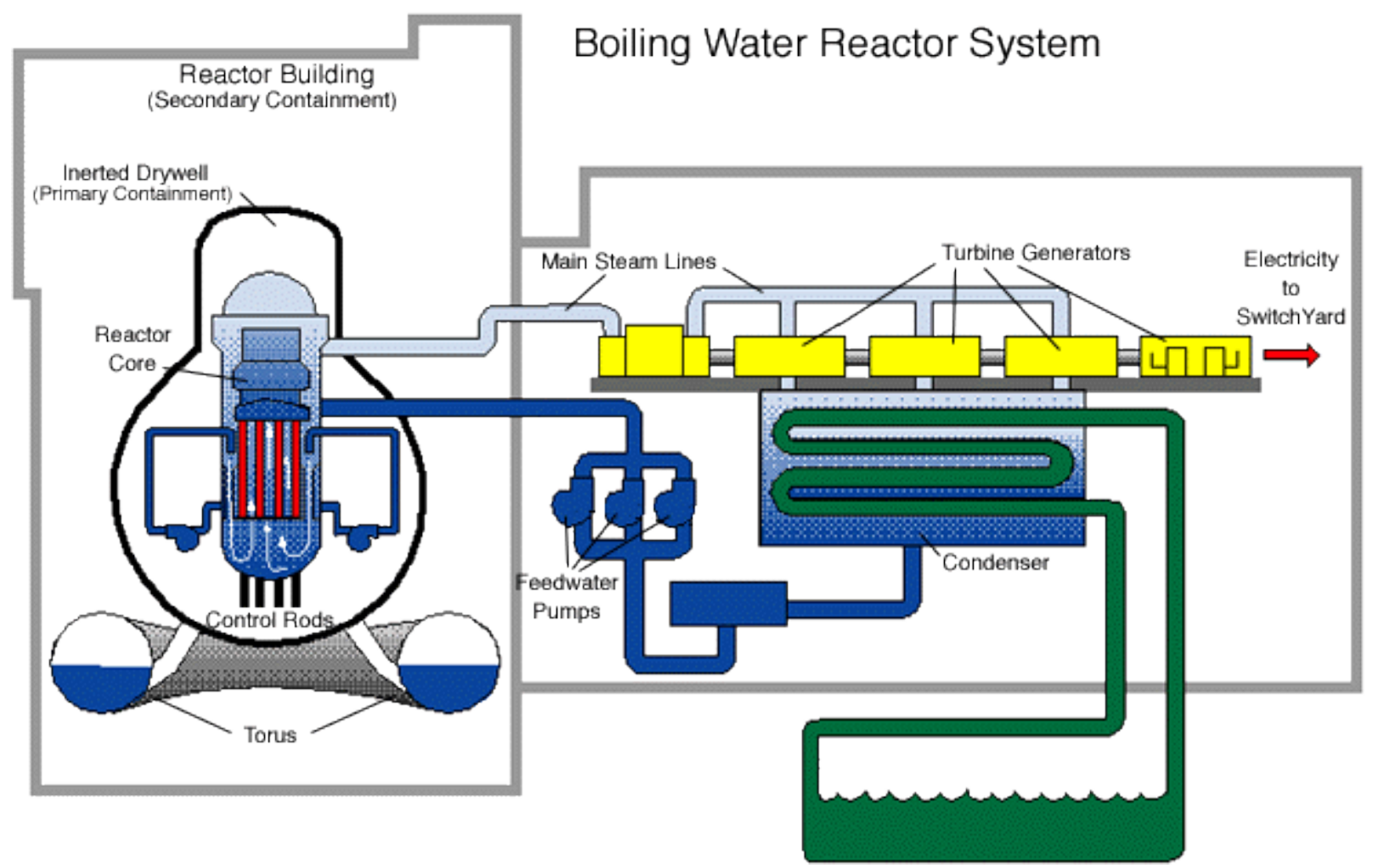

Figure 25. Diagram of the BWR system layout.

The figure below provides a more representative depiction of the main components within a BWR reactor building (secondary containment). The highlighted spent fuel pool is adjacent to the vessel and hosts the reactor fuel after irradiation. The steel containment vessel (primary containment) surrounds the reactor vessel (i.e., RPV) as shown in the illustration. 


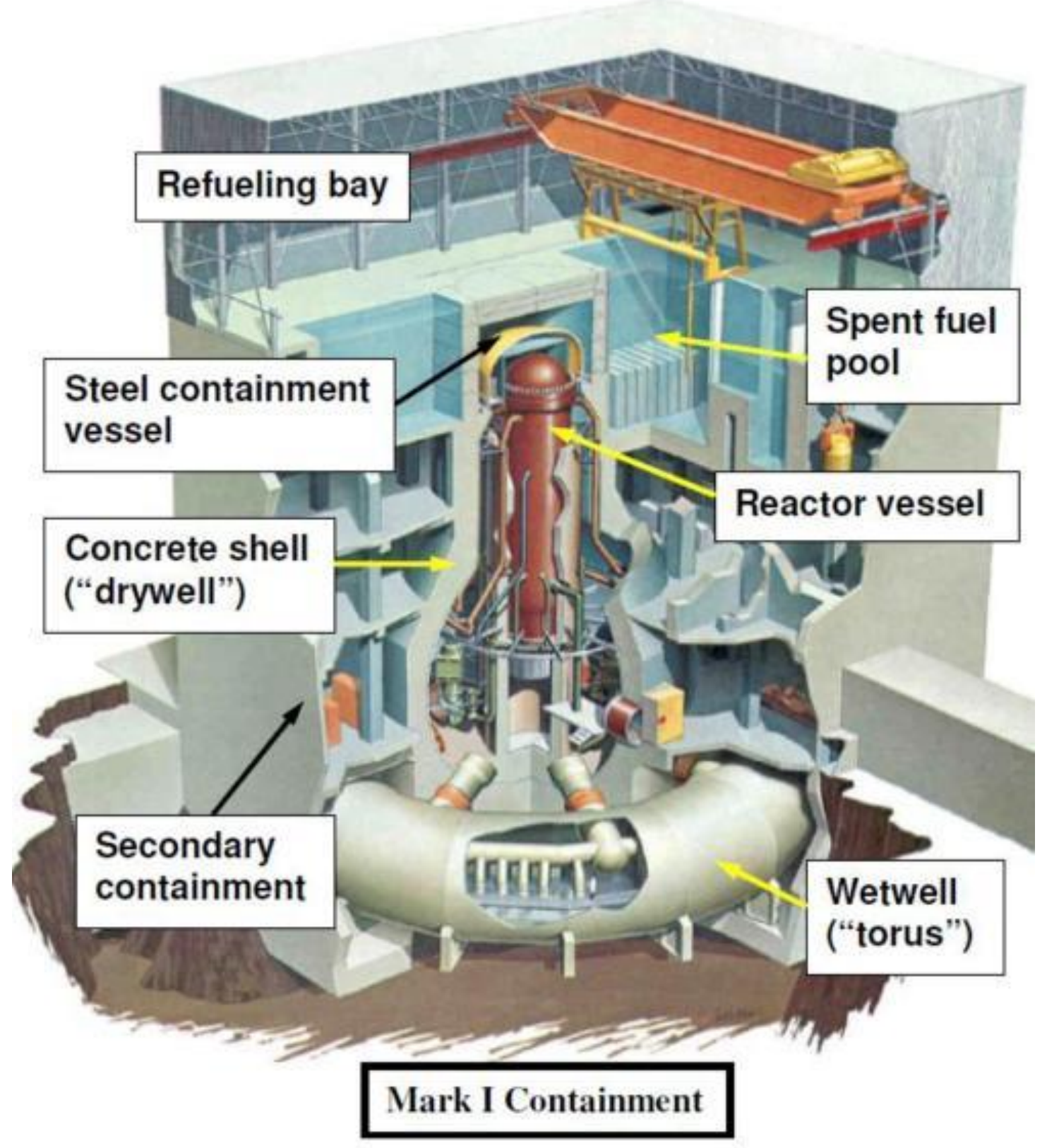

Figure 26. Illustration of the BWR containment building systems.

\subsubsection{Reactor Pressure Vessel Layout}

BWR Reactor Pressure Vessels (RPV) are more complex than their PWR counterpart since they combine multiple functions. Feedwater flows down the vessel wall, then back up through the reactor core where it is heated. In light of the lower pressure (around 75 bars versus 155 for the PWR), nucleate boiling occurs above the core midplane. The saturated steam is then directed to a separator and dryer system that removes any water droplets from the output and directs this water back down to the core. The high-quality steam then exits the vessel and is fed to the turbine. Since the coolant is directly in contact with the nuclear fuel, the primary system as a whole (including the turbine) must be isolated and shielded to protect from the contaminated water. Contrary to a PWR, control rods are inserted from the bottom of the core rather than the top in this type of reactor (to avoid contact with the steam). 


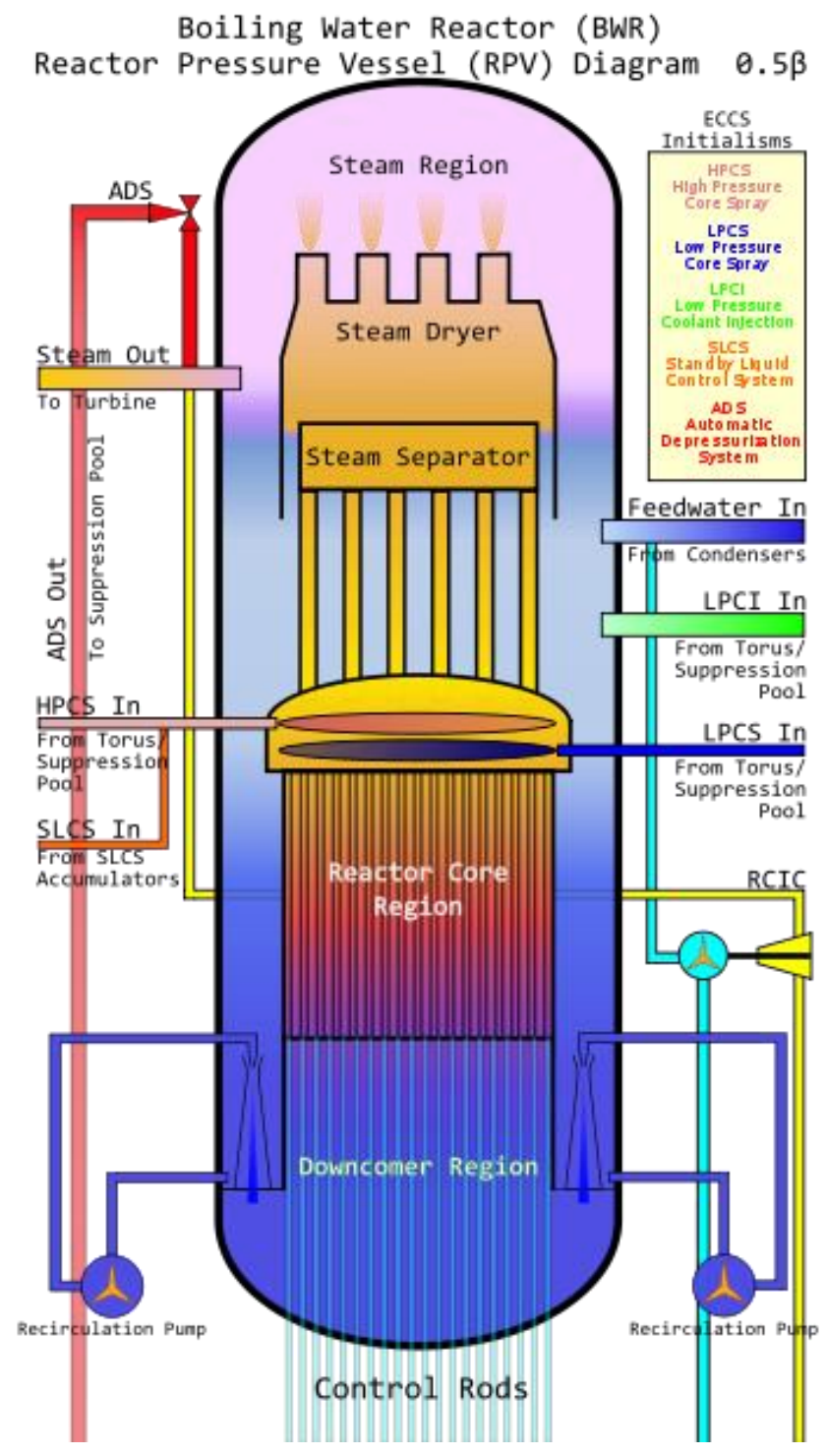

Figure 27. Cross-section view of the BWR pressure vessel.

\subsubsection{Fuel Assembly and Rods}

BWR assemblies resembles that of the PWR. Fuel rods containing $\mathrm{UO}_{2}$ pellet and a Zircaloy 2 alloy are arranged in a square assembly. The inside of fuel rods is back-filled with helium as well and sealed by welding the end plugs at each end of the tubes. The active assembly height (containing the fuel) is about $3.8 \mathrm{~m}$ long. A portion above the fuel pellets is kept empty to provide space for the plenum hosting the fission gases. A spring above the pellets provides a downward force on the pellets keeping them in place during handling. Each assembly bundles consists of around 100 rods that are held together via spacers. The lower tie plate has a nosepiece allowing it to fit inside the fuel support piece and to adequately distribute coolant to the fuel channels. The upper tie plate contains a handle for transferring and moving the fuel assembly during shuffling. The two pieces are made up of stainless steel. ${ }^{235} \mathrm{U}$ enrichment in a BWR can range between 1.7 to $2.2 \%$. The enrichment is varied throughout the same assembly in order to mitigate power peaking effects. 


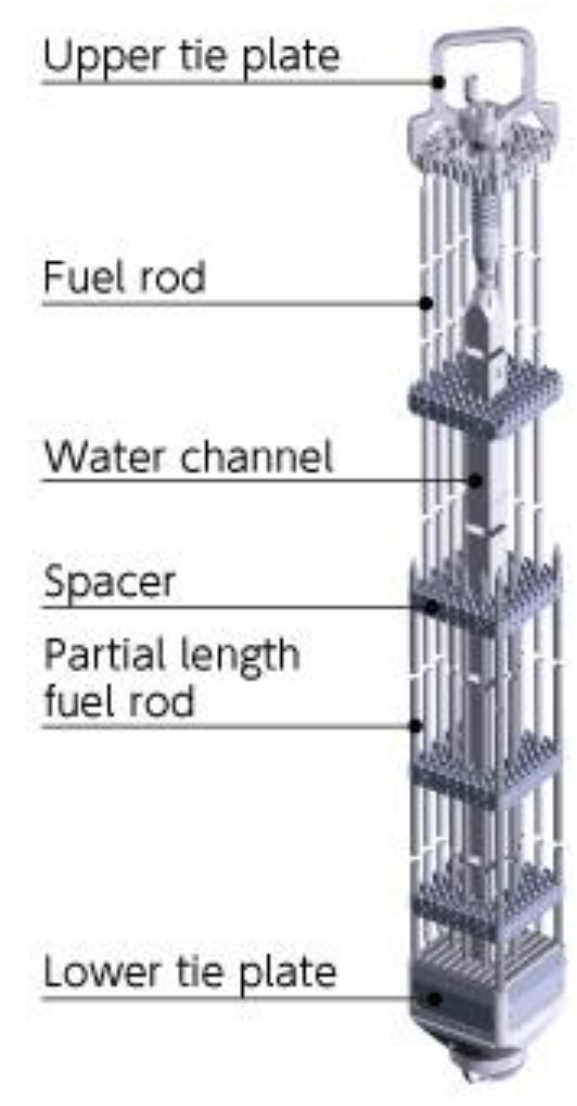

Figure 28. Layout of the BWR fuel assembly.

\subsubsection{Normal Operations}

A BWR has five modes of normal operation that are summarized below. They are determined by the state coolant temperature and reactor mode switch,

- Mode 1 - Normal Power: The mode switch is set to 'run'. Inlet temperature is around $215^{\circ} \mathrm{C}$, and outlet steam is at around $290^{\circ} \mathrm{C}$. Pressure is between $70-75$ bar,

- Mode 2 - Start-up: The mode switch is set to 'startup/hot-standby'. Inlet temperature is progressively increasing to the normal power condition. Pressure is the same as for mode 1.

- Mode 3 - Hot Shutdown: The mode switch is set to 'shutdown' and the coolant temperature is above $100^{\circ} \mathrm{C}$.

- Mode 4- Cold Shutdown: The mode switch is set to 'shutdown' and the coolant temperature is below $100^{\circ} \mathrm{C}$.

- Mode 5 - Refueling: The mode switch is set to 'refuel'. Temperature is below $100^{\circ} \mathrm{C}$, and the RPV is de-pressurized.

Coolant heat up is achieved using the reactor itself (rather than the pump in the case of the PWR). Steam dump is used for initial cooldown, the residual heat removal system is then used once the pressure is less than 10 bar.

In a BWR, reactor startup is achieved by control rod withdrawal. Criticality is forecast by monitoring the reactivity balance using nuclear instruments. The reactor power level is controlled either by the control rods or by varying the recirculation flow (relying on the reactivity feedback effects). The steam 
pressure is held constant at the turbine level. When power generated inside the reactor is increased, the steam pressure increases, and the turbine valves open to control and take more electrical load.

\subsubsection{Auxiliary Systems}

In a BWR, the auxiliary systems serve two essential functions: control the water chemistry and protect the reactor core. Some of the auxiliary subsystems are used for normal operations (including startup/shutdown) while others are relied upon for abnormal conditions. The main systems can be summarized as:

- The Reactor Water Cleanup (RWC) system.

- The fuel building, containment pools cooling, and filtering system.

- The closed cooling water system for reactor services.

- The shutdown cooling function of the residual heat removal system.

- The radioactive waste treatment system.

- The off-gas treatment system.

The main purpose of the RWC is to maintain high water quality by removing fission products, corrosion products, and soluble/insoluble impurities. The system also provides a means to remove water from the core when water volume is larger than during normal operations (e.g. cold shutdown). The total water volume can be processed in approximately 3 hours.

Water pool systems within the fuel building and containment pool are tasked with managing spent fuel cooling and drywell heat transfer to the upper containment pool. The system consists of circulating pumps, heat exchangers, filters, vales, piping, and instrumentation. The residual heat removal system is also available to supplement the fuel pool cooling.

\subsubsection{Engineered Safety Features}

Similar to the PWR, the Engineered Safety Systems for the BWR has the direct responsibility to protect the public from the release of core damaging fission products. It does so by multiple means:

- Emergency Core Cooling Systems that rapidly inject water into the reactor to maintain the first boundary to the release of fission products, the cladding. These systems also provide long term cooling water flow.

- Containment Systems that can contain the entire leakage of the reactor coolant system without major release to the atmosphere. These also include Containment Cooling and Spray systems to remove the heat and lower the pressure; as well as Hydrogen control systems that prevent explosions that could challenge the integrity of the containment.

- Essential Cooling systems that remove the long term decay heat from the reactor and transport it to the "ultimate heat sink." This ultimate heat sink is established as part of the siting criteria and is the river, lake, ocean, or a man-made created reservoir.

- Emergency Electrical Power systems that provide the necessary motive force for the pumps and systems to provide their safety functions. This is typically Emergency Diesel Generators or other independent power sources.

The BWR ECCS provides alternative core cooling in response to a LOCA. It consists of a two high pressure and two low pressure injection systems. The high pressure systems are the BWR High Pressure Coolant Injection (HPCI) system and the Automatic Depressurization System (ADS). The low pressure systems are the BWR LPCI mode of the heat removal system and the Core Spray system. 
The BWR-HPCI system has similar functionality as the PWR-HPCI. It is designed to provide auxiliary cooling and coolant makeup in the event of an accident where pressure does not decrease appreciably. Several HPCI designs exist, however a typical BWR-HPCI has its own turbine which draws work energy from steam being bled-off from the BWRs main steam line. The BWR-HPCI turbine drives its own pump, thus it does not rely on an emergency diesel generator.

The ADS consists of redundant control logic capable of opening selected relief valves, when required, to depressurize the BWR for events involving accidents that require additional energy release. It is used to lower the reactor pressure in order to recover the RPV water level.

The BWR-LPCI system has similar functionality as the PWR-LPCI. The BWR-LPCI coolant injection mode is used to restore coolant inventory to the RPV. It also can recirculate coolant from the containment suppression pool (or wet well), cools it via the residual heat removal heat exchanger before returning it to the RPV. The associated pumps and RHRs heat exchanger are used to remove residual heat from the BWR during startup to normal operation. The Core Spray system is also used for some BWR designs and supplies low pressure recirculated water directly to the top of the reactor vis spray nozzles.

The Containment Spray system recirculates water from the wet-well and sprays it into the drywell structures after being cooled in the RHRS heat exchanger. Similar to the PWR spray system, it mitigates heat-up of the containment systems as well as attempts to condense released steam so that it can be collected in the wet-well. The reactor design also relies on a 'torus' for pressure suppression. Safety-relief valves allow the venting of overpressures to below the surface of a pool of liquid water housed within the containment.

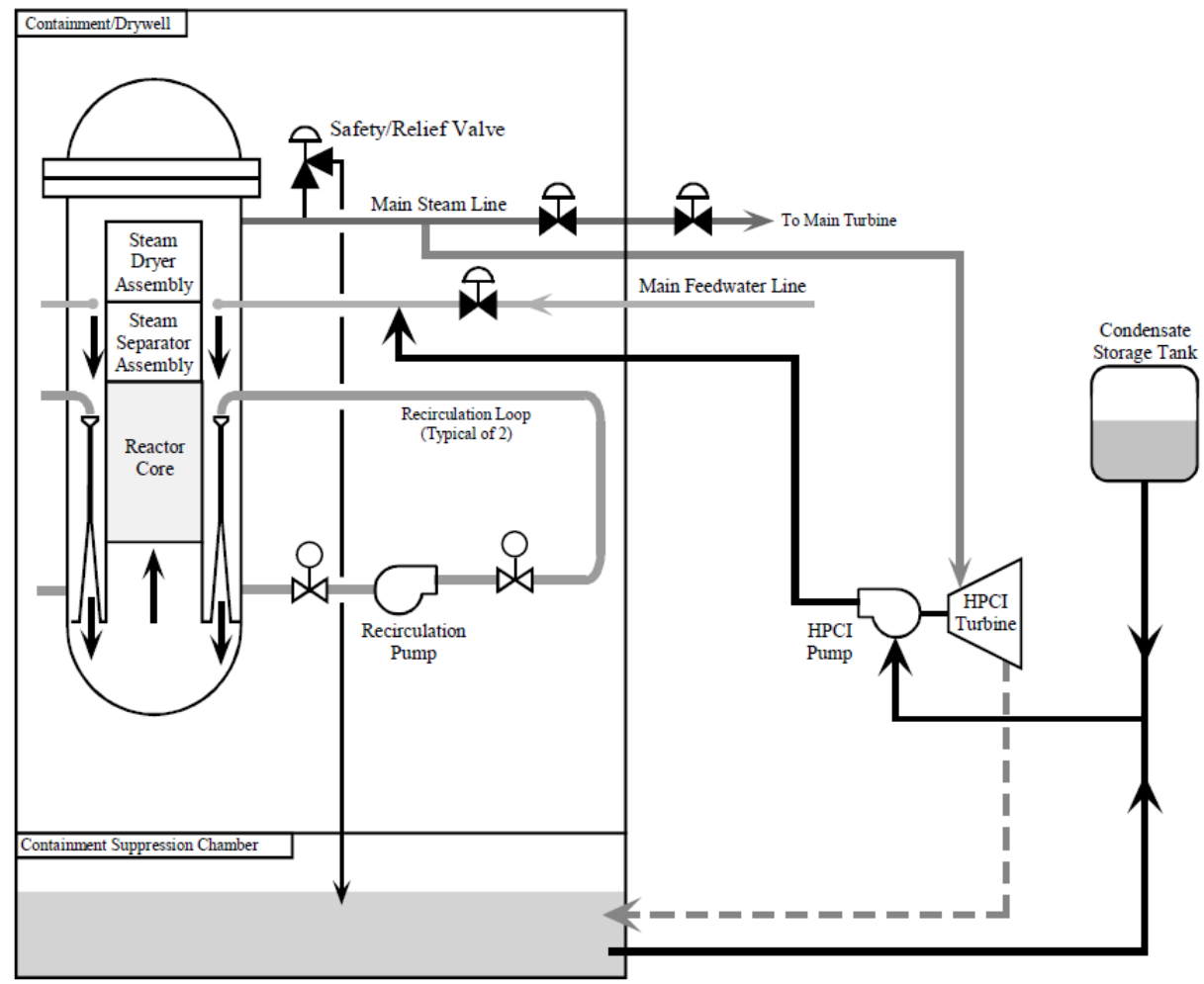

Figure 29. Diagram of the BWR high pressure Emergency Core Cooling System [13]. 


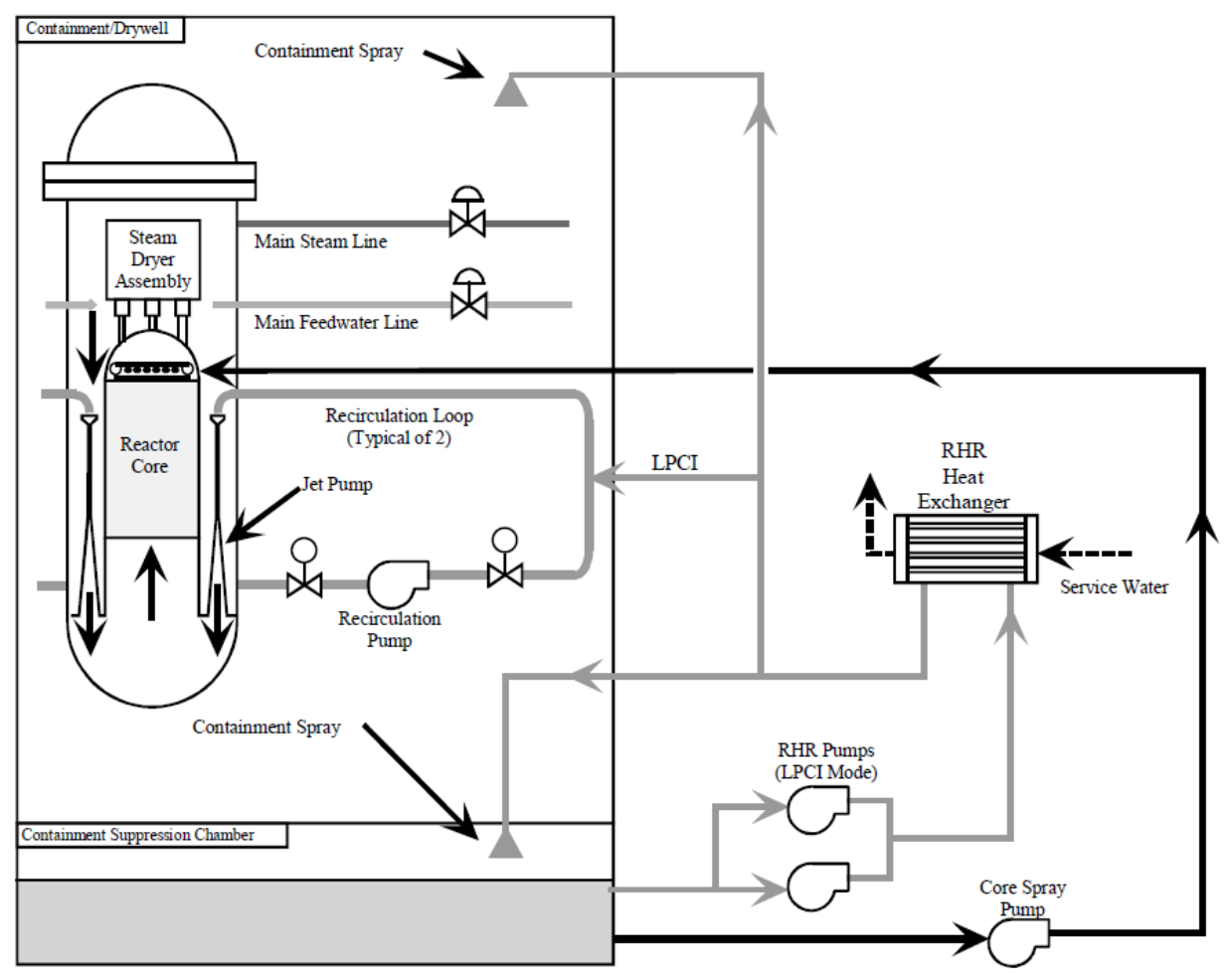

Figure 30. Diagram of the BWR low pressure Emergency Core Cooling System [13].

\subsubsection{Primary Containment Structure}

Similar to PWRs, BWRS have a primary containment structure made of steel reinforced concreate or steel. However, unlike PWRs, in BWR Mark I and II constructions this structure typically encapsulates the RPV. The Mark III construction has a primary containment building similar to that of PWRs. Each of these designs follows is a design evolution of the previous design. The Mark I and Mark II BWRs have a secondary confinement building for which the RPV, recirculation pumps, and safety systems reside.

\section{Materials Degradation Issues}

In addition to satisfying standard materials design criteria based on tensile properties, thermal creep, cycle fatigue, structural materials for LWRs must provide adequate resistance to two additional overarching environmental degradation phenomena: chemical compatibility and radiation damage.

\subsection{Water Chemistry Issues}

\subsubsection{Corrosion}

All LWR systems are impacted by corrosion in light of their aqueous environment. Corrosion can yield particles in both the primary and secondary loops, that can break loose and travel throughout the system. In the primary system, this is termed 'CRUD' and gets activated as it travels through the reactor, as discussed in greater detail in the following subsection. In the secondary system (PWR), corrosion particles can cause fouling of heat exchangers. These particles tend to concentrate inside the Steam Generator due to boiling effects and can results in large deposits of sludge on the tube sheets. They can be cleaned during outages by high pressure 'sludge lancing'. These different phenomena are mitigated by strict chemistry control inside the systems.

Corrosion can impact crack propagation inside a reactor component via what is termed 'stress corrosion cracking' (SCC). This is defined as the growth of a crack due the simultaneous action of an 
applied stress (can be residual stress) and a corrosive environment. SCC is a complex phenomenon that is driven by the synergistic interaction of mechanical, electrochemical, and metallurgical factors as illustrated below. Mechanical loads and machining defects are known causes of crack propagation. SCC adds to this a chemical dimension that can accelerate the growth and initiation of a crack (relative to an inert environment).

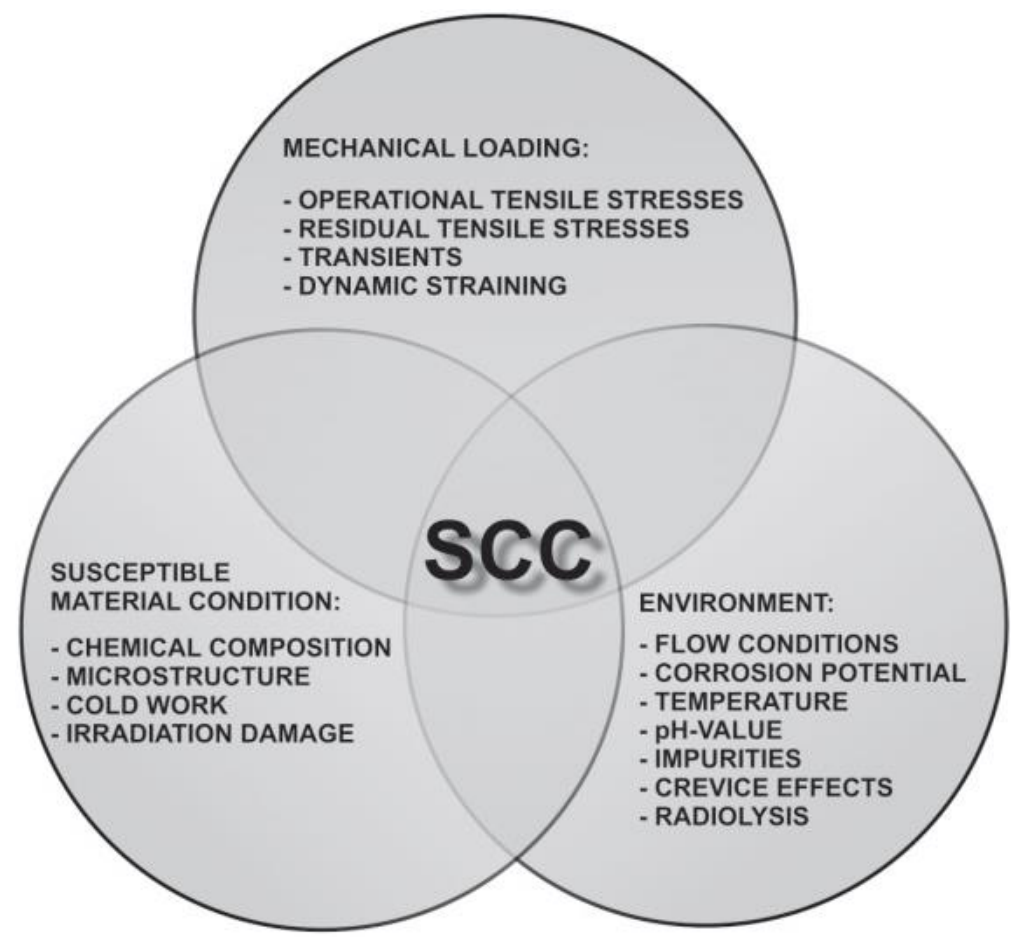

Figure 31. Illustration of aspects affecting stress corrosion cracking (SCC).

There are different mechanisms for how SCC occurs. One dominant mechanism in PWRs is via hydrogen embrittlement (shown below). Hydrogen atoms can diffuse through the crack tip, thus weakening the surrounding material and accelerating the crack propagation. Once a critical crack length is reached, sudden material failure can occur. These cracks can be very difficult to detect during maintenance. The corrosive environment can also be the initiating condition for a crack formation. Microscopic pits can be formed due to the dissolution of structural material into the water. As these pits increase in size, different corrosion cracking phenomena become dominant and lead to the formation and growth of the crack. 


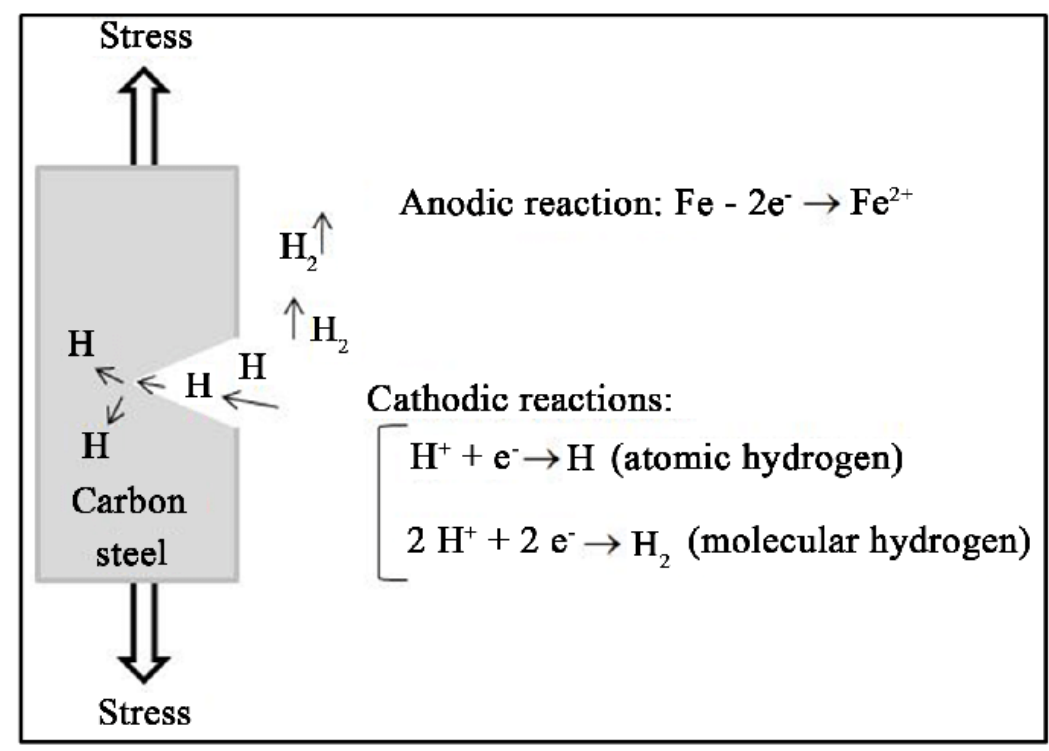

Figure 32. Illustration of stress corrosion cracking process.

In PWR systems, components made of alloy 600, can experience stress corrosion cracking. This includes the steam generator tubes, the pressurizer instrument penetrations, the heater sleeves, the control rod drive mechanism nozzles, and hot leg penetrations. Inside BWRs, stress corrosion cracking occurs mostly in materials made of austenitic steels or nickel-based alloys. Examples include the recirculation piping, the core internals and parts of the RPV (e.g. in-core monitor housing, and control rod drive stub tubes). Intergranular stress corrosion cracking has been the cause of significant ageing degradation in these components as well.

\subsubsection{CRUD}

Some of the radical byproducts formed by various chemical reactions are termed CRUD once they are deposited in crevices and downstream piping. This includes corrosion and wear products (e.g. rust particles) that became radioactive (via neutron activation) inside the reactor. They can have a wide range of impacts primarily on dose to workers, but can also impact performances. The presence of boron buildup in CRUD can affect the neutronic performance of the reactor. CRUD can also cause localized underdeposit corrosion and degrade surface heat transfer properties. It also increases the radioactivity of the entire coolant system, both PWR and BWR, due to the addition of radioactive particles.
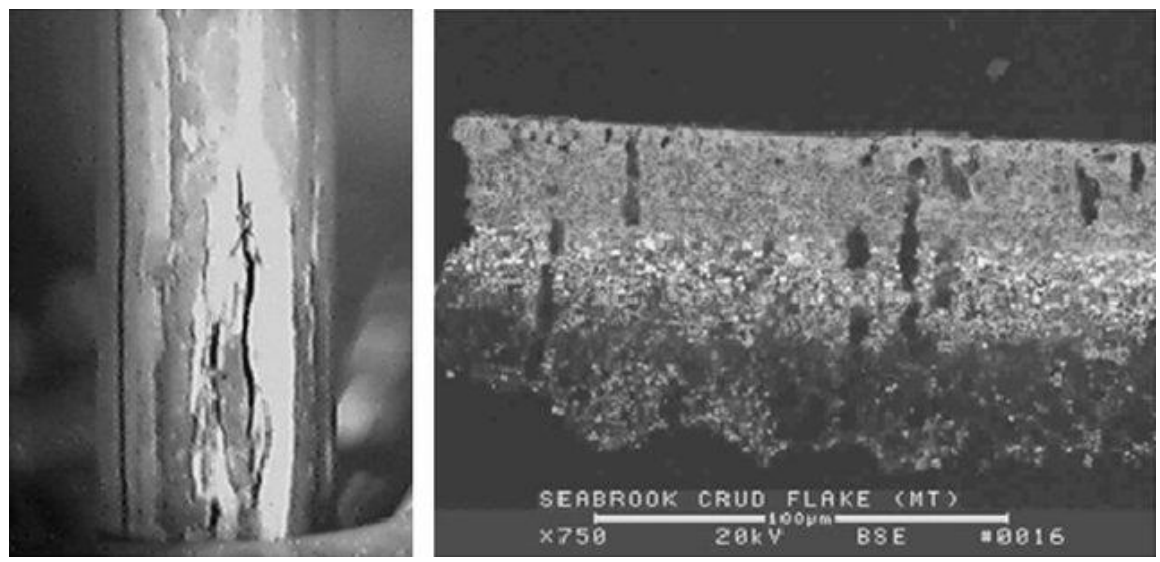

Figure 33. Picture of CRUD formation on a PWR fuel rod (taken from [14]). 


\subsubsection{Water Chemistry Control}

Radiolysis is a process where neutron collisions with the water molecule causing one of its hydrogen atoms to break away. The resulting hydrogen radicals decreases the $\mathrm{pH}$ of the coolant, thus making it more corrosive. Free oxygen radicals make the coolant more oxidizing. Also, the hydrogen and oxygen radicals will recombine to form various new molecular combinations of $\mathrm{H}$ and $\mathrm{O}$, e.g., $\mathrm{H}_{2} \mathrm{O}_{2}$. The oxygen and radiolysis products attack the outer layers of the stainless steel or nickel based alloys in the reactor structure and can lead to the before mentioned CRUD deposits on the fuel. The decreasing $\mathrm{pH}$ (i.e., increasing acidity) of the water by the hydrogen radicals attacks cladding and core structures through SCC. Radioactive particulates formed by oxidation and corrosion can transport though the RCS and plate out in parts of the plant that can increase out-of-core radiation fields and worker exposure. Therefore, controlling water chemistry improves fuel reliability, component life, and helps the radiation protection program.

In PWRs, primary de-oxygenation is forced by the addition of diatomic hydrogen, $\mathrm{H}_{2}$, for oxygen scavenging. $\mathrm{H}_{2}$ is added as a gas in the Chemical and Volume Control System volume control tank to ensure reaction leans towards zero $\mathrm{O}_{2}$. $\mathrm{Li}-\mathrm{OH}$ hydroxide ions are introduced for $\mathrm{pH}$ control to compensate for the low $\mathrm{pH}$ created by the presence of boric acid. However, lithium is also formed by the ${ }^{10} \mathrm{~B}(\mathrm{n}, \alpha){ }^{7} \mathrm{Li}$ absorption reaction in the dissolved boron (i.e., the boric acid chemical shim). This additional lithium must be slowly removed during operation. Lithium is slowly removed via an ion exchange bed. As the fuel depletes its reactivity decreases. Therefore, the reactivity hold-down of the boric acid must also be decreased. This is accomplished by either slowly removing the boron over time by the Boron Thermal Regeneration System, i.e., a temperature dependent ion exchange process involving a resin bed, or by the dilution of the RCS. The Li-OH level must be carefully adjusted to compensate for boric acid as it is diluted [11].

BWRs do not use chemical shim for burnup compensation. Therefore, there is not a need to add hydroxide ions to compensate for boric acid. Instead they modulate the amount of moderation in the core by changing the void fraction. This is accomplished by changing the flow rate of the recirculation pumps. Similar to PWRs, hydrogen water chemistry is considered a viable method for reducing dissolved oxygen in BWRs. In some cases chemistry modification can help with one issue, but worsen another. For example, addition of $\mathrm{H}_{2}$ helps prevent $\mathrm{SCC}$, by removing free oxygen products, but does not remove nitrogen products. This is significant because during irradiation a small amount of the oxygen in the core (bound in $\mathrm{H}_{2} \mathrm{O}$ or otherwise) undergoes the high energy neutron absorption reaction, ${ }^{16} \mathrm{~N}(\mathrm{n}, \mathrm{p})^{16} \mathrm{~N}$. Radiolysis ${ }^{16} \mathrm{~N}$ products, such as $\mathrm{N}_{2}, \mathrm{NO}$, and $\mathrm{NH}_{3}$, are not removed by oxygen. ${ }^{16} \mathrm{~N}$ decays by beta and gamma emission back into ${ }^{16} \mathrm{O}$ with a half-life of $7.1 \mathrm{~s}$ which is sufficiently long-lived to be transported out of the core to deliver high gamma-ray fields throughout the BWR feed-water system. Therefore, it is well known for BWRs that increasing $\mathrm{pH}$ is generally associated with increasing ${ }^{16} \mathrm{~N}$ exposure rates surrounding feedwater systems [15].

There are a multitude of secondary measures for chemistry control. Most PWRs now use All Volatile Treatment (AVT). AVT chemistry typically utilizes Hydrazine as the principal addition. Hydrazine removes oxygen in lower temperature conditions then transforms to ammonium to make the $\mathrm{pH}$ alkaline at higher temperatures. In BWRs, Noble Metal Chemical Addition (NMCA) is used. NMCA reduces the amount of hydrogen required by addition of Platinum and Rhodium. BWRs also use a process called Condensate Polishing to reduce iron and other contaminants. Both PWRs and BWRs use zinc additives to compensate for SCC.

Corrosion products can be removed mechanically in some cases. Steam generators use a bottom connection near the top of the tube sheet to "blowdown" concentrates and particulates. Specialty chemicals such as boric acid are added to suppress tube denting at support plates. 


\subsection{Fuel and Structural Materials Issues}

The amount of radiation damage produced in materials due to collisions with neutrons is quantified by the internationally recognized parameter of displacements per atom (DPA). A displacement damage of $1 \mathrm{dpa}$ means that, on average, each atom has been displaced from its lattice site once. Damage to reactor materials can range anywhere from $15 \mathrm{dpa}$ over five years for the fuel cladding to $0.05 \mathrm{dpa}$ after 40 years for the RPV, to $80 \mathrm{dpa}$ after 40 years for reactor internals structures. The amount of irradiation damage that a component is allowed to have is related to the temperature, pressure, and desired chemical compatibility throughout its service life. There are five key radiation degradation effects: low temperature radiation hardening and embrittlement, radiation induced segregation, irradiation creep, void swelling, and high temperature helium embrittlement [16].
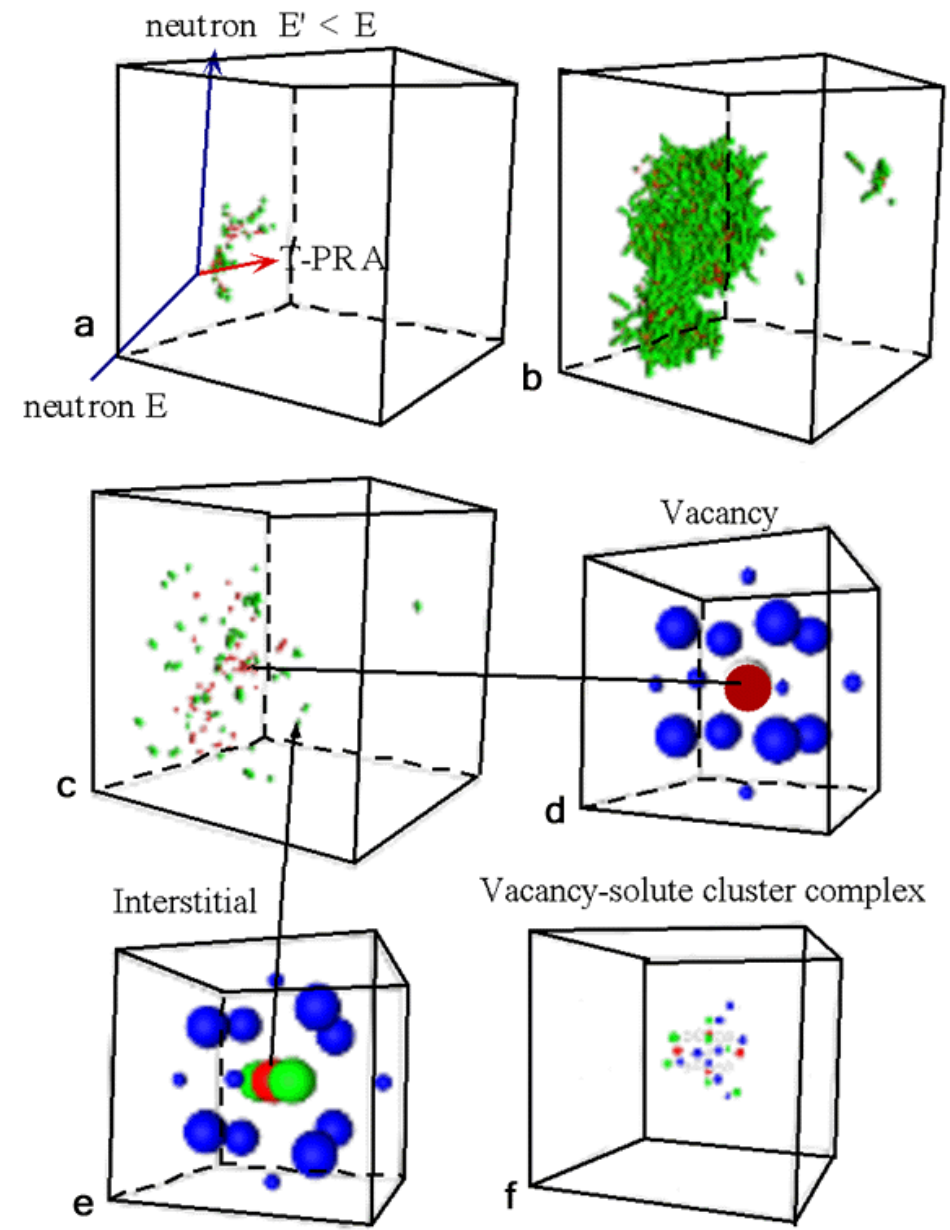

Figure 34. Neutron damage cascade production of: Primary Knock-on Atom (PKA) (a), dislocation cascade (b), interstitial/vacancy self-annihilation (c), final dynamic stage of displacement cascade (d-e), ultimate vacancy formation into voids and dislocation precipitation [17].

\subsubsection{Low Temperature Radiation Hardening and Embrittlement}

Solid materials at the atomic level are arranged as a repeating lattice of atoms forming a crystaline structure. These crystals form grains. Grains form a material. A solid is not a pure crystal, but many microscopic crystals called grains. When a force or shear stress is applied to a material (e.g., internal pressure within the fuel rod or RPV) it will deform, but will elastically return to its original position after the load is removed. However, if sufficient shear stress is applied "plastic" deformation can occur where some dimensionality is lost along with strength. Plastic deformation occurs when atoms are dislocated by 
the shear stress, and slip in crystallographic directions favorable to the applied stress. Since the ease with which a material is capable of plastic deformation is a function of dislocation mobility, restricting dislocation motion increases hardness and strength.

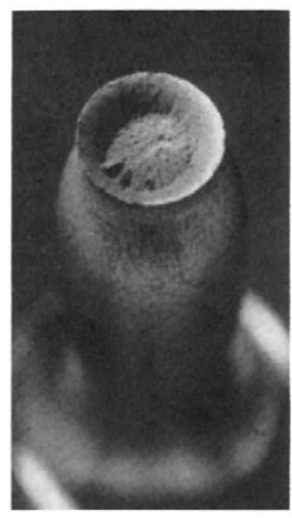

(a)

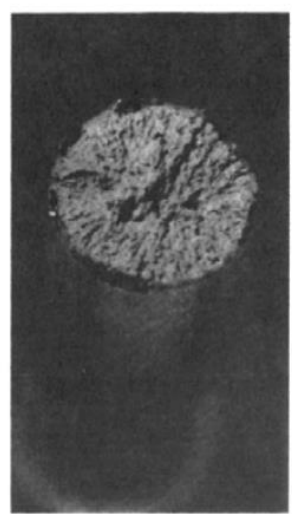

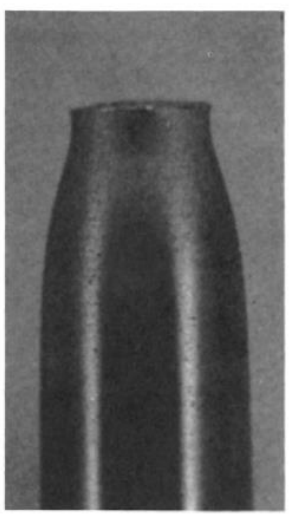

(b)

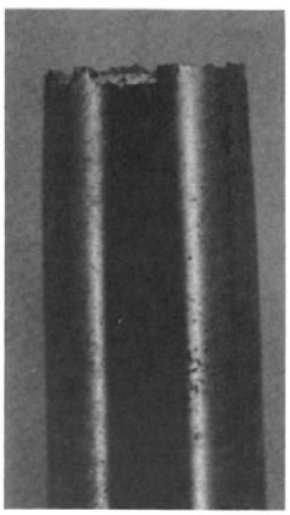

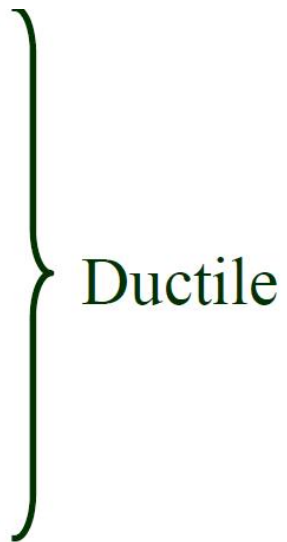

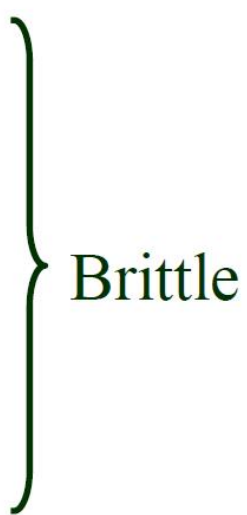

Figure 35. Example of ductile versus brittle failure. Ductile materials will deform plastically before "total elongation" occurs. Brittle materials will experience elastic yield until fracture. Irradiation induced defects generally cause metals to become more brittle.

Irradiation knocks out atoms from the crystalline structure. Usually, these dislocated atoms (and their vacancies) rapidly recombine to reconstitute the crystalline structure, though not completely. The displaced atoms can settle into an "interstitial" location within the lattice, i.e., lodged into a non-lattice location. Similarly, the vacancy left in the lattice remains un-filled. Dislocated atoms eventually form dislocation barriers that inhibit slip. Vacancies ultimately can coalesce to form voids. Because of the formation of dislocation barriers, neutron damage can produce pronounced hardening at low and intermediate temperatures due to the production of high densities of nanoscale defect clusters (i.e., dislocation loops, helium bubbles, etc.). These defects in the material's atomic crystalline structure can serve as obstacles to dislocation motion. Generally, increasing strength is desirable, but not at the expense of embrittlement. Radiation damage causes the material's elastic yield strength to increase, but the level of plastic deformation capability is greatly diminished. 


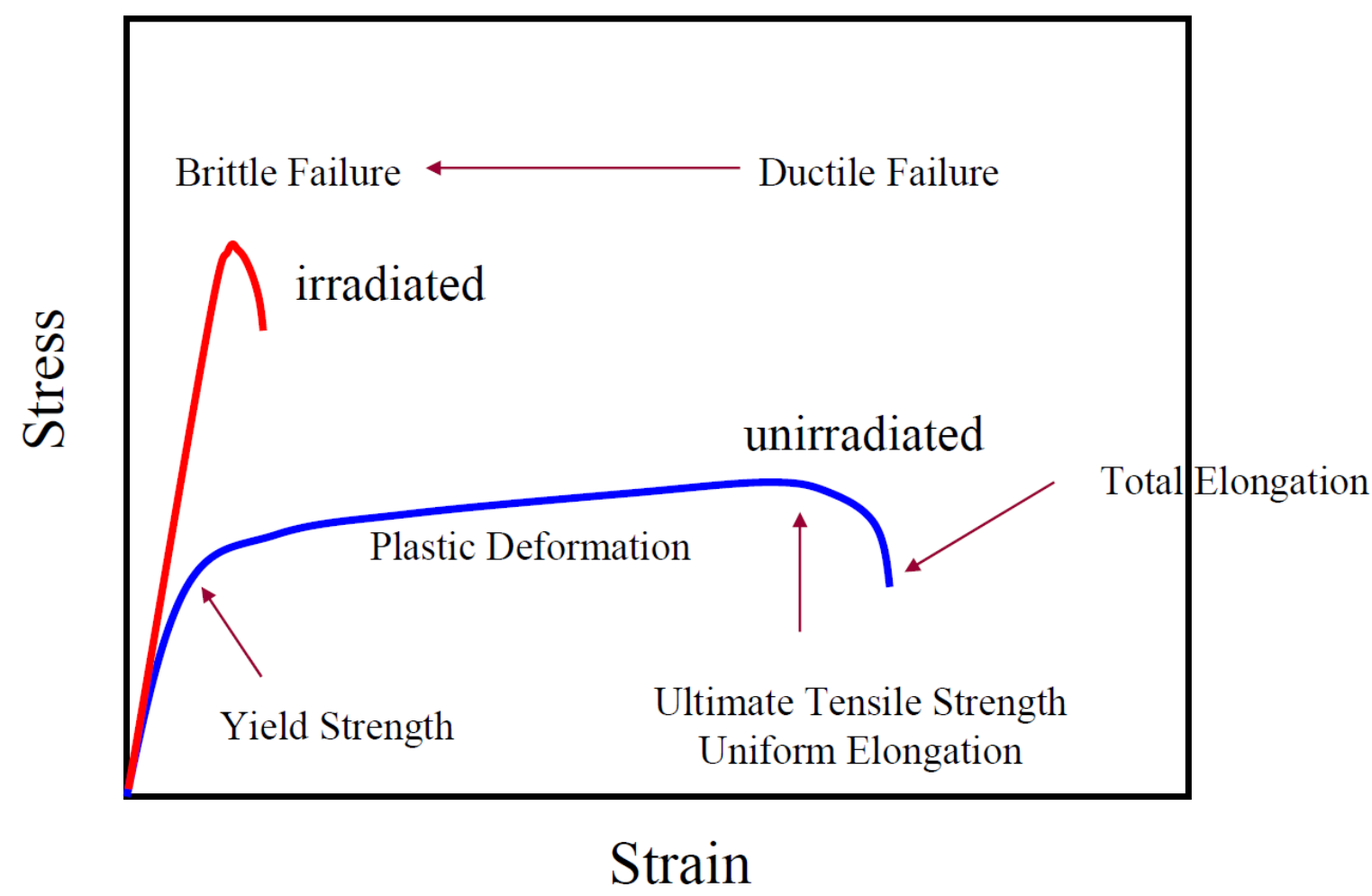

Figure 36. Stress-strain curve showing loss of ductility due to irradiation hardeing.

The neutron damage rate in the RPV is orders of magnitude less than that of the fuel, but is still of sufficient intensity to cause irradiation hardening which could lead to fracture toughness embrittlement. It is important to maintain fracture toughness over a wide range of operating conditions, including normal operation, cold shutdown for refueling and maintenance, and postulated transient accident scenarios. One such scenario is where cold water is inadvertently injected into the reactor while it is operating at hot full power conditions thus creating large shock of thermal stresses leading to crack propoagation.

\subsubsection{Radiation Induced Solute Segregation or Phase Change}

Alloys are generally a "solid solution" of metallic elements, but it can also contain separate phases of these elements. These occur within regions of the alloy whose composition and properties are homogeneous, but distinct from other regions of the alloy. Radiation damage in alloys will strongly influence the elemental distribution and can frequently lead to phase changes that are not observed in alloys aged thermally at the same temperature. In radiation-induced segregation, point defects (vacancies and self-interstitials) generated as a result of displacement damage migrate to the grain boundaries. As a result of interactions with vacancies, faster diffusing elements tend to deplete at the boundary, while slow moving elements tend to enrich. This causes new phases to form and segregate (also known as precipitation) within the solid solution. This process can improve material properties as the new phases can serve as obstacles to crystallographic slip, thus adding strength. However, segregation can also reduce strength at the grain boundary increasing susceptibility to cracking. When combined with the chemical environment, high temperature and stress, the material may be more susceptible to irradiationassisted SCC.

\subsubsection{Void Swelling}

Void swelling is caused by the nucleation, coalescence, and ultimately stabilization of atomic vacations left-over after atomic nuclei have been knocked out by neutron collision. The stabilization of a vacancy or bubble is usually aided by the presence of inert gasses such as transmutation helium. Void 
swelling is characterized by an initial low-swelling incubation regime where void nucleation and growth is occurring. This is followed by a steady-state swelling regime where volumetric swelling increases proportionately to dose.

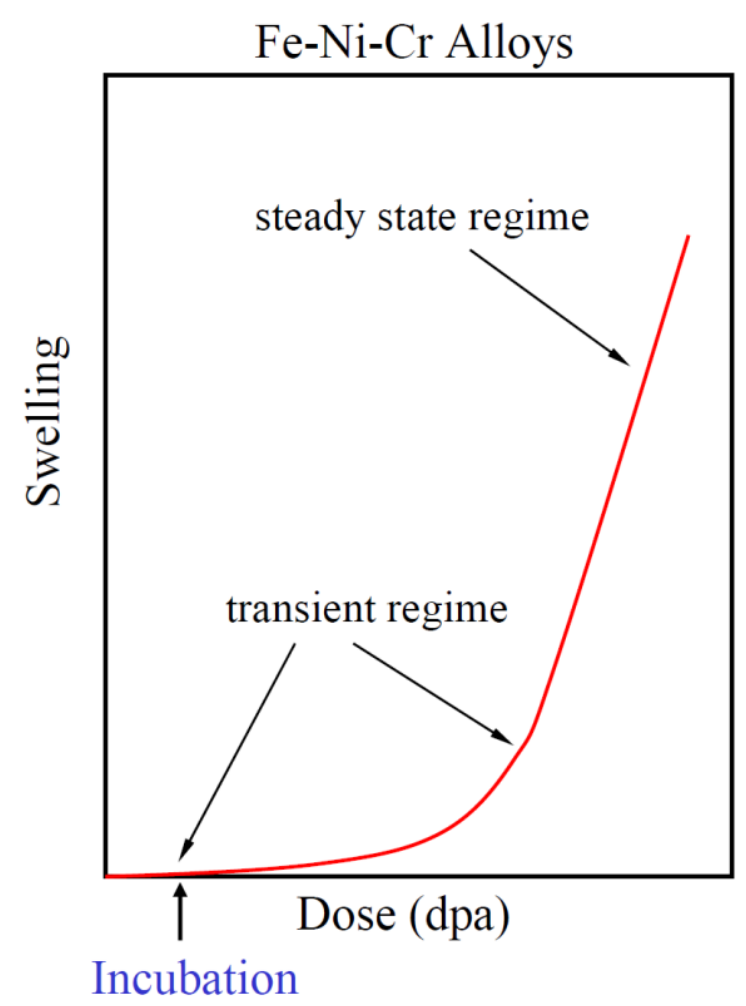

Figure 37. Evolution of swelling regimes due to neutron dose.

However, heating caused by the ionizing energy produced by fission prompt gamma-rays can cause thicker non-fuel components to have temperatures as high as $380^{\circ} \mathrm{C}$, which is within range for transient swelling void swelling to occur in austenitic stainless steels. Reactor coolant outlet temperatures are in the range of $\sim 300^{\circ} \mathrm{C}$. Baffle-former bolts in PWRs have developed voids at damage levels as low $7.5 \mathrm{dpa}$ [16]. The baffle-former is a PWR core internals structure that surrounds the fuel assembly lattice. The BWR shroud forms a similar function. This reactor hardware serves as a flow boundary between downward flowing cold-leg coolant (returning from the condenser (BWR) or steam-generator (PWR) and the upward flowing hot-leg coolant flowing through the fuel assemblies.

Also, the zirconium cladding is susceptible to some swelling due to the dose that it receives.

\subsubsection{Irradiation Creep}

Creep is a time-dependent deformation under an applied load. The majority of creep mechanisms involve dislocations slowing climbing past obstacles over time. Its time dependent nature separates it from dislocation slip as in plastic deformation. Creep is typically associated with high temperature. However, irradiation can allow it to occur at low temperature. Unlike swelling where the material undergoes a change in volume (density reduction), creep is a constant volume shape change. Therefore, creep causes elongation in a given dimension with shrinkage (or at least relaxation of stress) in the other dimensions. The amount of deformation from irradiation creep is typically proportional to the applied stress and the irradiation exposure. One consequence of irradiation creep is that it can induce undesirable stress relaxation of bolts and springs. 
Grid-to-rod fretting is induced by coolant flow-induced vibrations of the cladding against the spacer grids that ensure separation between the fuel rods. This vibration is caused by coolant turbulent crossflow and jetting between fuel rods. Grid-to-rod fretting is not a major issue in BWRs because the fuel pins are surrounded by a flow duct that minimizes cross-flow between fuel assemblies. At high irradiation damage, the spring force between cladding and the spacer grids is relaxed due to irradiation creep, thus exacerbating fretting.

\subsubsection{High Temperature Helium Embrittlement}

At high temperatures ( 0.5 to 0.6 times that of the melting temperature), the efficient annealing of lattice defects produces recovery of most of the radiation damage. One notable exception is transmutation helium dissolved within the metal as a result of $(n, \alpha)$ nuclear reactions in nickel if nickel is used as an alloying constituent. Some structural materials also contain dilute additions of boron which also undergo $(n, \alpha)$ reactions. The helium can diffuse to the grain boundaries, where it can form large bubbles that weaken the grain boundary strength and cause dramatic reductions in total elongation (i.e., the amount of plastic deformation before failure under an applied force). Though LWRs do not normally operate in such a way that structural materials are within $>0.5$ times their melting temperature, nickel containing austenitic stainless steels are common as they are corrosion resistant. Helium induced embrittlement is also known for causing weld cracking.

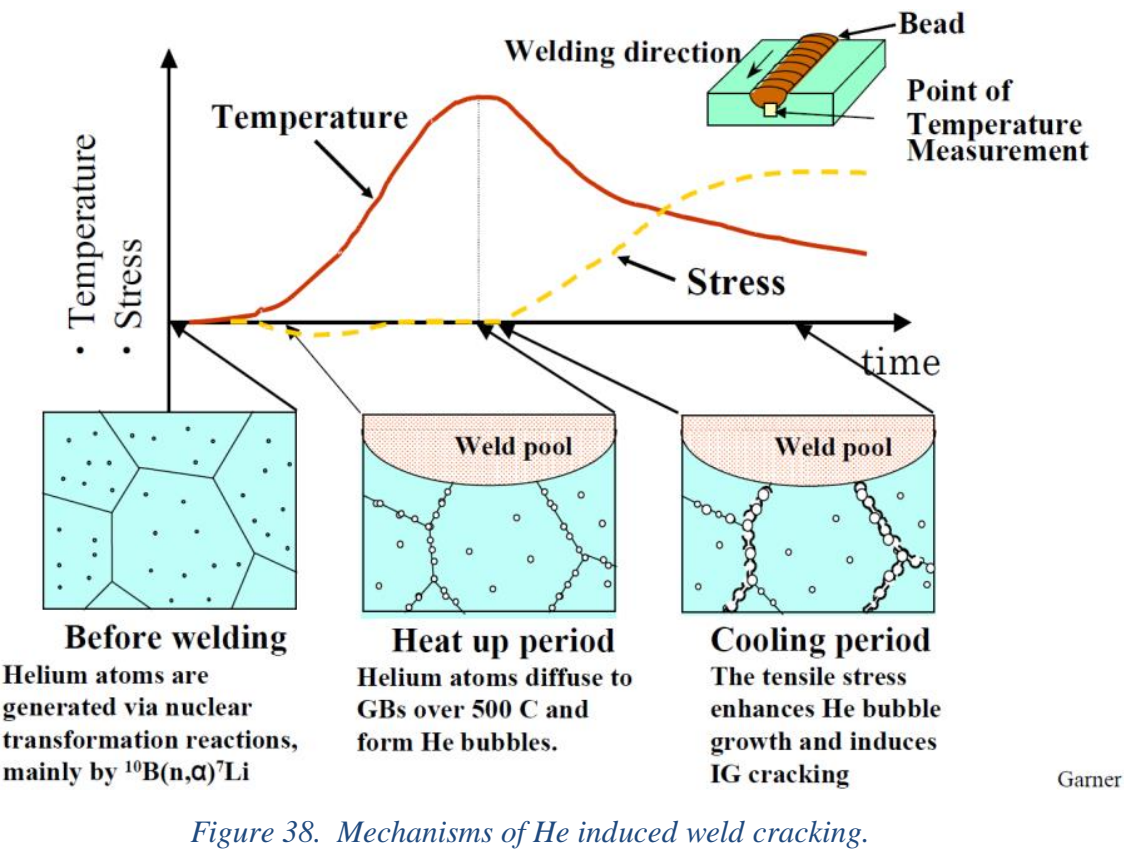

\section{Safety Analysis}

The Nuclear Regulatory Commission (NRC) licenses and regulates the operation of commercial nuclear power plants in the United States. Currently operating nuclear power plants have been licensed under a two-step process described in Title 10 of the Code of Federal Regulations under Part 50 (i.e., 10CFR50). This process requires both a construction permit and an operating license.

In an effort to improve regulatory efficiency and add greater predictability to the process, in 1989 the NRC established alternative licensing processes in 10CFR52 that included a combined license. The process combines a construction permit and an operating license with conditions for plant operation.

As part of the application to the NRC, an applicant must submit a Safety Analysis Report (SAR). The SAR contains the design information and criteria for the proposed reactor. It also discusses various hypothetical accident situations and the safety features of the plant that would prevent accidents or lessen 
their effects. Additionally, the applicant must provide a comprehensive assessment of the environmental impact of the proposed plant and demonstrate that the safety features of the plant provide adequate protection to workers, the public, and the surrounding (i.e., site specific) environment.

The structure of the SAR typically closely follows that of NUREG-0800 [18].

- Chapter 1: Introduction and Interfaces

- Chapter 2: Site Characteristics and Site Parameters

- Chapter 3: Design of Structures, Components, Equipment, and Systems

- Chapter 4: Reactor

- Chapter 5: Reactor Coolant Systems and Connected Systems

- Chapter 6: Engineering Safety Features

- Chapter 7: Instrumentation and Controls

- Chapter 8: Electric Power

- Chapter 9: Auxiliary Systems

- Chapter 10: Steam and Power Conversion System

- Chapter 11: Radioactive Waste Management

- Chapter 12: Radiation Protection

- Chapter 13: Conduct of Operations

- Chapter 14: Initial Test Program and ITAAC-Design Certification

- Chapter 15: Transient and Accident Analysis

- Chapter 16: Technical Specifications

- Chapter 17: Quality Assurance

- Chapter 18: Human Factors Engineering

- Chapter 19: Severe Accidents

- Appendices, References, etc.

Chapter 15 of RG 1.70 and NUREG-0800 discusses the safety and accident mitigation features of the reactor and is the subject of the following discussion.

\subsubsection{Initiating Events}

An initiating event is an event that creates a disturbance in the plant and has a potential to lead to core damage, depending on the successful operation of the various mitigation systems of the plant. Initiating events are categorized according to expected frequency of occurrence and by type. Generally, there is a graded approach such that more severe events are expected to occur with less frequency than lesser events. Initiating events can be the result of equipment failure, natural hazards (e.g., earthquake, flood, or fire) or human error. Initiating events can occur from within or from outside the reactor facility (e.g., tornado, air-craft crash, etc.). 


\subsubsection{Changes in Heat Removal}

Changes in heat removal summarily causes changes in reactor coolant temperature and pressure. Reactor power and coolant flow is not directly affected, but heat removal is affected at the moment the event is initiated. Examples of this are:

- Loss of normal Feedwater in the secondary loop (PWR).

- Loss of condenser cooling (PWR and BWR).

- Reactor-turbine load mismatch, including loss of load and turbine trip (PWR and BWR).

- Inadvertent moderator cool-down (PWR and BWR).

Changes in reactor state due to these events can result in either positive or negative reactivity insertion. Simultaneously to a change in reactivity can be an imminent challenge to fuel cladding or RPV temperature and thermal limits. For example, heat-up of reactor coolant in a PWR reduces water density and thus reduces moderation, but at the same time reduces boric acid concentration. However, during normal operation the boron concentration is kept at a concentration such that the loss of coolant moderator density is a net negative reactivity insertion. Conversely, an un-intended over-cooling of the reactor coolant would be considered a positive reactivity insertion.

\subsubsection{Changes in Coolant Flow}

Changes in coolant flow causes changes in reactor cool-ability. Reactor power and heat removal is not directly affected, but coolant flow through the core is affected at the moment the event is initiated. Examples of this are:

- Loss or interruption of core coolant flow (PWR).

- Depressurization by spurious operation of an active element, such as a relief valve (PWR and BWR).

- Blowdown of reactor coolant through a safety valve (PWR and BWR).

- Minor RCS leak or loss of reactor coolant such as from a small ruptured pipe or from a crack in a large pipe (PWR and BWR).

Changes in reactor state due to these types of events typically result in a loss of moderator density and heat-up of the fuel, thus a negative reactivity insertion. However, events such as the loss of coolant flow are challenging as they cause the temperature and pressure of the reactor coolant to increase. If not mitigated by reactor SCRAM shutdown or the ECCS, pressure buildup in the primary loop would ultimately lead to the need to release this pressure into the containment via relief and safety valves. Similarly, if temperature rise in the reactor fuel is not mitigated rupture of fuel cladding or incipient melting of the fuel could occur (e.g., the events of Three Mile Island - Unit 2 in 1979).

\subsubsection{Power Transients}

Changes in reactor fuel or control poison concentration or configuration can lead to changes in reactor power. Coolant flow through the core or heat removal is not affected, but reactor power is affected at the moment the event is initiated. Examples are:

- Inadvertent control rod or rod group withdrawal (PWR and BWR).

- Inadvertent chemical shim dilution (PWR).

- Control rod drop or ejection (PWR and BWR).

Changes in reactor state due to these types of events (except PWR control rod drop) typically result in a reactivity insertion, thus leading to an increase in power. It is intuitive that unintended removal of 
neutron poison from the core should lead to a power ramp or excursion. Less intuitive is inadvertent control rod insertion in a PWR which can result in a prompt negative reactivity feedback. In this event, the reactor power experiences a prompt decrease resulting in a reduction in primary pressure and temperature. As the cooler moderator temperature ultimately recirculates back to the reactor, the reactor power recovers by some amount, however the core's power distribution is skewed by the inserted rod and power distribution limits can be exceeded.

\subsubsection{Anticipated frequency of Occurrence}

Each initiating event is categorized as either an Anticipated Operational Occurrence (AOO) or as a postulated accident. AOOs, as defined in 10CFR50, Appendix A, are those conditions of normal operation that are expected to occur one or more times during the life of the nuclear power unit. These are often referred to as Condition 1 events. Incidents of moderate frequency and infrequent events are known as Condition 2 and Condition 3 events, respectively. Postulated accidents, or un-anticipated occurrences are considered to be Condition 4 events. A Condition 4 event is considered only because its occurrence is feasible, but it is not expected to occur during the life of the nuclear power plant.

Generally, the amount of risk (probability of event weighted by severity of outcome) should be relatively the same for all Condition levels. Therefore, a lower level of Condition should not generate a more serious incident in a higher Condition level, or result in a consequential loss of function of the RCS or reactor containment barriers. For example, an AOO should not lead to Condition 2 event unless some other initiating event occurs. If this were possible, events of conceivably "high" probability could lead to outcomes of "higher" consequence thus leading to high risk.

According to NUREG-0800, the following are the specific criteria necessary to meet the requirements of General Design Criteria (GDC) for AOOs.

\subsubsection{Condition 1: Anticipated Operational Occurrences}

- Pressure in the reactor coolant and main steam systems should be maintained below $110 \%$ of the design values in accordance with the American Society of Mechanical Engineers Boiler and Pressure Vessel Code.

- Fuel cladding integrity shall be maintained by ensuring that the minimum DNBR remains above the $95 \%$ Statistical Confidence that $95 \%$ of occurrences fall above the DNBR limit for PWRs. Similarly for BWRs, the Critical Power Ratio (CPR) must remain above the Minimum Critical Power Ratio (MCPR).

\subsubsection{Condition 2: Faults of Moderate Frequency}

- The same acceptance criteria are used for Condition 2 event, though their initial event frequency is less.

\subsubsection{Condition 3: Infrequent Faults}

- No more than a small fraction of the fuel elements in the reactor are damaged, although sufficient fuel element damage might occur to preclude resumption of operation for a considerable outage time.

- Sometimes multiple modes of failure can be considered together as this is considered to be less frequent than single failure modes.

- For PWRs, the release of radioactive material may exceed guidelines in 10CFR20, but shall not be sufficient to interrupt public use of land beyond the exclusion radius. For BWRs, the offsite release is limited by 10CFR100. 


\subsubsection{Condition 4: Limiting Faults}

- Damage could preclude resumption of operation.

- Pressure in the RCS and main steam system should be maintained below acceptable design limits, considering both brittle and ductile failures.

- If the minimum DNBR or MCPR does not meet the 95/95 limit, it is assumed to have failed.

- The release of radioactive material shall not result in offsite doses in excess of 10CFR100 guidelines.

- There are explicit temperature, oxidation, hydrogen creation, etc. limits for LOCA.

- The core geometry must be amenable to cool-ability. The ECCS must be operable and able to remove decay heat.

\subsubsection{Severe Accident Analysis}

Per 10CFR50.46, accident analysis must be provided that proves that the ECCS can do the following postulated LOCAs of different sizes, locations, etc.:

- Limit peak clad temperature to $2200^{\circ} \mathrm{F}$.

- Total clad (Zircalloy) oxidation is limited to $<17 \%$ of its original thickness anywhere.

- Maximum $\mathrm{H} 2$ generation is limited to $1 \%$ of the total that would exist if all cladding were to undergo high temperature zirconium-water reaction.

- Cool-able geometry is maintained through the entire event.

- Long-term cooling is provided.

\subsubsection{Barriers of Defense}

Defense-in-depth consists of a hierarchical deployment of different levels of equipment, systems, and procedures in order to maintain the effectiveness of physical barriers designed to mitigate release of radioactive material. Defense-in-depth provides a graded approach to protect against postulated accidents. The general rationale for defense-in-depth is to mitigate the consequences of one type of event to evolve into the initiation of events of greater severity. Defense-in-depth is generally structured into five levels [19]. Should one level fail, the subsequent level comes into play.

\subsubsection{Prevention of Abnormal Operation}

It is desirable to prevent abnormal operation and failures throughout the reactor facilities life. This is best done through acceptably adequate and conservative design. Control of abnormal operation is attained by carefully designing and testing limiting and protection systems as well as ensuring the reactor facility has reliable surveillance features. Examples of steps that can be taken to promote safe operation:

- Clearly defining normal from abnormal operating conditions.

- Clearly define what reactor components and systems are (or are not) safety related.

- Ensure adequate safety margins in the design of components and systems considering reliability, robustness, and resistance to accident conditions.

- Design the facility with diverse and redundant safety systems and instrumentation and control systems

- Ensure there is adequate time for operators to respond to events and provide appropriate human-machine interfaces. 
- Provide appropriately selected workers with comprehensive training.

- Use accurate records management and evaluation procedures.

- Provide for knowledge transfer across the workforce.

- Use strong Verification and Validation practices of safety related hardware and software.

- Perform comprehensive preventative maintenance prioritized in accordance with the safety significance and reliability requirements of components and systems.

\subsubsection{Control of Abnormal Operation}

The systems to mitigate the consequences of events are designed to bring the plant back to normal operation as soon as possible. Examples of such systems are:

- Inherent plant features, such as core stability and thermal inertia.

- Diagnostic tools and equipment such as automatic control systems can provide corrective actions before reactor protection limits are reached. For transients evolving faster than operators can respond, it is important to have automatic systems that can take corrective action before damage occurs, e.g., automatic seismic-SCRAM systems.

- Plant Protection System (PPS): the reactor's plants safety related instrumentation and controls provide operators with safety awareness in real time.

- For failures occurring in a timeframe longer than normal instrumentation can track, inspection and compliance programs provide for reactor safety awareness.

\subsubsection{Control of Accidents}

Engineered safety features can help control the consequences of design basis events and accidents. These are often physical barriers with robustness commensurate with the risk level associated with their failure. A common understanding of these physical barriers are as follows:

- The fuel cladding ensure radioactive release to the primary cooling. It is well known that periodic breaches in cladding do occur. However, it is the goal of the quality program to drive these occurrences to zero. Therefore, fuel cladding failure is considered moderate frequency to infrequent, i.e. primary barrier for Condition 2 events.

- If the cladding ruptures, the next physical barrier is the RPV and primary coolant piping. Failure of this barrier is considered an AOO if it is a minor RCS leak or loss of reactor coolant such as from a small ruptured pipe or from a crack in a large pipe. It is assumed that a small fraction of fuel is damaged, thus it is considered the primary barrier for Condition 3 events.

- If the primary system is breached, the radiologic release must be confined within the reactor containment (or confinement) structures. Leakage of radioactive material from this structure must be such that the dose to the public at the facility's exclusion radius is below that specified by 10CFR100. Depending on the largest credible energetic release and radioactive source term by any Condition 4 accident, the robustness of such a containment structure can range from steel reinforced to a sheet-metal structure. 


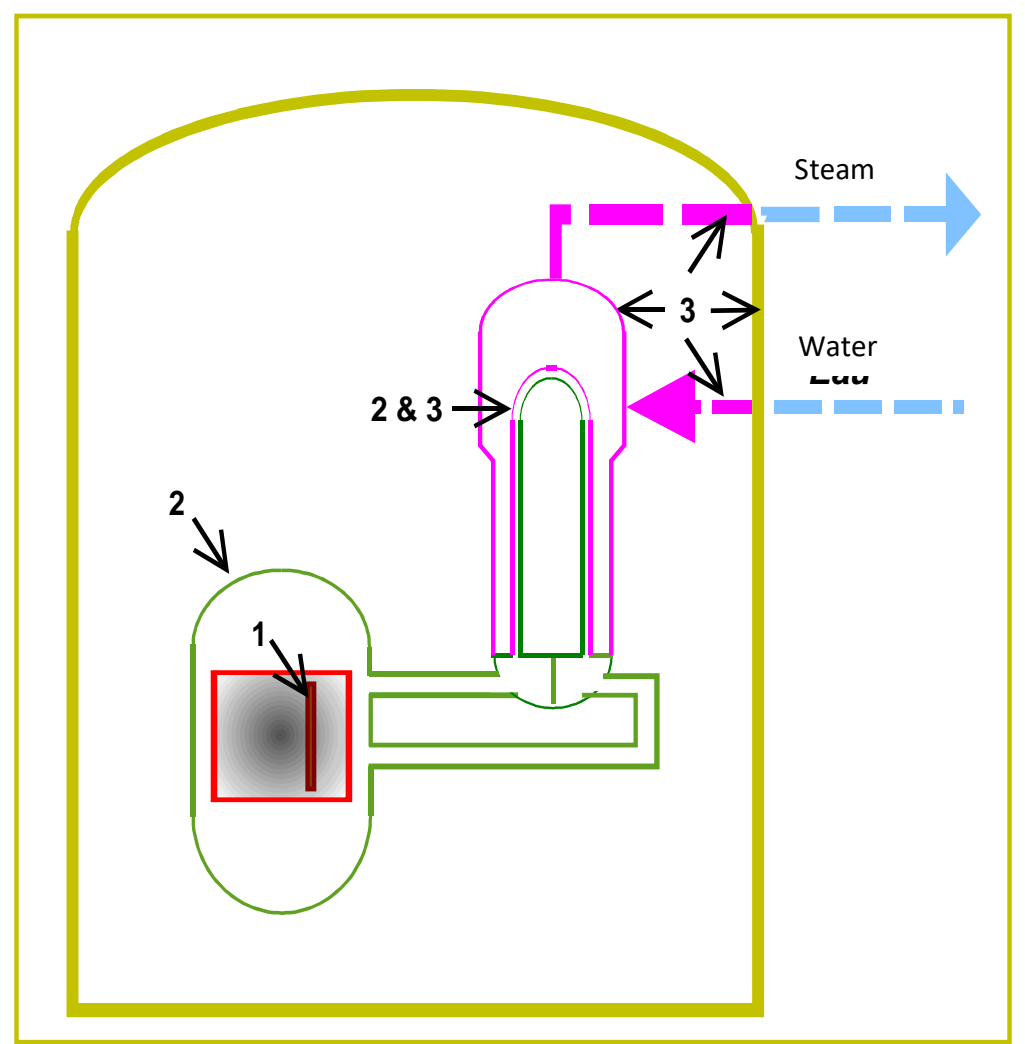

Figure 39: The physical barriers to limit radioactive release: (1) the fuel cladding, (2) the reactor cooling system, and (3) the reactor containment structure.

Even with these physical barriers it is important to be cognizant of possible common mode failures. Common mode failure is where: Two or more components or systems fail within a specified period of time such that the success of the system is compromised, or failure of components result from a single shared cause.

\subsubsection{Control of Severe Plant Conditions}

Many reactor transients occur at time-frames precluding operator intervention. Existing inherent, engineered, and computer systems are the only barrier to damage or radioactive release for those events. However, some transients or events can take minutes or even hours to progress. Instrumentation, observable information, and operator training are essential to gain situational awareness. Ensuring coolability and sub-criticality are also key elements of accident response by both engineered systems and worker response to the accident.

\subsubsection{Mitigation of Radiological Consequences}

The reactor design features for controlling accidents can be augmented by proactive emergency planning, emergency response, procedures, and training. Off-site emergency procedures are prepared in consultation with the reactor facility operator. Both on-site and off-site emergency plans are exercised periodically to the extent necessary to ensure readiness of the organizations involved.

\subsubsection{The Single Failure Criterion}

Systems that perform safety functions during incidents or accidents, together with their support systems, must be able to continue performing their function in the event of one of their components fails. To protect against single point failures, nuclear reactor designs typically have multiple redundant and diverse safety features. An example of this is to have multiple identical mechanical systems performing 
the same function, i.e., redundancy. Another example is to have two different types of mechanical equipment having the same functional requirements, but fundamentally different in design. Still other examples are to have multiple independent power supplies supporting electrical equipment.

\section{Reactor Instrumentation and Control}

The success of defense-in-depth to reduce risk and ensure safe operation is only made possible by accurate information of the sate-of-affairs in the reactor power and thermal-hydraulic system. This information is collected by instrumentation both inside and outside the reactor core. This section discusses primarily PWR information and of select major systems. However, the typical reactor plant has multiple sub-systems. Generally, the technology and design philosophy of reactor instrumentation is the same between PWR and BWR.

\subsection{Reactor Data Acquisition System}

\subsubsection{Temperature and Pressure}

Temperature and pressure detectors provide four basic functions: indication, alarm, protection and control [20]. Two common types of temperature detectors are Resistance Temperature Detectors (RTD) and thermocouples. Two common types of pressure detectors are bellows-type and bourdon tube-type.

Temperature and pressure instruments are sensitive to variations in the ambient temperature and atmospheric pressure surrounding the detector, respectively. They are both sensitive to the presence of humidity, especially on their associated electronic equipment. This moisture can cause short circuits, grounds, and corrosion, which in turn may damage components. Therefore, the ambient temperature, pressure and humidity need to be assumed for the accuracy of the instruments. This environmental effect is critical to the qualification of the instruments and what values are used when making decisions by the operators.

Typically redundant temperature and pressure detectors are used within the same sheath extending into the reactor coolant environment. Temperature detectors are located in both hot and cold legs of the RCS. Pressure detectors are located in the pressurizer as well as the in the residual heat removal system near its penetration into the hot-leg.

Knowing the temperature difference across the core as well as the mass flow rate provides information for a calorimetric indication of power using the familiar heat equation, $q=\dot{m} \times C_{p} \times \Delta T$. Where $\dot{m}$ is the mass flow rate, $C_{p}$ is the coolant's heat capacity, and $\Delta \mathrm{T}$ is the difference between the hot and cold leg temperature indication. Because LWRs have multiple modes of operation associated with different plant activities (e.g., refueling, startup, full-power), the reactor instrumentation will be comprised of a diverse system of "wide-range" and "narrow-range" detectors. Wide range detectors can sense reactor conditions over a broad range of conditions (e.g., room temperature to $700^{\circ} \mathrm{F}$ ), whereas narrow range detectors are calibrated over a finer range (e.g., at hot full-power). 


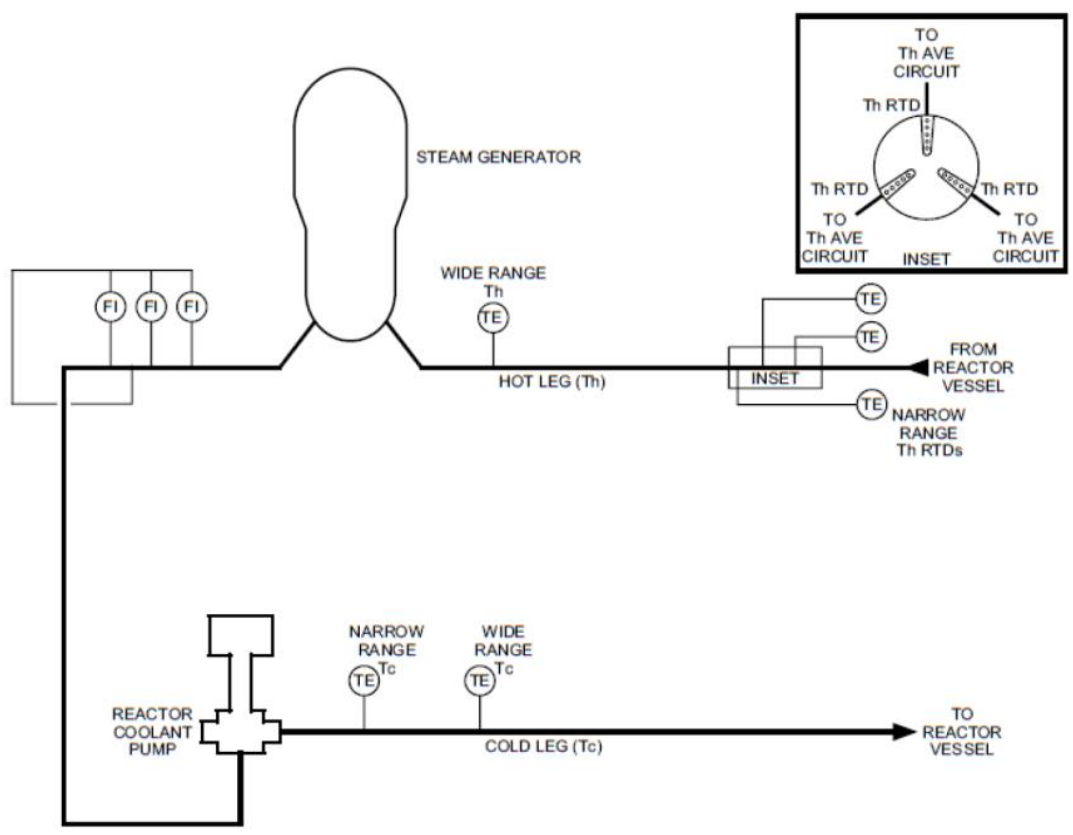

Figure 40. Simplified sketch of the PWR RCS loop instrumentation without bypass manifolds. $T_{h}$ stands for hot leg temperature. Tc stands for cold leg temperature [21].

\subsubsection{Coolant Flow}

Elbow taps are a unique design used by some PWRs in the RCS to indicate the status of the reactor coolant flow. The elbow flow instrument measures the differential pressure between the inner and outer radius of the intermediate leg piping elbow. The outer radius will experience a slightly higher pressure due to the dynamic effects of coolant flow. The square root of the difference between the pressure at the outside radius and that of the inside radius of the bend is proportional to flow.

$$
\frac{\Delta P}{\Delta P_{o}}=\frac{\omega^{2}}{\omega_{o}^{2}}
$$

Where $\Delta \mathrm{P}$ is the pressure difference between outside and inside of the bend. $\omega$ is the flow rate. $\Delta \mathrm{P}_{\mathrm{o}}$ and $\omega_{\mathrm{o}}$ are the pressure differential and flow rate corresponding to an initial reference value.

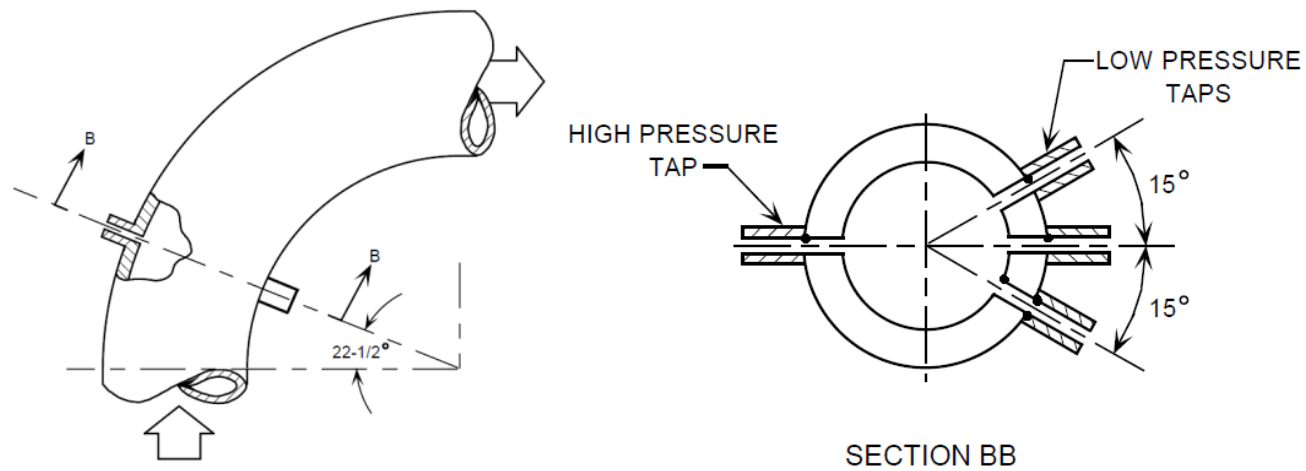

Figure 41. Reactor coolant flow detection via pressure traps in the intermediate-leg pipe bend. The intermediate-leg connects the steam generator to the primary coolant pump [22]. 


\subsubsection{Coolant Level}

The RPV water level indicating system is designed to provide a reliable method of indicating the water level within the reactor under normal and accident conditions. It should be understood that this instrument is not providing an indication of RPV level per se during forced circulation, but an indication of the relative void fraction of the reactor coolant. Penetrations for this system into the RPV are made through a spare control rod drive mechanism penetration near its center. This is the low pressure tap. Another penetration near the bottom of the core serves as the high pressure tap. RTDs are also used in this system to compensate for temperature effects on water density.

\subsubsection{Leak Detection}

Detection of leakage from the RCS is accomplished by a number of diverse systems:

- Particulate radioactivity in the air monitoring system of the reactor containment building.

- Changes to reactor containment building pressure, temperature, humidity, and condensate in the containment sump water level.

- An unanticipated change in the makeup water required by the pressurizer.

- Leakage between the RPV vessel head and vessel closure joint will result in a temperature alarm.

\subsubsection{In-Core Instrumentation System}

The purpose of the in-core instrumentation system is to provide information on neutron flux distribution and fuel assembly outlet temperatures at selected core locations. The in-core instrumentation system provides data acquisition only and performs no protective or plant operational control functions.

In a PWR, the fuel assembly outlet temperature is measured with thermocouples. These thermocouples enter the RPV through vessel head ports on the reactor vessel head and extend to a position above the upper core plate of the vessel internals. An alternate thermocouple placement mounts the in-core thermocouple at the end of double walled flux thimbles.

PWRs have the ability to map the reactor power in 3D during full power operation. Retractable thimbles of cold-worked stainless steel are pushed into the reactor core through thimble guide tubes, which extend from the bottom of the RPV down through the concrete shield area, then to a thimble seal plate. When fully inserted they extend from the seal plate through the shield and up into specified fuel assemblies. The center-most guide tube in the fuel assembly is reserved for the movable flux monitor at the end of the thimble wire. 


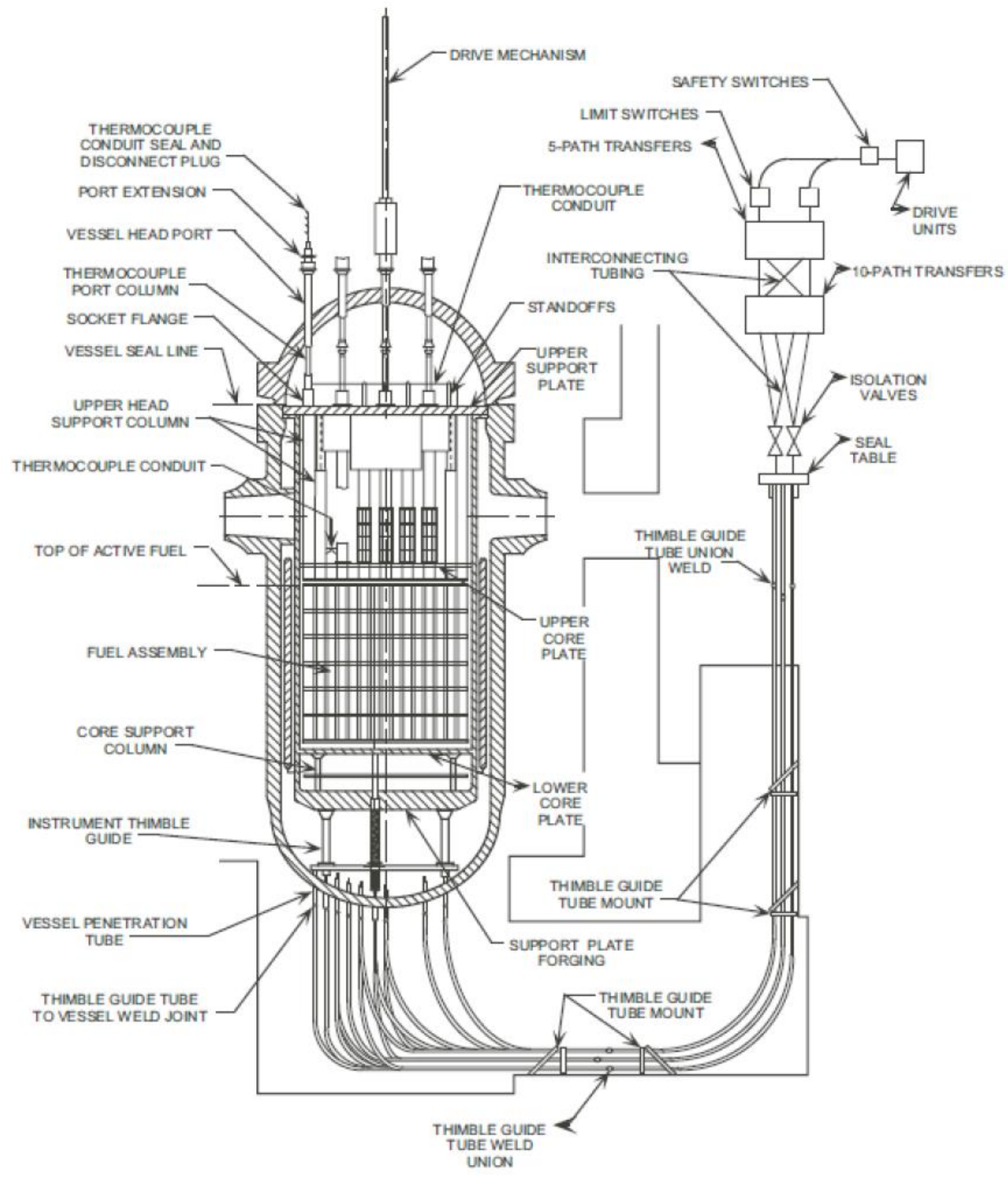

Figure 42. PWR In-Core Instrumentation [23]

\subsubsection{Ex-Core Power Measurement System}

The primary function of the ex-core power measurement system is to protect the reactor core from overpower by monitoring the neutron flux [24]. Neutron detectors are placed on the outside of the RPV and measure the amount of neutron leakage from the reactor core. These detectors provide reactor power indication at reactor startup up to overpower conditions. The system also provides axial and radial power distribution information during power operations. There are typically three different overlapping ranges 
of neutron flux measurement. These ranges together span 12 orders of magnitude. Each range corresponds to a different type of radiation detector measurement system.

- Source Range: The lowest observable neutron count rate depends on the strength of neutron sources already in the core (e.g., spontaneous fission, and/or a startup source). $\mathrm{A} \mathrm{BF}_{3}$ proportional detector is used. The circuitry of this detection system discriminates against gammas and background noise. This range is used for reactor startup.

- Intermediate Range: A gamma-ray compensated ion chamber is used. This range is used for power ascension to full power.

- Power Range: An uncompensated ion chamber is used. This range is used for full power operation

Gamma-ray discrimination is important at the source and intermediate ranges because at such small count rates, the gamma-ray sources from activation products and fission product decay can mask the count rate due to neutrons in the detector. The discrimination is performed using a detector that is sensitive to only gamma-rays.

\subsection{Reactor Protection \& Engineered Safety Feature Actuation System}

Engineered Safety Feature Actuation System (ESFAS) is a collection of multiple redundant detectors, electronics, and actuators that engage the LWR's engineered safety systems in response to a detected initiated event. The ESFAS will actuate safety related systems, equipment, and/or components as well as isolate non-safety related systems. The protective action signal(s) feeds an associated master relay. Each master relay operates contacts which energize downstream slave relays. The slave relays actuate the actual engineered safety system equipment. To ensure independence and redundancy, the ESFAS will have multiple independent actuation trains.

In the Reactor Protection System (RPS), multiple analog signals from various safety related detectors (e.g., temperature, pressure, flow, level, and neutron flux) are compared against predetermined set-points. A protective action is generated when sufficient number and combinations of these set-points have been met or exceeded.

Redundancy is used for both RPS and ESFAS in that a minimum of two trains of protection are provided in order to ensure a single failure will not defeat the safety function. The following actuation signals generally corresponding to PWRs is discussed here [25].

\subsubsection{Reactor Trip}

The Reactor Trip (or SCRAM) is actuated to rapidly shutdown the neutron chain reaction by the rapid insertion of all control rods. In PWRs these rods are held out of the top of the reactor by coils and once these coils are deenergized, the rods fall into the reactor via gravity. BWR rods are held out below the reactor and are hydraulically inserted into the bottom of the reactor on a SCRAM.

Reactor Protection is initiated on a variety of signals that are intended to protect the reactor from damaging the cladding via DNB (CHF for BWR). Overpower, coolant low flow, coolant high temperature, low pressure are all typical parameters that result in a reactor trip. ESFAS also, of course, would initiate a reactor trip.

On a PWR the deenergizing of the rod's coils is accomplished by opening two reactor trip circuit breakers that are in electrical series to allow for single failure. Each breaker is actuated by a train of the protection system. It appeared highly unlikely that a failure to trip the reactor could occur, until it did in 1983 at the Salem nuclear plant. Both reactor trip circuit breakers failed to open when an automatic trip signal was generated by the protection system. The cause was inadequate maintenance and cleanliness of 
the circuit breakers. This event resulted in the requirements for all nuclear plants to provide both systems to mitigate and operator actions to respond to an Anticipated Transient Without Trip (ATWT) event. (ATWS for SCRAM). At Salem, no core damage resulted because the operators initiated a manual trip signal which used different relays to open the circuit breakers and were successful.

\subsubsection{Safety Injection Actuation}

The Safety Injection (SI) is initiated to limit the consequences of infrequent faults (Condition 3 events) and limiting faults (Condition 4 events). The SI actuation shuts down the reactor (if it is still operating), maintains the reactor in a shutdown state, ensures sufficient core cooling to limit possible fuel damage, ensures coolant containment, and places plant support systems in appropriate post-accident alignments. The following signals can lead to SI actuation:

- Low pressurizer pressure

- High containment pressure

- High steam-line coincident with either low steam line pressure or very low $\mathrm{T}_{\mathrm{avg}}$

- High Steam Line Differential Pressure

- Manual actuation

\subsubsection{Containment Spray Actuation}

The containment spray system is automatically actuated by a very high containment pressure signal. Because of the damage this spray can make to equipment this signal typically utilizes an increased coincidence logic to ensure no inadvertent actuations.

\subsubsection{Containment Isolation}

Redundant isolation valves and dampers, both inside and outside the containment building, are shut in all non-essential lines which penetrate the containment building to ensure no leakage from containment to the environment. The exception to this is primary component cooling water and the return lines from the reactor coolant pumps.

\subsubsection{Steam Line Isolation}

The main steam lines (i.e., from steam generator to turbine) will automatically isolate on high containment pressure, or high steam flow coincident with low steam pressure, or other low steam pressure combinations. This isolation ensures that a steam break accident downstream of the valves is isolated, and if upstream (in containment) only one steam generator is discharged. For a PWR, this is not a containment isolation function; however for a BWR it directly is isolating the reactor from the environment.

\subsubsection{Feedwater Isolation (PWR)}

Any Safety injection signal causes all Feedwater regulating valves, bypass regulating valves, and Feedwater isolation valves to close. A high steam generator water level and SI actuation also trip the main feed pumps and the main turbine.

\subsubsection{Auxiliary Feedwater Actuation (PWR)}

The auxiliary feedwater system provides a reliable safety-grade source of water to the steam generators to ensure that a reactor heat sink is available. The following signals can lead to auxiliary feedwater activation:

- SI actuation

- Very low steam generator water level in any steam generator 
- The Engineered Safety System bus experiences under-voltage

- $\quad$ Trip of all main feed pumps

\section{References}

[1] D. Halliday, R. Resnick and J. Walker, Fundamentals of Physics, Fifth Edition, New York: John Wiley and Sonc, Inc., 1997.

[2] "Bohr Model," Britannica, Encylopedia, 28 March 2019. [Online]. Available: https://www.britannica.com/science/Bohr-atomic-model/media/71700/155372. [Accessed 2 April 2019].

[3] R. Faw and J. Shultis, Radiological Assessment: Sources and Doses, La Grange Park, Illinois: American Nuclear Society, 1999.

[4] C. o. F. Regulations, "Standards for Protection Against Radiation, 10CFR20," Nuclear Regulatory Commission, 21 May 1991. [Online]. Available: https://www.nrc.gov/reading-rm/doccollections/cfr/part020/part020-1001.html. [Accessed 2 April 2019].

[5] J. Lamarsh, Nuclear Reactor Theory, Reading, Massachusetts: Addison-Wesley Publishing Company, Inc., 1966.

[6] "Nuclear Fission," Nuclear Energy, 18 March 2019. [Online]. Available: https://nuclearenergy.net/what-is-nuclear-energy/nuclear-fission. [Accessed 18 March 2019].

[7] "DOE Fundamentals Handbook - Nuclear Physics and Reactor Theory," Department of Energy, Washington, D.C., 1993.

[8] R. G. Cochran and N. Tsoulfanidis, The Nuclear Fuel Cycle: Analysis and Management, 2nd Edition, La Grange Park, Illinois: American Nuclear Society, 1990.

[9] S. Z. Rouhani and M. S. Sohal, "Two-Phase Flow Patterns: A Review of Resaerch Results," Progress in Nuclear Energy, vol. 11, no. 3, pp. 219-259, 1982.

[10] J. Yan, Q. Bi, G. Zhu, L. Cai, Q. Yuan and H. Lv, "Critical heat flux of highly subcooled water flow boiling in circular tubes with and without internal twisted tapes under high mass fluxes,"

International Journal of Heat and Mass Transfer, vol. 95, pp. 606-619, 2016.

[11] J. Dahlheimer, E. Elhauge, L. Greenberg, J. Jacobs, W. Kabbert, H. Keel, G. Masche, C. Moran, D. Petrie, R. Seid and T. Weiss, "The Westinghouse Pressurized Water Reactor," Westinghouse Electric Corporation, Pittsburgh, Pennsylvania, 1984.

[12] USNRC Technical Training Center, "Reactor Concepts Manual, Pressurized Water Reactor (PWR), R-100 Course," Nuclear Regulatory Committee, 2012. [Online]. Available:

https://www.nrc.gov/reading-rm/basic-ref/students/for-educators/04.pdf. [Accessed 18 March 2019].

[13] USNRC Technical Training Center, "Reactor Concepts Manual, Boiling Water Reactor (BWR), R100 Course," Nuclear Regulatory Committee, 2012. [Online]. Available: https://www.nrc.gov/reading-rm/basic-ref/students/for-educators/03.pdf. [Accessed 18 March 2019].

[14] P. J. Turinksy and D. B. Kothe, "Modeling and simulation challenges pursued by the Consortium for Advanced Simulation of Light Water Reactors (CASL)," Journal of Computational Physics, vol. 313, pp. 367-376, 2016.

[15] S. Uchida and Y. Katsumura, "Water Chemistry Technology - One of the Key Technologies for Safe and Reliable Nuclear Power Plant Operation," Journal of Nuclear Science and Technology, vol. 50, no. 4, pp. 346-362, 2013.

[16] S. Zinkle and G. Was, "Materials Challenges in Nuclear Energy," Acta Materialia, vol. 61, no. 3, pp. 735-758, 2013. 
[17] G. Odette and G. Lucas, "Embrittlement of Nuclear Reactor Pressure Vessels," JOM: The Journal of the Minerals, Metals and Materials Society, vol. 53, no. 7, pp. 18-22, 2001.

[18] "Standard Review Plan for the Review of Safety Analysis Reports for Nuclear Power Plants - LWR Edition (NUREG-0800, Formerly issued as NUREG-75/087)," United States Nuclear Regulatory Commission, Washington DC, 1987.

[19] "Defense in Depth in Nuclear Safety (ISAG-10)," International Atomic Energy Agency, Vienna, Austria, 1996.

[20] "DOE Fundamentals Handbook - Instrumentation and Control," Department of Energy, Washington, D.C., 1992.

[21] U. T. T. Center, "Westinghouse Technology Systems Manual - Reactor Coolant Instrumentation, R304p Course, Section 10.1," US Nuclear Regulatory Committee, [Online]. Available: https://www.nrc.gov/docs/ML1122/ML11223A281.pdf. [Accessed 20 March 2019].

[22] U. T. T. Center, "Westinghouse Technology Systems Manual - Reactor Coolant System, R-304p Course, Section 3.2," US Nuclear Regulatory Commission, [Online]. Available: https://www.nrc.gov/docs/ML1122/ML11223A213.pdf. [Accessed 20 March 2019].

[23] U. T. T. Center, "Westinghouse Technology Systems Manual - Incore Instrumentation, R-304p Course, Section 9.2," US Nuclear Regulatory Commission, [Online]. Available: https://www.nrc.gov/docs/ML1122/ML11223A264.pdf. [Accessed 20 March 2019].

[24] U. T. T. Center, "Westinghouse Technology Systems Manual - Excore Instrumentation, R-304p Course, Section 9.1," US Nuclear Regulatory Commission, [Online]. Available: https://www.nrc.gov/docs/ML1122/ML11223A263.pdf. [Accessed 20 March 2019].

[25] U. T. T. Center, "Westinghouse Technology Systems Manual - Reactor Protection System Engineered Safety Features Actuation Signals, R-304p Course, Section 12.3," US Nuclear Regulatory Commission, [Online]. Available: https://www.nrc.gov/docs/ML1122/ML11223A310.pdf. [Accessed 20 March 2019].

[26] G. Knoll, Radiation Detection and Measurement, Third Edition, New York: John Wiley and Sons, Inc., 2000.

[27] J. Shultis and R. Faw, Radiation Shielding, La Grange Park, Illinois: American Nuclear Society, 2000. 